\begin{tabular}{|c|c|c|}
\hline 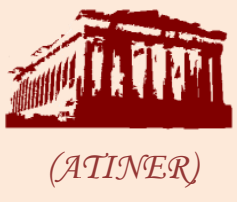 & $\begin{array}{l}\text { The Athens Journal of } \\
\text { Business \& Economics }\end{array}$ & (ATINER) \\
\hline \multicolumn{3}{|c|}{ Volume 7, Issue 1, January 2021} \\
\hline \multicolumn{3}{|c|}{ Front Pages } \\
\hline $\begin{array}{l}\text { CATHERII } \\
\text { Labor Proc } \\
\text { Inevitable }\end{array}$ & $\begin{array}{l}\text { UNEAU \& PIERRE-LUIS GIRARD } \\
\text { ity in France: Is the Slowdown of its } \\
\text { there Levers to fight it? }\end{array}$ & \\
\hline \multicolumn{3}{|c|}{ CARLO KLEIN } \\
\hline \multicolumn{3}{|c|}{ Objectives: Stability vs. Convergence or Stability and Convergence? } \\
\hline $\begin{array}{l}\text { KRISTINA } \\
\text { Sustainab } \\
\text { Prerequisi } \\
\text { Transition } \\
\end{array}$ & $\begin{array}{l}\text { NOVA } \\
\text { ernance and Knowledge-based Econ } \\
\text { Sustainable Development of the De } \\
\text { nomies }\end{array}$ & ng and \\
\hline $\begin{array}{l}\text { MRIDULA } \\
\text { Outcomes } \\
\text { City Proje }\end{array}$ & $\begin{array}{l}\text { \& SHEETAL THOMAS } \\
\text { Building Transparency in Governar } \\
\text { ndia: A Case Study of Panaji, Goa }\end{array}$ & a Smart \\
\hline $\begin{array}{l}\text { PETER JO } \\
\text { The Susta } \\
\text { Retailers }\end{array}$ & $\begin{array}{l}\text { DAPHNE COMFORT } \\
\text { Development Goals and Leading } \mathbf{E}\end{array}$ & \\
\hline
\end{tabular}




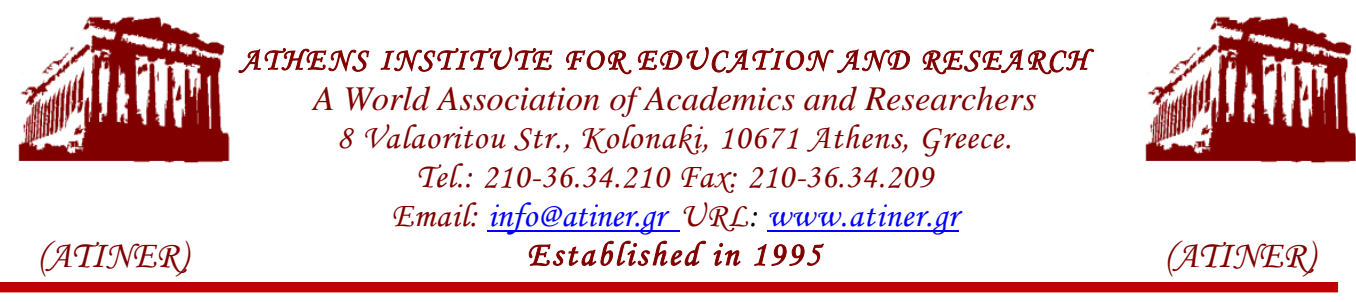

\section{Mission}

ATINER is an Athens-based World Association of Academics and Researchers based in Athens. ATINER is an independent and non-profit Association with a Mission to become a forum where Academics and Researchers from all over the world can meet in Athens, exchange ideas on their research and discuss future developments in their disciplines, as well as engage with professionals from other fields. Athens was chosen because of its long history of academic gatherings, which go back thousands of years to Plato's Academy and Aristotle's Lyceum. Both these historic places are within walking distance from ATINER's downtown offices. Since antiquity, Athens was an open city. In the words of Pericles, Athens"... is open to the world, we never expel a foreigner from learning or seeing". ("Pericles' Funeral Oration", in Thucydides, The History of the Peloponnesian War). It is ATINER's mission to revive the glory of Ancient Athens by inviting the World Academic Community to the city, to learn from each other in an environment of freedom and respect for other people's opinions and beliefs. After all, the free expression of one's opinion formed the basis for the development of democracy, and Athens was its cradle. As it turned out, the Golden Age of Athens was in fact, the Golden Age of the Western Civilization. Education and (Re)searching for the 'truth' are the pillars of any free (democratic) society. This is the reason why Education and Research are the two core words in ATINER's name. 
The Athens Journal of Business \& Economics

ISSN NUMBER: 2241-794X- DOI: 10.30958/ajbe

Volume 7, Issue 1, January 2021

Download the entire issue ( $\underline{\mathrm{PDF}})$

Front Pages

Labor Productivity in France: Is the Slowdown of its

Growth Inevitable or are there Levers to fight it?

Catherine Bruneau \& Pierre-Luis Girard

The Never-Ending Quest for the European Fiscal

Policy's Objectives: Stability vs. Convergence or

Stability and Convergence?

Carlo Klein

Sustainable Governance and Knowledge-based

Economy - Prerequisites for Sustainable Development of the Developing and Transitional Economies

Kristina Jovanova

Outcomes from Building Transparency in Governance in a Smart City Project in India: A Case Study of Panaji, Goa

Mridula Goel \& Sheetal Thomas

The Sustainable Development Goals and Leading

\section{European Retailers}

Peter Jones E Daphne Comfort 


\section{Athens Journal of Business \& Economics Editorial and Reviewers' Board}

\section{Editors}

- Dr. Christos Sakellariou, Associate Professor of Economics, Nanyang Technological University, Singapore \& Vice President of Administration and Finance, Athens Institute for Education and Research (ATINER).

- Dr. Gregory T. Papanikos, Honorary Professor, University of Stirling, UK \& President of ATINER.

- Dr. Peter Yannopoulos, Professor, Brock University, Canada \& Vice President of Global Communications, ATINER.

- Dr. Julia Underwood, Professor, Azusa Pacific University, USA \& Academic Member, ATINER.

- Dr. Nektarios Tzempelikos, Senior Lecturer in Marketing, Anglia Ruskin University, UK.

\section{Editorial Board}

- Dr. Panagiotis Petratos, Vice President of ICT, ATINER \& Professor, Department of Computer Information Systems, California State University (Stanislaus), USA.

- Dr. Michael P. Malloy, Director, Business \& Law Research Division, ATINER \& Distinguished Professor of Law, University of the Pacific, USA.

- Dr. Peter Koveos, Head, Accounting \& Finance Research Unit, ATINER \& Professor of Finance, Syracuse University, USA.

- Dr. Sharon Claire Bolton, Head, Management Research Unit, ATINER \& Professor, The Management School, University of Stirling, Scotland.

- Dr. Cleopatra Veloutsou, Head, Marketing Research Unit, ATINER \& Professor of Brand Management, University of Glasgow.

- Dr. John Thanopoulos, Professor of International Business (IB), and Dean, Business and Economics, IST

College \& Emeritus Professor, University of Piraeus, Greece.

- Dr. Elyas Elyasiani, Professor Finance and Economics, Fox School of Business and Management, Temple University, USA.

- Dr. Eduardo Segarra, Academic Member, ATINER \& Professor, Department of Agricultural \& Applied Economics, Texas Tech University, USA.

- Dr. Samuel Seaman, Academic Member, ATINER \& Professor of Decision Sciences, Graziadio School of Business and Management, Pepperdine University, USA.

- Dr. Hercules Haralambides, Academic Member, ATINER \& Professor of Maritime Economics and Logistics, Department of Econometrics, Erasmus University Rotterdam, The Netherlands.

- Dr. Steven Dellaportas, Academic Member, ATINER \& Professor of Accounting, RMIT (Royal Melbourne Institute of Technology) University, Australia.

- Dr. George V. Priovolos, Professor, Iona College, USA.

- Dr. George Saridakis, Director of Doctoral Programmes, Kingston Business School, Kingston University \&

Professor of Small Business and Entrepreneurship, Kingston Hill, Kingston Upon Thames, UK.

- Dr. Liliana Costa, Tutor, Department of Communication and Art, University of Aveiro, Portugal.

- Dr. Gilles Chemla, Academic Member, ATINER \& Professor, Imperial College Business School, UK.

- Dr. Nathalie Homlong, Associate Professor, University College Volda, Norway.

- Dr. Tatyana Boikova, Associate Professor, Business Administration Department, Baltic International Academy, Latvia.

- Dr. Zubin Sethna, Associate Professor of Entrepreneurial Marketing, Regent's University London, UK.

- General Managing Editor of all ATINER's Publications: Ms. Afrodete Papanikou

- ICT Managing Editor of all ATINER's Publications: Mr. Kostas Spyropoulos

- Managing Editor of this Journal: Ms. Eirini Lentzou (bio)

\section{Reviewers' Board}

Click Here 


\section{President's Message}

All ATINER's publications including its e-journals are open access without any costs (submission, processing, publishing, open access paid by authors, open access paid by readers etc.) and is independent of presentations at any of the many small events (conferences, symposiums, forums, colloquiums, courses, roundtable discussions) organized by ATINER throughout the year and entail significant costs of participating. The intellectual property rights of the submitting papers remain with the author. Before you submit, please make sure your paper meets the basic academic standards, which includes proper English. Some articles will be selected from the numerous papers that have been presented at the various annual international academic conferences organized by the different divisions and units of the Athens Institute for Education and Research. The plethora of papers presented every year will enable the editorial board of each journal to select the best, and in so doing produce a top-quality academic journal. In addition to papers presented, ATINER will encourage the independent submission of papers to be evaluated for publication.

The current issue is the first of the seventh volume of the Athens Journal of Business \& Economics (AJBE), published by the Business \& Law Division and the Economics Unit of ATINER. 


\section{Athens Institute for Education and Research}

A World Association of Academics and Researchers

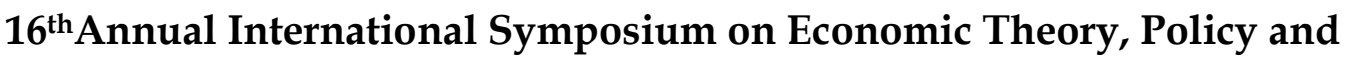 Applications 28-30 June \& 1 July 2021, Athens, Greece}

The Economics Unit of ATINER, will hold its 15 th Annual International Symposium on Economic Theory, Policy and Applications, 29-30 June \& 1-2 July 2021, Athens, Greece sponsored by the Athens Journal of Business \& Economics. The aim of the conference is to bring together academics and researchers of all areas of economics and other related disciplines. You may participate as panel organizer, presenter of one paper, chair a session or observer. Please submit a proposal using the form available (https:// www.atiner.gr/2021/FORM-ECO.doc).

\section{Academic Members Responsible for the Conference}

- Dr. Gregory T. Papanikos, President, ATINER \& Honorary Professor, University of Stirling, UK.

- Dr. Chris Sakellariou, Head, Economics Unit \& Associate Professor of Economics, Nanyang Technological University, Singapore.

\section{Important Dates}

- Abstract Submission: $\mathbf{3 0}$ November 2020

- Acceptance of Abstract: 4 Weeks after Submission

- Submission of Paper: 1 June 2021

\section{Social and Educational Program}

The Social Program Emphasizes the Educational Aspect of the Academic Meetings of Atiner.

- Greek Night Entertainment (This is the official dinner of the conference)

- Athens Sightseeing: Old and New-An Educational Urban Walk

- Social Dinner

- Mycenae Visit

- Exploration of the Aegean Islands

- Delphi Visit

- Ancient Corinth and Cape Sounion

\section{Conference Fees}

Conference fees vary from $400 €$ to $2000 €$

Details can be found at: https://www.atiner.gr/2019fees 


\section{Athens Institute for Education and Research}

A World Association of Academics and Researchers

\section{$8^{\text {th }}$ Annual International Conference on Business, Law \& Economics 3-6 May 2021, Athens, Greece}

The Business, Economics and Law Division (BLRD) of ATINER is organizing its $8^{\text {th }}$ Annual International Conference on Business, Law \& Economics, 3-6 May 2021, Athens, Greece, sponsored by the Athens Journal of Business \& Economics and the Athens Journal of Law. In the past, the six units of BLRD have organized more than 50 annual international conferences on accounting, finance, management, marketing, law and economics. This annual international conference offers an opportunity for cross disciplinary presentations on all aspects of business, law and economics. This annual international conference offers an opportunity for cross disciplinary presentations on all aspects of business, law and economics. Please submit an abstract (email only) to: atiner@atiner.gr, using the abstract submission form (https://www.atiner.gr/2021/FORM-BLE.doc)

\section{(a)}

- Abstract Submission: 5 January 2021

\section{Important Dates}

- Acceptance of Abstract: 4 Weeks after Submission

- Submission of Paper: 5 April 2021

\section{Academic Member Responsible for the Conference}

- Dr. Gregory T. Papanikos, President, ATINER.

- Dr. Michael P. Malloy, Director, Business, Economics and Law Division, ATINER \& Distinguished Professor \& Scholar, University of the Pacific, USA.

- Dr. David A. Frenkel, LL.D., Head, Law Research Unit, ATINER \& Emeritus Professor, Law Area, Guilford Glazer Faculty of Business and Management, Ben-Gurion University of the Negev, Beer-Sheva, Israel.

\section{Social and Educational Program}

The Social Program Emphasizes the Educational Aspect of the Academic Meetings of Atiner.

- Greek Night Entertainment (This is the official dinner of the conference)

- Athens Sightseeing: Old and New-An Educational Urban Walk

- Social Dinner

- Mycenae Visit

- Exploration of the Aegean Islands

- Delphi Visit

- Ancient Corinth and Cape Sounion

More information can be found here: https://www.atiner.gr/social-program

\section{Conference Fees}

Conference fees vary from $400 €$ to $2000 €$

Details can be found at: https://www.atiner.gr/2019fees 




\title{
Labor Productivity in France: Is the Slowdown of its Growth Inevitable or are there Levers to fight it?
}

\author{
By Catherine Bruneau* \& Pierre-Luis Girard ${ }^{ \pm}$
}

\begin{abstract}
Labour productivity in most advanced countries has slowed in successive stages since the 1970's and, after the 2008 crisis, it has reached its lowest level since World War II. Here we analyze the trend evolution of the aggregate labor productivity per hour worked in France, over the last four decades, with two main questions. 1) Is the slowdown of labor productivity growth a process which began far before the Great Recession and should it continue with just temporary yet persistent effects of the 2008 crisis and 2) are there levers to reverse the current trend? We proceed in two steps. First, the trend (log) productivity is described as a deterministic piecewise linear function of time, involving so-called structural breaks, and, second, without breaks, as a linear function of fundamentals derived from an augmented growth model including Human capital. We propose a thorough econometric investigation with multiple robustness analyses involving sector-specific analyses. The structural specification we retain is able to explain the evolution of labor productivity over the last four decades. The accumulation of human capital has been the main driver of productivity growth over the period of interest while France is close to the technological frontier.
\end{abstract}

Keywords: labor productivity, trend component, structural breaks, long run target, augmented growth model with human capital

\section{Introduction and Literature Review}

"Finally, and most ambitiously, as a society, we should explore ways to raise productivity growth. Stronger productivity growth would tend to raise the average level of interest rates (...) But more importantly, stronger productivity growth would enhance Americans' living standards. (...) Many possibilities in this arena are worth considering, including improving our educational system and investing more in worker training; promoting capital investment and research spending, both private and public; and looking for ways to reduce regulatory burdens while protecting important economic, financial, and social goals." - Janet Yellen, speech made on 8/26/2016.

Changes in labor productivity are one of the most watched international statistics. First, considering labor productivity, measured as GDP or gross value added per hour worked, is important as its evolution determines the growth path of other aggregate variables of interest. Its growth is decisive in determining the

*Professor, University Paris I Panthéon-Sorbonne and Scientific Adviser, France Stratégie, France. ${ }^{ \pm}$Scientific Adviser, France Stratégie, France. 
average growth in worker's compensations (Feldstein 2008, Biesebroeck 2015, Cahuc et al. 2014). Moreover, productivity growth historically contributed to explain the increase in average standards of living (Koen et al. 2004, Ivanic and Marin 2018) particularly in terms of consumption and savings (Fournier and Koske 2010).

More specifically, it is broadly accepted that the slowdown of labor productivity growth is one important explanation for the sluggish growth in GDP experienced by advanced economies in recent years. In the context of the Great Recession, the average productivity growth rate reached its lowest level in most advanced economies since World War II. Indeed, the average growth of productivity measured by hours worked dropped from $2 \%$ to less than $1 \%$ per year, from the 1990's to the 2010's, in France, Germany, the United Kingdom and the United States (see Figure 1).

Figure 1. Evolution of Aggregate Labor Productivity per Hour Worked (GDP per Hour Worked, in US Dollars, Constant Prices and PPPS) in the Main Developed Countries Labor Productivity is measured as

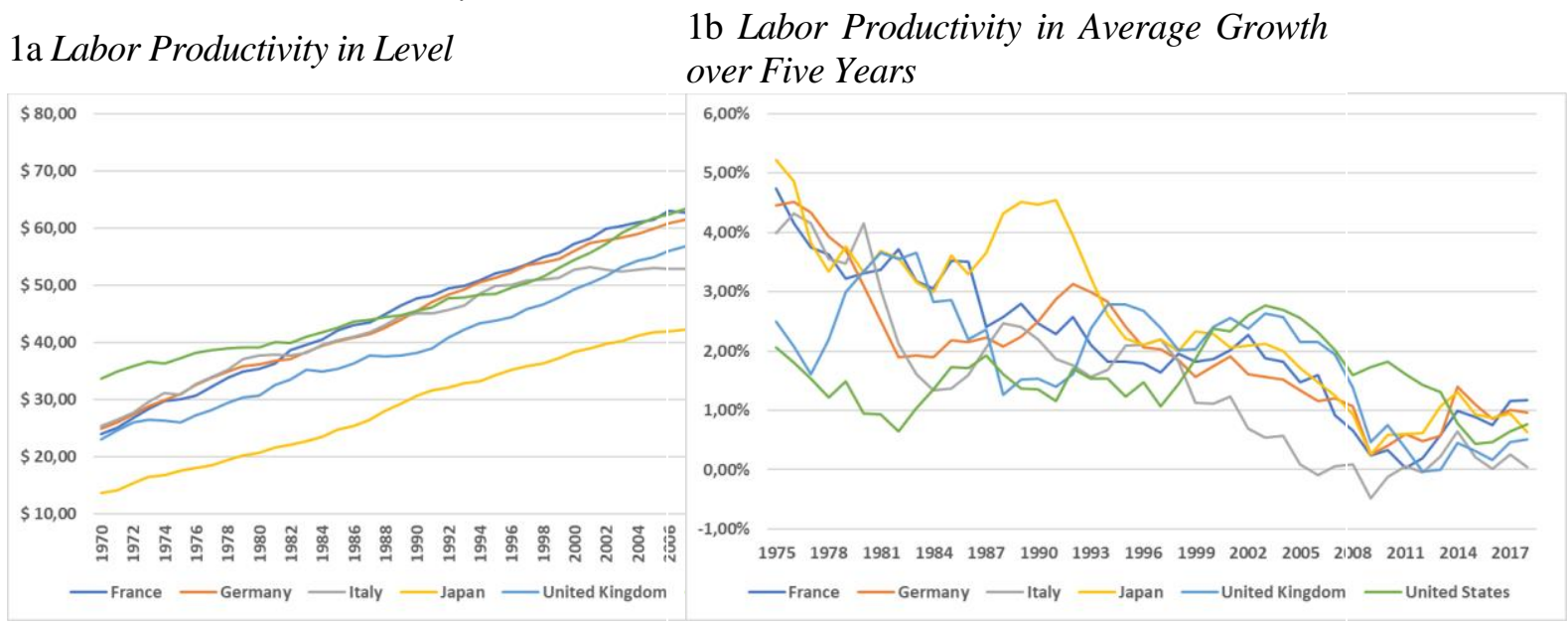

Source: $\mathrm{OECD}$

One often attributes the slowdown of productivity growth observed over the past decades in mature economies to the 2008-2009 crisis. The slowdown could be seen as a persistent yet temporary effect of the financial crisis, and, more precisely as the result of a resource misallocation and/or a fall in demand. Conversely, following the Hansen's thesis developed during the Great Depression in the 1930s, Summers (2014) or Baldwin and Teulings (2014) emphasize persistent weaknesses in demand or excess savings, jointly with structural imbalances (notably zero-lower bound interest rates and ageing population), to explain the productivity slowdown.

Yet, in some countries, productivity growth slowed before the Great Recession and did not yet returned to the growth rates of the 1990s and early 2000s (Cette et al. 2017). Some authors, such as Robert Gordon (Gordon 2012, 2013, 2014, 2015), argue that the low productivity growth measured in all major countries since the beginning of the $21^{\text {st }}$ century could be a sustainable phenomenon, due to the 
inability of current technological innovations to generate productivity gains comparable to those observed after the previous technological revolutions. In response, some economists argue that developed countries are experiencing a mere temporary slowdown in technological progress: a widespread digitalization of the economy, with the development of AI and robotics, will be a leading driver of both economic growth and radical changes in labour demand in the near future when technology enters "deployment phase" (Van Ark et al. 2016).

Besides these discussions on technological progress that are often concomitant with periods of economic slowdown and transition between two industrial revolutions (Mokyr et al. 2015), some authors highlight national specificities, changes in labor market and globalization as factors leading to productivity slowdown. Globalization has accelerated the tertiarization process of the developed economies via the outsourcing of manufacturing productions. Moreover, globalization increases productivity dispersion among firms: frontier firms can increase their market shares and their capacity to adopt innovations whereas market openness may be detrimental to laggard firms (Andrews et al. 2016).

A question therefore arises from these discussions: can we ascertain whether the impact of the 2008 crisis on productivity is structural and thus lasting or, despite persistent effects, it only contributes to cyclical fluctuations and the structural breaks is prior to 2008 ?

To answer this question, we propose a robust econometric analysis of the trend behavior of the labor productivity. We focus on the French case, note only to decide whether the effect of the 2008 crisis on the labor productivity is temporary or lasting, but also to identify levers that could allow to reverse the current trend of labor productivity. Nowadays, France experiences one of the highest labor productivity level, close to the one measured in the United States, after experimenting a slowdown in its labor productivity growth since the late 1990, like other OECD economies.

We use aggregate data over the last four decades to determine fundamentals of the trend labor productivity. Beyond mere academic interest, investigating the sources of the slowdown of labor productivity growth is important for public as well as for private sectors of the economy. Indeed, without understanding the forces which cause productivity slowdown, firms cannot have realistic expectations about future growth. What's more, it will be difficult for policy makers to design proper policy tools to enhance productivity growth.

The econometric analysis we propose provides us with robust results. We organize it in two steps.

First, we adopt a deterministic characterization of the trend component of the labor productivity and, more precisely, as a linear time trend with a few breaks in the level and in the slope. We obtain a decreasing step function specification which other authors already adopted in the literature (Bergeaud et al. 2015, Cette et al. 2017). However, contrary to previous analyses, the dates of the breaks are identified in order to isolate the cyclical component, obtained as a stationary series after removing the piecewise linear trend from the observed labor productivity. 
Second, we aim at finding observable factors which can explain the trend component of labor productivity with the usual linear time-trend accounting for technology progress but without breaks. In short, we look for explanatory factors that can replace the structural breaks. Thus, as Arnold et al. (2007) and Thévenon et al. (2012), we refer to an economic model - more precisely the Solow growth model augmented with human capital - to find a coherent set of relevant explanatory factors whose combination allows to define a long run target labor productivity. This target is expected to exert an error-correcting mechanism which contributes to the evolution of the productivity growth.

We find that human capital captured through education is the main determinant beside propensity to invest in physical productive capital, or workforce population growth. This result is robust to changes in the measure of education level.

First, our paper contributes to the literature studying the identification and the nature of breaks (i.e., cyclical or structural) in the evolution of productivity, either labor or total factor productivity. Most of articles on this issue use the Bai-Perron test (1998) to identify them. This test, for which changes in equilibrium productivity growth occur at specific dates, aims at identifying jointly the optimal number of breaks and their dates. We can mention the analyses by Bosquet and Fouquin (2008) Bergeaud et al. (2015) and Cette et al. (2017) which cover respectively the periods 1960-2008, 1890-2012 and 1976-2016 and focus respectively on the main developed countries, developed and emerging countries and France. Note that Benati (2007) compares the Bai-Perron test with Stock and Watson $(1996,1998)$ methodology which allows variable coefficients, from which a progressive change in growth regime can be tested.

We adopt the Bai-Perron test to analyze the hourly labor productivity adjusted or not by the capacity utilization rate (CUR) in manufacturing industry at an aggregate level but also at a sectoral level to better explain the origin of breaks identified for the global economy. Three over different estimation periods are considered for robustness checks ${ }^{1}$.

Second, we contribute to the literature on the macroeconomic impact of human capital on productivity growth. These studies are mainly based on the papers by Mankiw et al. (1992), and Lucas (1988), which, broadly speaking, focus on the analysis of the determinants of convergence processes towards the technological frontier. The first paper refers to the Solow growth model and includes a stock of human capital, which accumulates like physical capital, with decreasing returns to scale and transitional effects of productive investment on economic growth. The second paper considers human capital as a labor augmenting input in order to have perfect substitute between these two terms, with constant returns to scale and persistent effect of investment.

Early empirical estimates, mainly referring to Mankiw et al. (1992) model, like the ones obtained by Bernanke and Gurkaynak (2001), Canarella and Pollard (2003), find no evidence of such permanent effects of investment. This is the same

\footnotetext{
${ }^{1}$ The lack of robustness of the breaks we estimate with the Bai-Perron test is often highlighted: the specification of the period affects the identification of structural breaks.
} 
for studies which use expansions of this model, for instance, Bajo-Rubio (2000) who developed a generalized model with $n$ inputs and Daniels and Kakar (2017) who considered a CES production function instead of the Cobb-Douglas one. Yet, the augmented Solow growth model may be criticized because of the difficulty to appreciate the propensity to invest in human capital, which is usually measured by education-related variables only.

Arnold et al. (2007) and Thévenon et al. (2012) specify an alternative model which directly involves the stock of human capital, still restricted to education, instead of the propensity to invest in this type of capital. They also substitute a panel data approach to the usual cross-country approach. Their econometric strategy aims at estimating an error-correction model in which the productivity growth depends on error correction mechanism towards a steady state target, characterized from relevant long-term determinants. Their specification also has the advantage of being broad enough to allow to test both approaches by Mankiw et al. (1992) and Lucas (1988). They thus highlight a strong speed of convergence to the steady state, which is consistent with the Uzawa-Lucas model, instead of the augmented Solow growth model. Note also the work by Botev et al. (2019) who propose a new measure of human capital based on years of schooling with timevarying and country-specific returns. If they find a significant positive link between human capital and productivity for OECD countries, their estimates are statistically different from a one-to-one relationship assumed by the Uzawa-Lucas model.

Our contribution to this literature consists in estimating an augmented growth model with human capital in the lines of Arnold et al. (2007) by focusing on France over the last four decades. The use of error correction models aims at estimating successively 1) a two-step model (Phillips and Hansen, 1990) so to analyze the structural model augmented with the structural breaks we have identified before, 2) a univariate error correction model to confirm the results obtained with the first approach, and 3) a vector error correction model (Johansen 1995 ) to account for possible endogeneity issues. We also use two definitions of the stock of human capital and examine several estimation periods for robustness checks.

The paper is organized as follows. Next section presents the methodology, including the empirical models and the theoretical references. Afterwards, we precisely describe data, in particular, the variable of human capital, because we depart from the most usual specification adopted in the literature. Then follow the results and right after we discuss the robustness of our findings and finally we conclude.

\section{Methodology}

The aim is to propose a specification of the trend labor productivity and to examine how to estimate it. In the following section, we focus on the labour productivity per hour worked. 
$\operatorname{lprod}_{t}=\operatorname{lnV} A_{t}-\operatorname{LnH}_{t}=v a_{t}-h_{t}$

$\ln V A_{t}$ and $L n H_{t}$ are the Napierian logarithm of the real gross value added and the number of hours worked by both employees and independent workers respectively.

As announced in introduction, we propose two specifications. The first one is a deterministic one, for which trend productivity is characterized as a piecewise linear function of time. The shifts in the slope of the function at some specific dates account for what is called "structural" breaks.

The second characterization is more structural; it is obtained by linearly combining observable explanatory factors and a linear trend without breaks, which is usually justified to account for the technical progress.

Both specifications are complementary for the questions we address. By using the estimation results obtained for the deterministic specification, we can decide whether the 2008 crisis is associated with a structural break or not. On the other hand, the second specification allows us to identify possible determinants that may explain the slowdown in the labor productivity growth.

We adopt the same principles to identify the trend productivity for both specifications. As announced in introduction, the productivity, when adjusted for its trend component, must be stationary, i.e., without unit root, and therefore purely cyclical. Moreover, the trend productivity has to play the role of a long run target which constantly exerts an error mechanism in the short run fluctuations.

\section{Specification of the Trend Productivity as a Piecewise Linear Time Trend}

It is usually admitted that the technical progress contributes to the trend labor productivity. Generally, a linear function of time is used to capture the technological progress. When we consider such a linear time trend to characterize the trend of the log-productivity, we have to admit that the equilibrium labor productivity growth rate is constant over time.

However, when observing the time evolution of the French labor productivity (in logarithm) over the last four decades, we notice that it has an increasing trend but its growth rate displays a clear slowdown (Figure 2). This slowdown can be measured after the 2008 financial crisis but it was already significant at the beginning of the 2000's. The same type of evolution can be observed for other European countries and for the US.

So, we conclude that a specification with only linear time trend is not adapted to capture the trend component of our productivity series. A simple way to modify this linear time trend involves adding changes in the level and/or the slope at some dates which have to be in limited number. Thus, the productivity growth rate is rather piecewise constant and the trend labor productivity is a decreasing step function. This characterization has already been adopted, notably by Jimeno et al. (2006), Bergeaud et al. (2015) or Cette et al. (2017). Except in Jimeno et al. (2006), who develop a multivariate analysis, all of these analyses use the Bai and Perron test to identify structural breaks in labor productivity. 
Figure 2. Evolution of Aggregate Labor Productivity per Hour Worked (Value Added per Hour Worked, in Euro, Constant Prices) in France with Structural Breaks

2a Labor Productivity in Level

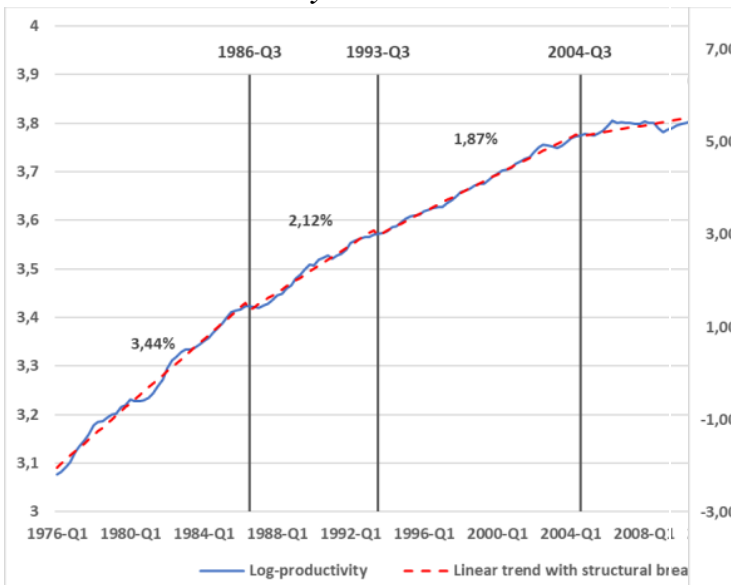

2b Labor Productivity Growth Rate

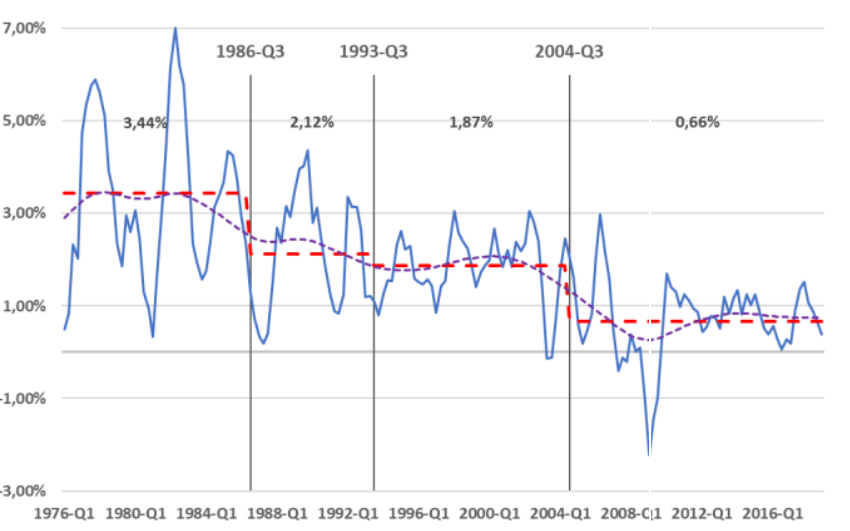

$\begin{array}{llllllllllllllll}1976-Q 1 & 1980-Q 1 & 1984-Q 1 & 1988-Q 1 & 1992-Q 1 & 1996-Q 1 & 2000-Q 1 & 2004-Q 1 & 2008-Q 1 & 2012-Q 1 & 2016-Q 1\end{array}$

Source: INSEE.

According to a terminology that has been broadly used since the contributions of Perron $(1990,1994)$ to analyze the interplay between structural change and unit root, we interpret these rare changes of the trend component as structural breaks in the $(\log )$ productivity. breaks.

Thus, the aim is to identify the number of the breaks and the dates of these

The logarithm of the productivity is decomposed into a long run component $\operatorname{lprod}_{t}^{l T}$ and a cyclical part according to:

$$
\operatorname{lprod}_{t}=\operatorname{lprod}_{t}^{l T}\left(+\mu * C U R_{t}\right)+Z_{t}
$$

with $C U R_{t}$ the capacity utilization rate and $Z_{t}$ the error-correcting variable, which contributes to the short-run fluctuation besides $U_{t}$ according to:

$$
\Delta \operatorname{lprod}_{t}=\gamma * Z_{t-1}+U_{t}
$$

$C U R_{t}, Z_{t}$ and $U_{t}$ have no unit root contrary to $\operatorname{lprod}_{t}^{l T}$.

The capacity utilization rate is supposed to capture cyclical fluctuations and to allow a better identification of lprod $_{t}^{l T}$ according to Lequien and Montaut (2014) and Cette et al. (2017).

Moreover, the trend (log)productivity $\operatorname{lprod}_{t}^{l T}$ is specified as a deterministic piecewise linear function of time:

$$
\operatorname{lprod}_{t}^{l T}=\alpha+\sum_{k=0}^{m} \alpha_{k} \mathbb{1}_{t \geq t_{k}}+\beta t+\sum_{k=0}^{m} \beta_{k} \mathbb{1}_{t \geq t_{k}} * t
$$


where $\mathbb{1}_{t \geqq t_{k}}$ is a dummy variable which is equal to 1 if date $t$ is posterior to the break date $t_{k}$ and to 0 otherwise.

We aim at finding the smallest set of break dates, $K$, which allows to make the series $\left(Z_{t}\right)_{t}$ stationary (i.e. without unit root). To do so, we refer to the Bai et Perron test (1998); the set of breaks $K$ and the break dates $t_{k}, k=1, \ldots, K$ are determined by calculating the OLS estimates of the $\alpha_{k}$ and $\beta_{k}$ parameters for all K-partitions and by choosing the partition which minimizes the sum of the corresponding squared residuals $Z_{t}$. An important point is thus that the test procedure rules out the possibility to have unit roots in the errors $Z_{t}$, which is precisely a main requirement we have imposed $a$ priori.

To check that this property is verified, we perform an ADF unit root test on the series o $Z$ (residual of the linear regression corresponding to equation (1). The critical thresholds are then obtained by simulation because the standard thresholds given by MacKinnon (2010) are relevant only in the absence of breaks.

We then consider the equation of the growth rate of productivity:

$$
\Delta \operatorname{lprod}_{t}=b_{0}+\sum_{k=1}^{m} b_{k} \mathbb{1}_{t \geqq t_{k}}+\gamma * \hat{Z}_{t-1}+\sum_{j=1}^{p-1} \varphi_{j} \Delta \operatorname{lprod}_{t-j}+u_{t}
$$

with not serially correlated residuals $u_{t}$ and $p$ the optimal number of lags that we determine with the usual information criteria. We check that the coefficient $\gamma$ of $Z_{t-1}$ is significantly negative, which proves the existence of an error-correcting mechanism, according to the two-step cointegration analysis proposed by Engle and Granger (1987). All parameters are estimated with the two-steps Fully Modified OLS (FMOLS) method introduced by Phillips and Hansen (1990).

Finally, we make sure that the break dates can be interpreted from a retrospective review of the main structural changes which may have influenced the evolution of hourly labor productivity (notably changes in technology or in public policy).

\section{Structural Approach: Trend Productivity and its Fundamentals}

Then, we aim at finding observable factors $X_{i}, i=1, \ldots, I$, which explains the trend productivity and remove all structural breaks entering the first specification, according to equation (2), which replaces equation (1):

$$
\operatorname{lprod}_{t}=a+b t\left(+m * C U R_{t}\right)+\sum_{i=1}^{I} \delta_{i} X_{i t}+Z_{t}
$$


In that case, the trend (log)productivity $\operatorname{lprod}_{t}^{l T}$ is stochastic and specified as a linear combination of relevant determinants $X_{i t}$, in the lines of Arnold et al. (2007) and Thévenon et al. (2012) for example. These determinants must be persistent, that is they must have a unit root like the log-productivity. More precisely, they must share common (stochastic) trends with productivity, which is equivalent to say that productivity and determinants are cointegrated (Wickens 1996).

Thus, as before, $Z_{t}$, which represents the cyclical component, is expected to have no unit root and to enter the so-called short-term equation of the productivity growth according to an error-correction mechanism:

$$
\begin{aligned}
\operatorname{sprod}_{t}= & b_{0}+\gamma * \hat{Z}_{t-1} \\
& +\sum_{j=1}^{p-1} \varphi_{11, j} \Delta \operatorname{lprod}_{t-j}+\sum_{i=1}^{I} \sum_{j=1}^{p-1} \varphi_{1 i, j} \Delta X_{i, t-j}+u_{t}
\end{aligned}
$$

If the series $Z_{t}$ has no unit root with $\gamma$ significantly negative, the $X_{i t}$-factors are defined as fundamental determinants of labor productivity. In this case, there is no need to refer to ad hoc critical thresholds obtained by simulation to check the stationary behavior of the $Z$-series. Indeed, as there are no breaks, we can directly use the standard critical thresholds (MacKinnon 2010).

Hence, our set of factors explains a structural break if 1) the introduction of factors allows to remove breaks whose coefficients become not significant and 2) the model has all the relevant features: stationary long-term residual, significant error-correction term and not serially i.i.d. short-term residual $u_{t}$, whether we estimate the model with or without the non-significant break.

For the estimation of the parameters, we proceed in the same way as for the first specification; that is with a two-step FMOLS estimation procedure. First, we estimate the long-term equation with the labor productivity in level depending on factors and potential breaks according to equation (2). We then verify that the series of residuals, $Z_{t}$, is stationary by computing the usual stationarity ADF tests which we compare with critical thresholds obtained by simulation ${ }^{2}$. We then estimate the short-term equation (equation (3)) to confirm the existence of an error-correction mechanism and we verify that the error terms $u_{t}$ are not serially correlated. We proceed as long as structural breaks remain in the specification. Once all structural breaks are "explained", we use the Bai and Perron test to check whether residual breaks remain.

Let us mention that we have performed different robustness analyses. In particular, we have examined how results about the structural breaks are affected by the estimation period. To do that we have considered different periods which start respectively in 1949, 1960, 1976 and 1980. The results are not modified.

${ }^{2}$ Because the introduction of breaks makes the asymptotic distribution of the ADF statistics not standard. 
Concerning the structural model, we have used two additional estimation procedures to confirm the results obtained with the two-step procedure proposed by Phillips and Hansen (1990). First, in the lines of Banerjee et al. (1997), the long run parameters $\delta_{i}$ are estimated alongside the remaining $\varphi_{11, j}, \varphi_{1 i, j}$ and $\gamma$ in a single step using nonlinear least squares (NLS).

Second, to exclude any endogeneity issue, a multivariate approach is adopted to estimate the dynamics of the system composed of the log-labor productivity lprod $_{t}$ and its fundamentals $X_{i t}$. We use the Johansen (1988) and Johansen and Juselius (1990) procedure with the test of information criteria and the rank cointegration test. We then estimate a Vector Error Correcting model (VECM).

Note that we have also identified the breaks at a sectoral level, notably to improve the interpretation of the structural breaks identified for the global economy. Finally, we have examined how the breaks can be removed, or not, depending on the choice of the structural fundamentals in particular, depending on the variable retained to capture the human capital.

As announced in introduction, we have to justify the set of these fundamentals from a theoretical point of view. Thus, we refer to the generic augmented growth model with human capital, by Arnold et al. (2007), which allows to study convergence process to steady state, and whose principles and main predictions are presented in next section.

\section{The Augmented Growth Model with Human Capital}

We consider the human capital-augmented Solow growth model first presented by Mankiw et al. (1992) to analyze labor productivity in the long run. Following Arnold et al. (2007), this model provides a framework in which output per worker can be expressed as a function of the propensities to invest in productive physical capital, the stock of human capital, the working age population growth rate, the level of technological progress, captured by the average growth rate of the total factor productivity, and the constant depreciation rate of capital. Moreover, this approach allows to study output per worker in as well as out a steady state: the change in output per worker depends on a convergence components, technological progress and other determinants measured in level that may shift the steady-state output per worker in long-run. We also describe how changes in these determinants may influence output per worker in the short-term. Studying productivity by hours worked also involves augmenting the model with the total amount of hours worked by workers, which has decreased over time. Yet, the decline in working time observed at the macroeconomic level in most developed countries is linked to several trends whose effects are difficult to disentangle through econometrics (Beffy and Fourcade 2004), like:

1) Development of part-time jobs and greater flexibility in the labor market. Generally following policies which aimed at reducing unemployment; for example, targeted tax cuts on low skilled workers to lower their relative cost with respect to capital and skilled workers. 
2) Technical progress which allows to optimize the production process and the use of inputs thanks to productivity gains, either by reducing the number of hours worked per head or by reallocating it for other activities. The impact mainly depends on the exposure of company to competition and the degree of rigidity within the production unit and in the markets for goods, services and labor.

3) Development of new information and communication technologies from the 1980s to 1990s which might also have induced a decline in working time and (low) productivity gains observed in the manufacturing sector in some developed countries.

4) Finally, the reduction in working time may results from political decisions to reduce unemployment (e.g., the 35-hour workweek law in France). These policies aim at redistributing the total stock of hours worked and increasing job creation. Indirectly, they can have an impact on the restructuring of production process within companies: they can either optimize the use of their workforce or adopt new productive and/or managerial practices (Crépon et al. 2004).

Following Mankiw et al. (1992) and Beffy and Fourcade (2004), we consider a standard Cobb-Douglas function augmented with a stock of human capital and hours worked per worker

$$
Y(t)=K(t)^{\alpha} Q(t)^{\beta}\left(A(t) h^{\rho} L(t)\right)^{1-\alpha-\beta}
$$

where $K(t)$ and $Q(t)$ stand for productive physical capital and human capital respectively, $L(t)$ is the total amount of labor, $A(t)$ the level of technology, $h$ the number of hours worked by workers. $\alpha$ and $\beta$ are the partial elasticities of output with respect to physical and human capital. These coefficients also represent the share of each input in value added. The parameter $\rho$ measures the potential impact of a change in hours worked on labor productivity. Depending on the inputs' substitutability, a decrease in hours worked may boost hours productivity as well as slow down productivity per employee.

Both types of capital can be accumulated according to:

$\dot{K}(t)=s_{K}(t) Y(t)-\delta K(t)$

$\dot{Q}(t)=s_{Q}(t) Y(t)-\delta Q(t)$

where $s_{K}$ and $s_{Q}$ stands for the propensity to invest in productive physical and human capitals and $\delta$ for the rate of depreciation of capital, supposed to be the same for the two types of capital. Having different depreciation rates would not change the general results.

We assume there are two exogenous sources of growth, technological progress and working age population, which is equal to the total amount of labor. Both of them evolve according to: 
$\dot{A}(t)=g_{A}(t) A(t)$

$\dot{L}(t)=g_{L}(t) L(t)$

where $g_{A}(t)$ and $g_{L}(t)$ stand for the corresponding growth rates.

By dividing the variables $\mathrm{Y}(t), \mathrm{K}(t)$ and $Q(t)$ by $A(t) L(t)$, we obtain new variables (in small letters) entering a stationary model from which we can deduce the expression of labor productivity per hour worked:

$$
\begin{aligned}
& \operatorname{lnprod}(t)=\ln \left(A\left(t_{0}\right)\right)+\sum_{k=1}^{K} a_{k} \mathbb{1}_{t \geqq t_{k}}+g_{A}\left(t-t_{0}\right)+\sum_{k=1}^{K} b_{k} \mathbb{1}_{t \geqq t_{k}}\left(t-t_{0}\right) \\
& -\left(1-\gamma \frac{1-\alpha-\beta}{1-\alpha}\right) \ln (h(t))+\frac{\alpha}{1-\alpha} \ln \left(s_{K}(t)\right) \\
& +\frac{\beta}{1-\alpha} \ln \left(s_{Q}(t)\right)-\frac{\alpha}{1-\alpha} \ln \left(g_{A}(t)+g_{L}(t)+\delta\right)
\end{aligned}
$$

See Appendix 1 for the details of the derivation.

\section{Data}

We mainly use INSEE database, but also other specific databases for some variables of interest. The data are measured at quarterly levels, in national currency for monetary variables, and according to domestic concepts for employment variables. We consider the period 1976-2018 to analyze the productivity which allows us 1) to use the full dataset on capacity utilization rate for the identification of structural breaks, 2) to analyze productivity over four decades and 3) to avoid the high volatility in the data prior to the oil shock.

We focus on Labor productivity in logarithm, i.e. the difference between the logarithms of the gross value added and of the number of hours worked. The gross valued added is better adapted to sectoral analyses, although we may face misallocation issues when we analyze specific sectors and activities. Following OECD, we choose to refer the total amount of hours worked as the unit of labor input measure, which is more precise than productivity per employee. This way, we are able to capture the impact of changes in hours worked and to account for self-employment or part-time employment.

We first focus on the aggregate economy which we split between non-farm business sector on the one side and farm activity and public administrations on the other side. Analyzing the non-farm business sector that aggregates the $\mathrm{B}$ to $\mathrm{N}$ and $\mathrm{R}$ to $\mathrm{T}$ activities according to the ISIC rev. 4 allows to emphasize its role as the main driver of economic fluctuations. Considering the public administrations enables to have an exhaustive overview of aggregate economy, although the way 
of measuring productivity in this specific sector is controversial. Finally, we break down non-farm business sector into three different sectors, manufacturing industries (the $\mathrm{C}$ activity in ISIC rev. 4), business services (which aggregate the $\mathrm{G}$ to $\mathrm{N}$ and $\mathrm{R}$ to $\mathrm{T}$ activities) and construction (the $\mathrm{F}$ activity). This split aims at comparing productivity dynamics in different sectors and better capturing the nature of the structural breaks we identify in the aggregate economy and non-farm business sector.

Gross value added is measured in Laspeyres chain-linked volume with 2014 as reference year. Chain-linked index reflects the changes within the structure of the domestic economy as well as the mutual relations between prices and quantities produced. Yet, the main weakness of this method is the loss of additive consistency, i.e., the total is no longer equal to the sum of its parts apart from the reference period and the next one. Thus, for sector analysis, we use a specific method proposed by Eyraud (2007). For all details, see Bruneau and Girard (2020).

We define the average number of hours worked per worker as the ratio between the total number of hours worked in a quarter and the total number of workers. Considering both employees and self-employed people from domestic concept allows us to have the real contribution of workforce to the production. Likewise we question the precision of valued added measurement, the number of workers and hours worked may be misallocated too, because of part-time employment and overtime working hours.

Investment propensity is defined as the non-dwelling gross fixed capital formation to value added ratio. It measures the acquisition of immaterial and material fixed assets less the disposals. We do not account for the households' investments, i.e., the subsection "Dwelling" in national accounts database, to focus on productive investment from business sector and general government. As for value added, we also use the method of Eyraud (2007) to avoid miscalculating business investment whose components are measured in chain-linked volume prices.

Concerning human capital, it is approximated by education variables, either the share of 25-64 years-old people with a given level of education in workforce or their average total years of schooling.

We use two different databases, by Barro and Lee (2013) and Goujon et al. (2016) with the double benefit of using harmonized data for many countries over long-term periods. Both of them provide five-year data from 1950 to 2010 and from 1950 to 2020 respectively. To estimate the missing values for the Barro-Lee dataset over the period 2010-2018, we use the method by Lee-Lee, (2016) which involves estimating a logistic model from which the missing value can be extrapolated. Therefore, we consider two sets of variables, the average years of schooling of adults, and the share of adults with at least secondary schooling. See appendix 2 for the derivation of these variables. Moreover, the data are interpolated 
to have quarterly ${ }^{3}$ series although it may generate potential autocorrelation issues. It gives an approximation of what the data would have been at quarterly level, while assuming, as very long-term variables, their short-term variations are very small or null. However, we face correlation issues between trend and education trend variable(s), which may bias the coefficient estimates (Thévenon et al. 2012).

The population growth rate is measured over the working age population, that is the 15-64-year-old population, and we interpolate the intra-annual missing values, from which we can either compute the quarter-to-quarter growth rate or the growth rate compared to the same quarter of the previous year. Following Mankiw et al. (1992) and other studies of growth model, we assume constant depreciation and technical progress rates $^{4}$ we compute from data over France, from INSEE and AMECO.

As announced before, to better identify the trend productivity, we use the capacity utilization rate in manufacturing industry, measured over 1976-2018. Cette et al. (2017) also use this variable to adjust the deterministic relation in order to identify the effective structural breaks. Although the measure is restricted to the industry which accounts for less than $10 \%$ of gross value added in France, this activity is still the main engine of the rest of economy growth. We also use an alternative measure of capacity utilization rate in the business sector, over the period 1980-2016, calculated from the European commission's methodology, to test the robustness of our results.

\section{Results}

First, we present and discuss the results on the identification of the structural breaks when the trend labor productivity is characterized as a piecewise linear function. Then we turn to the structural analysis including the fundamentals derived from the augmented growth model with human capital. Here, we focus on total economy. Finally, we present and comment the results of some robustness analyses.

\section{Identification of the Structural Breaks in Aggregated Labor Productivity}

As explained before, the period we retain is 1976Q1-2018Q4. First, we check that the logarithm of the labor productivity has a unit root, for the total economy as well as for the sectors which will be considered later. We find that none of the series is stationary, i.e., they have all a unit root.

\footnotetext{
${ }^{3}$ We interpolate the data with the following formula $\left(\frac{q^{25-64}(\mathrm{j}, \mathrm{a})}{q^{25-64}(\mathrm{j}, \mathrm{a}-5)}-1\right)^{\frac{1}{20}}$, where $q^{25-64}(\mathrm{j}, \mathrm{a})$ is our human capital variable (either years of schooling or educational attainment $j$ over the adult population, at the year $a$.

${ }^{4}$ We could have considered varying depreciation and technical progress growth rates as we did for population growth rate. Yet, not using a constant value for technical progress growth might have biased the estimation of the linear trend coefficient due to simultaneity issue.
} 
Then we implement the Bai-Perron test to identify the structural breaks, dates and magnitude, for the total economy. These dates are given in Table 1. We find at most four structural breaks, one in each of the four decades. As expected, the number of breaks and the corresponding dates depend on whether capacity utilization is included or not.

Table 1. Results of the Bai-Perron Test for the Global Labor Productivity per Hour over the Period 1976-2018

\begin{tabular}{|l|c|c|c|c|}
\hline $\begin{array}{l}\text { Deterministic } \\
\text { Trend }\end{array}$ & & & & \\
\hline $\begin{array}{l}\text { CUR-adjusted } \\
\text { productivity }\end{array}$ & 1986 Q3 & $1993 Q 3$ & $2004 Q 3$ & \\
\hline $\begin{array}{l}\text { Observed } \\
\text { productivity }\end{array}$ & $1986 Q 3$ & $1993 Q 1$ & 2002Q2 & 2008Q2 \\
\hline
\end{tabular}

Source: France Stratégie.

The first break is found in 1986, the second break in 1993 and the third one in 2002, without CUR, and 2004, when we include the CUR. A break in 2008 only appears when productivity is not adjusted with the capacity utilization rate in manufacturing industry. This result tends to indicate that the effect of the 2008 crisis rather contributes to cyclical fluctuations of the productivity. In other words, the economic crisis in 2008 did not cause a structural break in equilibrium labor productivity, but it might have amplified a previous structural break.

Table 2 gives the estimations. All parameters are significant at $1 \%$ except the break in level in 2008. There is a significant error correction term in the short-term equations and $40 \%$ to $50 \%$ of the variance of the productivity growth rate is thus predicted. Yet, without CUR, the residual displays some heteroskedasticity. Figure 2 give the aggregate labor productivity in level and in growth with the breaks we identify with the capacity utilization rate. Figure $2 b$ gives the effective growth rate compared to the same quarter of the previous year, the average growth rate between two structural breaks and the trend growth rate obtained with a HodrickPrescott filter.

To explain the break in the 1980s, Cette et al. (2017) emphasize the impact of the two oil shocks that occurred in the 1970's. The important variations in the price of oil would have brought out structural imbalances in developed countries and the underlying inflation of the 1960's accelerated in the 1970's and the 1980's due to overinvestments, inflationist structure of the financial system and the wage growth. Moreover, at the beginning of the 1980's (in 1983 in France with the socalled "Tournant de la rigueur"), the fight against inflation became a priority in most of developed countries. In France, the government explicitly removed the wage indexation to inflation in 1982. More generally, governments in developed countries aimed at removing the relation between inflation and wage increases, and promoted flexibility and targeted the relative cost of low-skilled jobs vis-à-vis high-skilled jobs through targeted social tax cuts (Bergeaud et al. 2016). 
Table 2. Estimation Results for the Deterministic Long-Term Productivity Equation

\begin{tabular}{|c|c|c|}
\hline & $\begin{array}{c}\text { Breaks identified with the CUR } \\
\text { included }\end{array}$ & $\begin{array}{l}\text { Breaks identified for the } \\
\text { observed productivity }\end{array}$ \\
\hline \multirow{2}{*}{ Intercept } & $3.083 * * *$ & $3.083^{* * *}$ \\
\hline & 0.005 & 0.004 \\
\hline \multirow{2}{*}{ Time-trend } & $0.0083 * * *$ & $0.0083 * * *$ \\
\hline & 0.0002 & 0.0002 \\
\hline \multirow{2}{*}{ Break86 } & $0.071 * * *$ & $0.061 * * *$ \\
\hline & 0.020 & 0.018 \\
\hline \multirow{2}{*}{ Break93 } & $0.073 * * *$ & $0.088 * * *$ \\
\hline & 0.026 & 0.024 \\
\hline \multirow{2}{*}{ Break02 } & & $0.225 * * *$ \\
\hline & & 0.042 \\
\hline \multirow{2}{*}{ Break04 } & $0.366 * * *$ & \\
\hline & 0.024 & \\
\hline \multirow{2}{*}{ Break08 } & & 0.071 \\
\hline & & 0.044 \\
\hline \multirow{2}{*}{ Break86*t } & $-0.0022 * * *$ & $-0.0019 * * *$ \\
\hline & 0.0004 & 0.0003 \\
\hline \multirow{2}{*}{ Break93*t } & $-0.0013 * * *$ & $-0.0015 * * *$ \\
\hline & 0.0004 & 0.0004 \\
\hline \multirow{2}{*}{ Break02*t } & & $-0.0020 * * *$ \\
\hline & & 0.0004 \\
\hline \multirow{2}{*}{ Break04*t } & $-0.0032 * * *$ & \\
\hline & 0.0002 & \\
\hline \multirow{2}{*}{ Break08*t } & & $-0.0007 * *$ \\
\hline & & 0.0004 \\
\hline ADF statistics & -5.965 & -6.528 \\
\hline \multirow{2}{*}{$\begin{array}{l}\text { Lagged Error-correcting } \\
\text { term }\end{array}$} & $-0.327 * * *$ & $-0.436 * * *$ \\
\hline & 0.044 & 0.059 \\
\hline Adjusted $\mathrm{R}^{2}$ & 0.403 & 0.497 \\
\hline $\begin{array}{l}\text { Jarque-Bera test: P- } \\
\text { value }\end{array}$ & 0.106 & 0.030 \\
\hline $\begin{array}{l}\text { Heteroskedasticity BPG } \\
\text { test P-value }\end{array}$ & 0.969 & 0.907 \\
\hline Number of observations & 172 & 172 \\
\hline
\end{tabular}

Source: Authors Calculations. FMOLS Estimation; Break02 is a dummy variable which is equal to 0 until last quarter of 2001 (included) and 1 otherwise. The associated coefficient measures the change in the level at first quarter of 2002 (2002Q1). The coefficient of Break02*t measures the change in the slope at the same date. $* * *$ and $* * *$ indicate significant coefficients at $10 \%, 5 \%$ and $1 \%$ risk levels respectively. The error-correcting term is the lagged $Z$ variable It is associated with a negative and significant coefficient, which confirms the existence of an error correcting mechanism toward the long run target. ADF statistics indicates the value of the Unit Root test statistics. The coefficient associated to each break in the slope indicates the magnitude of the decrease of the productivity growth rate from the corresponding date until the end of the observation period. Accordingly, one can calculate the average growth rate between two successive dates of break $t_{j}$ and $t_{j+1}$ is the sum of the coefficients associated with all changes in the slope until date $t_{j}$ included. The BPG test (resp. JaqueBera) is the Breusch Pagan Geoffrey test for heteroskedasticity (resp. for normality) applied to the short run residuals.

Concerning the break in the 1990s, it is well documented in the literature. The employment policy, as structural policy, may have caused the slowdown of 
productivity in this period, as claimed by Beffy and Fourcade (2004,) who identify a break in 1992 when they analyze the labor productivity in the French non-farm business sector over the period 1978-2003. Cette et al. (2017) identify a break either in 1995 or 1996 depending on whether the series of productivity is adjusted or not. Finally, the relatively slow spread of information and communication technologies (vis-à-vis the United States mainly) may have contributed to the weak productivity growths. In particular, economists noticed a gap between the productivity growth rate in the United States and the one in the other developed countries. Economic literature highlights the role of market rigidities and lower educational level as main determinants (Cette and Lopez 2012).

Concerning the break in the 2000's, it is identified in 2002 by Cette et al (2017) who focus on the capacity utilization-adjusted productivity and in 2000 by Bergeaud et al. (2016) who consider productivity without adjustment but over a far longer period (1890-2012). It corresponds to the most important decrease in the labor productivity growth over the period 1976-2018. If economists still highlight the role of employment policy as its effects may last over decades, other economists point out the more global impact of innovation. According to some of them (Gordon 2012, 2013, 2014, 2015), the third industrial revolutions already ended and did not cause a wave of productivity growth as important as the second revolution did. On the contrary, other economists emphasize a resources misallocation issue among sectors which slows down the reallocation process or the real industrial revolution is about to happen with the deployment of new technologies, like Artificial Intelligence for instance (Van Ark et al., 2016).

The second step of our analysis involves estimating a structural model based on an augmented growth model with human capital to substitute determinants to the structural breaks. We start with the previous specification including the CUR in manufacturing industry.

\section{Estimation of the Structural Model for the Global Economy}

To estimate the augmented growth model, we have investigated different measures of human capital, notably the average total years of schooling and the share of adults with at least secondary education. The former measure rather captures the stock of human capital while the latter emphasizes the qualitative evolution of education output. However, we only present the results obtained with the share of adults with at least secondary education as a measure of human capital, using the database by Barro and Lee (2013). Indeed, this specification allows to remove all structural breaks and, accordingly, to adopt a multivariate estimation method in addition to the single-equation analyses, which the specification with the years of schooling does not allow to do. The results obtained with the other specifications of Human capital using this database, and the one by Goujon et al. (2016), are available upon request.

The period is 1976-2018. The estimation results are reported in Table 3. As we are able to specify a stationary model without structural breaks, we can estimate the VECM to avoid any endogeneity issue. If the break in 1993 finally 
remains significant at 5\%, the specification of the model without this specific break has meanwhile the desired properties (stationarity of the long-term residual, significant coefficients with expected signs in the long-run equations, and significant error-correction mechanism).

Table 3. Different Estimation of the Structural Form of the Trend (log) Productivity

\begin{tabular}{|c|c|c|c|}
\hline $\begin{array}{l}\text { Hourly labor (log-) } \\
\text { productivity }\end{array}$ & $\begin{array}{l}\text { FMOLS in two } \\
\text { steps }\end{array}$ & $\begin{array}{l}\text { Univariate error } \\
\text { correcting model }\end{array}$ & VECM \\
\hline \multirow{2}{*}{$\ln \left(h_{t}\right)$} & $-0.843^{* * *}$ & $-0.988^{* * *}$ & $-0.859 * * *$ \\
\hline & 0.074 & 0.105 & 0.111 \\
\hline \multirow{2}{*}{$\ln \left(s_{K . t}\right)$} & $0.039 *$ & 0.048 & $0.116 * * *$ \\
\hline & 0.021 & 0.013 & 0.028 \\
\hline \multirow{2}{*}{$\ln \left(q_{t}\right)$} & $0.397 * * *$ & $0.363 * * *$ & $0.382 * * *$ \\
\hline & 0.019 & 0.039 & 0.027 \\
\hline \multirow{2}{*}{$\ln \left(n_{t}+g^{t o t}+\delta\right)$} & -0.029 & -0.071 & $-0.077 * *$ \\
\hline & 0.021 & 0.015 & 0.033 \\
\hline \multirow{2}{*}{ Intercept } & $8.755^{* * *}$ & $9.560 * * *$ & 8.887 \\
\hline & 0.433 & 0.948 & \\
\hline \multirow{2}{*}{ Time trend } & $0.0007 * * *$ & $0.0005 * * *$ & $0.0003 * *$ \\
\hline & $6.82 \mathrm{E}-05$ & $6.50 \mathrm{E}-05$ & 0.0001 \\
\hline \multirow{2}{*}{$\begin{array}{l}\text { Error correcting } \\
\text { variable } Z_{\mathrm{t}-1}\end{array}$} & $-0.283 * * *$ & $-0.362 * * *$ & $-0.205 * * *$ \\
\hline & 0.090 & 0.098 & 0.046 \\
\hline ADF statistics & -5.539 & & \\
\hline 5\%-Critical threshold & -4.817 & & \\
\hline Adjusted $\mathrm{R}^{2}$ & 0.353 & 0.362 & 0.487 \\
\hline $\begin{array}{l}\text { Jarque-Bera test: P- } \\
\text { value }\end{array}$ & 0.515 & 0.874 & \\
\hline $\begin{array}{l}\text { Heteroskedasticity } \\
\text { BPG test P-value }\end{array}$ & 0.587 & 0.176 & \\
\hline $\begin{array}{l}\text { Number of } \\
\text { observations }\end{array}$ & 172 & 172 & 172 \\
\hline
\end{tabular}

Source: Authors Calculations.

For the estimation of the error-correcting equation in a single stage, the long-term coefficients have been divided by the estimated value of the coefficient of the error correcting variable, in order to be compared with the estimated values obtained with the other estimation methods.

$*$, ** et *** désigne respectivement une significativité à 10\%, 5\% et $1 \%$.

ADF: ADF Unit Root test statistics. 5\% critical threshold comes from Mac-Kinnon tables (2010).

The error-correcting term is the lagged $Z$ variable It is associated with a negative and significant coefficient, which confirms the existence of an error correcting mechanism toward the long run target.

The adjusted $R^{2}$ is related to the short-term equation. We do not indicate the adjusted $R^{2}$ for the long-term equation which is artificially close to 1 while the Durbin-Watson test is significantly different from 2.

The BPG test is the Breusch Pagan Godfrey test for heteroskedasticity in the residual of the shortterm equation, for which we give the $\mathrm{T} * \mathrm{R}^{2}$ statistic and its $\mathrm{p}$-value. If we only refer to the BPG test, we also considered the ARCH LM test and the White test. 
It is worth emphasizing that the results obtained with the different estimation methods are very similar: the two single-equation approaches, either in two steps with FMOLS, in the lines of Phillips and Hansen (1990) or in one step according to the non-linear estimation proposed by Banerjee et al. (1997) provide results which are very close to the ones obtained with the multivariate approach of Johansen (1990). Therefore, we can be confident in the results; in particular we can exclude any endogeneity issue. When focusing on the results obtained when estimating the VECM, the rank test indicates one cointegration relationship. The estimates of the long run parameters are consistent with what is expected from the Solow growth model. In particular, we have symmetry in our results for the parameters of propensity to invest and workforce population growth rate.

The estimated elasticity of productivity to the propensity to invest in productive physical capital is significantly positive and in the low range of estimates found in the literature. On the contrary, the estimated elasticity of productivity to hours worked per worker is significantly negative and falls into the high range of estimates found in the literature. This result is consistent with the growth model previously derived without the coefficient $\rho$ in the equation 3 . This indicates that any change in working hours is offset by changes in the hourly labor productivity in the long-term. ${ }^{5}$

When we refer to the results obtained in the literature for the OECD countries, whose economies are heterogeneous, yet comparable to France we can conclude that our results are similar to the ones obtained in the literature, in terms of significance and magnitude.

Finally, we assess the contribution of the different determinants to the annual growth rate of the labor productivity and we examine how these contributions evolve over time. The contributions are derived from the long run equation by differentiating the theoretical equation as follows:

$$
\begin{aligned}
& \frac{\text { lprod }_{t}-\text { lprod }_{t-4}}{\operatorname{lprod}_{t-4}} \approx \theta_{1} \frac{h_{t}-h_{t-4}}{h_{t-4}}+\theta_{2} \frac{s_{k, t}-s_{k, t-4}}{s_{k, t-4}} \\
& +\theta_{3} \frac{q_{t}-q_{t-4}}{q_{t-4}}+\theta_{4} \frac{g_{L, t}-g_{L, t-4}}{g_{L, t-4}}+4 * g_{A}+\Delta \varepsilon_{t}
\end{aligned}
$$

The $\theta$ - parameters take the values which are estimated with the two-step FMOLS procedure. The results are summarized in Figure 3.

\footnotetext{
${ }^{5}$ Note that Beffy and Fourcade, (2004) augment a CES production function with a strictly positive compensation factor which is supposed to vary between 0 and 1, so that part of the working hours can be redistributed in the form of job creation. Such redistribution mechanism can therefore reduce the equilibrium aggregate productivity growth over the medium term.
} 
Figure 3. Decomposition of the Annual Growth Rate of the Labor Productivity for the Whole Economy (1976-2018)

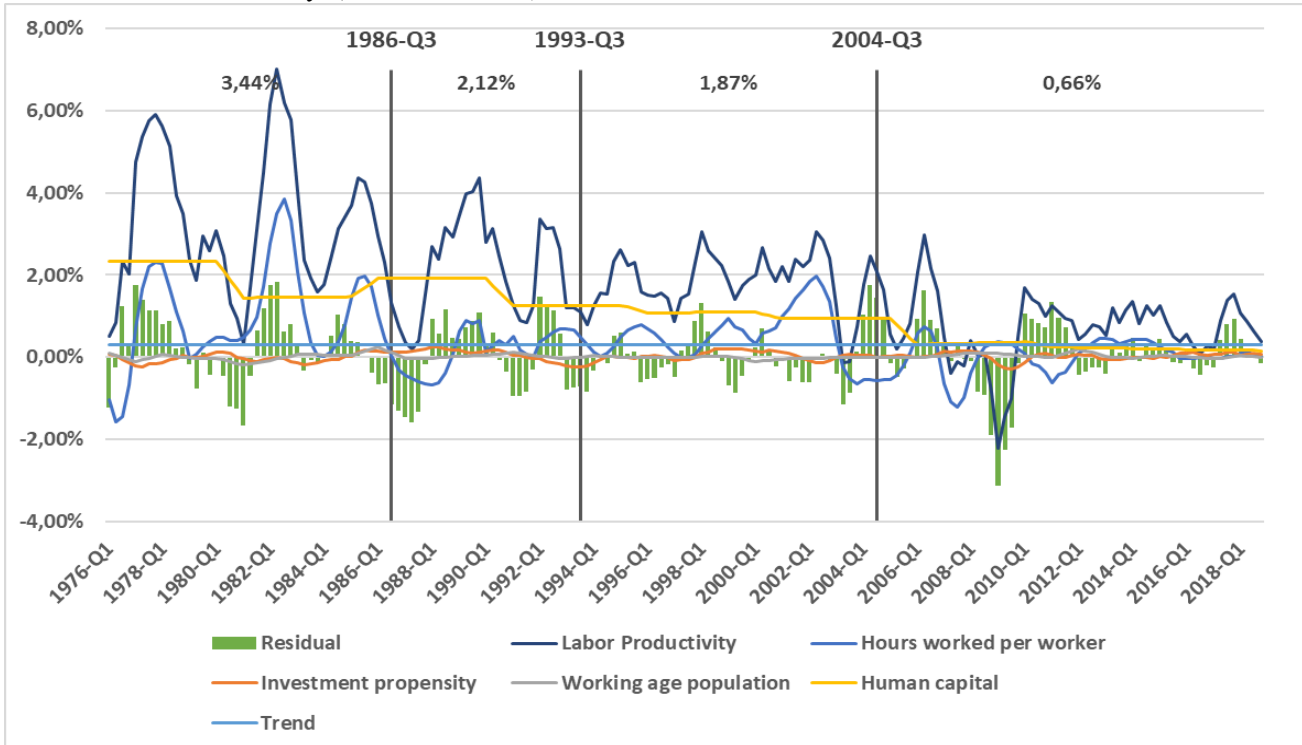

Source: Authors Calculations.

The growth rate of the labor productivity is decomposed into the contributions of the different determinants, with no remaining structural break. The stock of Human Capital is calculated from the data base of Barro and Lee (2013). The histogram indicated the part of the growth rate which is not explained by the model. A positive residual means that the productivity has increased more than its determinants.

We find a persistent effect of human capital on productivity growth until the beginning of the 2000s from which its contribution starts to decline. Neither the propensity to invest in physical productive capital nor workforce population growth rate has a persistent impact, which is consistent with the studies of Jones (1995). The residual is well cyclical, with a larger contribution during the 2008 crisis that the model does not capture totally. From the 2000s, a larger part of the productivity growth rate remains unexplained, due to the decrease in the contributions of human capital and hours worked. Hence, other factors may have contributed to the evolution of labor productivity.

\section{Discussion about the Robustness of the Results}

As announced before, we consider several estimation periods. In addition to the one used to get the estimations presented before, the period 1949-2018 allows us to account for the evolution of the French economy on all the available data on labor productivity. The period 1970-2018 includes the first oil shock, without the period of economic catching-up following the Second World War. Finally, the period 1980-2016 allows to emphasize the analysis after the period of high volatility that characterizes the decades prior to the 1980 's, and to use another 
measure of capacity utilization rate which is related to the business sector and computed according to European commission's methodology. The results presented in Table 4 are very similar to the first ones.

Table 4. Identification of the Structural Breaks for Different Estimation Periods and with/without CUR Adjustment

\begin{tabular}{|c|c|c|c|c|c|}
\hline Periods & \multicolumn{5}{|c|}{ Identified breaks } \\
\hline 1949Q1-2018Q4 & 1969Q2 & 1981Q4 & 1992Q3 & $2002 q 4$ & \\
\hline 1970Q1-2018Q4 & 1975Q1 & 198604 & 1991Q3 & $2002 \mathrm{O} 1$ & $2008 \mathrm{Q} 4$ \\
\hline $1976 \mathrm{O} 1-2018 \mathrm{O} 4$ & & 198603 & 199301 & 200201 & $2008 \mathrm{O} 2$ \\
\hline $\begin{array}{l}\text { 1976Q1-2018Q4 for } \\
\text { the CUR-adjusted } \\
\text { productivity }\end{array}$ & & 1986Q3 & 1993Q3 & 2004Q3 & \\
\hline 1980Q1-2016Q4 & & 1986Q3 & 1996Q2 & 2002Q2 & $2008 \mathrm{Q} 4$ \\
\hline $\begin{array}{l}\text { 1980Q1-2016Q4 for } \\
\text { the CUR-adjusted } \\
\text { productivity }\end{array}$ & & 1986Q3 & 1996Q1 & 2002Q2 & \\
\hline $\begin{array}{l}\text { 1980Q1-2016Q4 for } \\
\text { the CUR-adjusted } \\
\text { productivity }\end{array}$ & & 1987Q1 & 1995Q2 & 2002Q2 & $2009 \mathrm{Q} 3^{6}$ \\
\hline
\end{tabular}

Source: Authors Calculations.

Then, we turn to sectoral analyses of break identification following the same procedure as before. Here we just comment the results obtained without detailing the estimation results, which are available upon request. Beyond robustness analyses, this comparison allows us to improve the interpretation of the breaks that have been identified at the aggregate level.

For the non-farm business sector and public administration with farm activities, a first break is identified in the 1980s. The one identified for the nonfarm business sector is shared with total economy, which means a business origin. The break of the early 1990s and 2000s are shared by the two sectors considered (i.e., non-farm business sector and public administrations), as well as by the total economy. A break at the time of the 2008 crisis is identified only on the observed productivity for the two sectors. When we check for potential effects of cyclical components with the CUR in manufacturing industry, no significant structural break is identified for the public administration after the 1990's, while a break is identified before the crisis for the non-farm business sector in 2007.

The slowdown in productivity growth in the first decade of the 2000s was most pronounced in the non-farm business sectors than in the public administration whose productivity growth remains unchanged. In the non-farm business sector, it could be due to an increase in low-skilled and more precarious jobs which directly slows down aggregate productivity growth. On the other side, the development of high-skilled employment may affect the cyclicality of labor productivity: a firm is more likely to maintain this type of employment despite a slowdown in activity, as suggested by Askenazy and Erhel (2018).

${ }^{6}$ The break is not significant at $10 \%$. 
In all cases, all of our estimation procedures identify a significant convergence parameter with a negative sign. This result is consistent with the hypothesis of an error-correction mechanism that guarantees a convergence to a long-term equilibrium. The speed of convergence is higher for the non-farm business sector, whose estimated coefficient is close to the one we estimate for the total economy, than for public administrations.

It is worth noting that the non-farm business sector gets the same characteristics as the total economy, with the only difference being that a fourth break is identified just before the 2008 crisis. Only the analysis over the period 1949-2018 does not conclude that there was a break on that date. Indeed, we do observe a significant variation in labor productivity growth at this period, due to the joint evolution of manufacturing industries and business services.

Concerning the sectors of Manufacturing industries, business services and construction, the breaks are distributed in the same way as for total economy and for non-farm business sector. There is at most a break for each decade of the 1980s, 1990s and 2000s and a potential break after the 2008 crisis. Note that the sector of construction should be considered carefully. Indeed, the evolution of the productivity is indicated by a curve which shows a very marked concavity, which is not observed in the other sectors of the analysis. ${ }^{7}$

Several points can be made about estimated breaks for the sectoral activities. The structural breaks identified in the 1980s are common to manufacturing industries and business services. The break in the first part of the 1990s came from the business services as well as construction activities, while it did not concern manufacturing industries. Beffy and Fourcade (2004) already highlight these findings. The structural break identified in the early 2000s is shared by manufacturing and business services, with a stronger break for the former (whose growth rate yet remains higher than all other sectors or activities we have considered). Finally, it is noted that no slope break is identified after the 2008 crisis when we control for potential cyclical component in the observed labor productivity by adding the CUR in the deterministic specification for all sectors we analyze. Only the construction activity experienced an additional but positive break in 2012.

In the same way as before, we analyze labor productivity over other periods lengths and with another characterization of the CUR to test the robustness of structural breaks we identify over the period 1976-2018. The results are available upon request. The structural break of the late 1980s is the most robust and is shared by all sectors and activities, suggesting a global shock. For the manufacturing sector, the Bai-Perron test identifies a break in the early 2000s and/or before 2008, suggesting an origin other than the financial crisis. Similarly, the business services activities experienced a break before the last crisis, either the analysis is done over the period 1949-2018 or we control for the potential cyclical components in labor productivity with the CUR in manufacturing industry.

\footnotetext{
${ }^{7}$ In this case, there is not a decline in productivity gains - i.e., the growth rate of labor productivity in the early 1990s, but a decline in the level of productivity.
} 
For the second step of our study, we perform other robustness analyses concerning the estimation of the structural model. In particular, we estimate the growth model augmented with human capital for the total economy over different period lengths (1976-1999, 1976-2004, 1976-2007 and 1960-2018). We also consider alternative measures to approximate the stock of human capital, keeping the other variables unchanged. We still focus on the share of adults with at least secondary education we measure with the database by Goujon et al. (2016).

Hence, all specifications and estimations provide us with very similar results: they explain the structural breaks, display the relevant features and are robust to the different econometrical approaches. Accordingly, we can claim that the results we obtain and present above are very robust.

\section{Conclusion}

Considering that the labor productivity growth has reached its lowest level in most advanced economies since World War II, we investigate its evolution in France over the last four decades with two main questions. Is the slowdown of labor productivity growth a lasting process which has begun far before the Great Recession and the financial crisis in 2008 ? Or, on the contrary, is the last decrease observed after this crisis just cyclical and, in this case, are there levers to reverse the current trend?

To answer these questions, we proceed in two steps. First, we confirm stepwise slowdown of the trend (hourly) labor productivity growth. We identify what we call structural breaks, one per decade, which we interpret in the light of historical observations. Concerning the 2008 crisis, we find that its impact has rather induced a lasting but transitory demand shock, which may still have amplified the last structural break observed in the 2000s. This result is confirmed at a sectoral level, whatever the sectors may be considered.

Then we explain this slowdown from fundamentals we derive from an augmented growth model including Human capital, in addition to the propensity to invest in productive physical capital, the average number of hours worked per worker, the growth rate of the workforce population and a usual linear time trend. By introducing these determinants, we remove all structural breaks, keeping just a linear time trend to account for the technical progress, as it is usual in the literature. For both characterizations, two essential properties of the dynamics have been verified. First, the labor productivity, once corrected for its trend component, displays only cyclical (stationary) fluctuations and, second, the trend component acts as a long run target which permanently exerts an error correcting mechanism on the evolution of the productivity growth.

On the structural characterization, it is worth emphasizing that the augmented growth model proves to be very efficient to explain the trend labor productivity in France over the period of study, in particular when Human capital is captured by the share of adults with at least secondary educational level. We find a significantly positive elasticity of the trend productivity to the propensity to invest 
in productive physical capital, with a value in the low range of what is found in the literature. Therefore, propensity to invest in productive physical capital has a temporary effect on labor productivity, which is consistent with the augmented Solow approach. Yet, the high magnitude of the error-correction parameter is more consistent with endogenous growth model à la Uzawa-Lucas. The sensitivity of the trend productivity to hours worked per worker is significantly negative and close to -1 , indicating that any change in working hours is mainly offset by changes in the hourly labor productivity in the long-run. As predicted by the model, the growth rate of working-age population has a negative contribution, even if the significance is more fragile. Finally, human capital has as significant positive impact on the trend productivity, with an elasticity between 0.4 and 1 depending on the measure used to approximate the stock of human capital.

These results are robust, as proved by the different investigations we have conducted, with different estimation methods, over different periods, for different sectors and with different Human capital series. Accordingly, the augmented Solow growth model appears very efficient to account for the slowdown of the French labor productivity over the last four decades.

It is interesting to mention results we have obtained with the same type of analysis applied to other countries. For Germany, once the reunification shock is considered by limiting the analysis after 1991, we obtain similar results, except for the effect of the 2008 crisis which appears to have a stronger persistent effect, but this may be due to the relatively shorter observation period. However, for Italy and UK, it is not possible to find determinants derived from the Solow growth model to characterize the long-term labor productivity without structural breaks, respectively in the late 1990s and at the early 2000s.

In addition, it is worth adding a remark about the effect of hours worked. For both France and UK, a change in hours worked is largely offset by a change in hourly productivity. This is not the case for Italy and Germany, where such a change rather has an impact on the productivity per worker and thus job creation.

To come back to the French case, we can claim that the paradigm shift rather occurs at the beginning of the 2000's and the last decrease in the context of the Great Recession should be considered as transitory. Moreover, the slowdown in labor productivity could be mainly explained by a decline in the trend growth of Human capital. We claim that acting on this capital could be particularly profitable in the case of France whose economy is close to the technological frontier.

Investing in education and professional training in tight relation with technological innovations could be the best lever to revert the decreasing trend of the labor productivity growth. Assuming that new technologies, such that AI and robotics, will drive productivity growth in the long-run, the improvement of the quality of training aims at reducing their cost of adoption and skill mismatch, while the contribution of secondary education to productivity growth reaches its lower bound and more and more people have tertiary education.

However, taking this result as given, the unexplained part of the trend productivity appears to be relatively more important over the most recent period. This finding should be confirmed by additional investigations exploiting finer 
information about the worker training to improve the measure of human capital. For instance, a micro-founded labor quality index from a Mincerian perspective, based on both education and experience of workers, could be used to better approximate the stock of human capital. Such measure would allow to take into account the evolution of the labor market and the rise of low-skill works. Moreover, we just consider a quantitative measure of human capital calculated over the number of years of schooling or the share of adults with at least secondary schooling. Thereby, measures of changes in the quality of education and skills may allow to improve our approximation. Finally, the study could be extended to other developed countries to analyze the contribution of human capital to the evolution of labour productivity and to verify whether the persistent effect of human capital's accumulation on productivity growth is shared.

\section{References}

Andrews D, Criscuolo C, Gal P (2016) The global productivity slowdown, technology divergence and public policy: a firm level perspective. OECD Productivity Working Papers, No. 5.

Arnold J, Bassanini A, Scarpetta S (2007) Solow or Lucas?: Testing growth models using panel data from OECD countries. OECD Economics Department Working Papers, No. 592, Paris: OCDE.

Askenazy P, Erhel C (2015) Exploring the French productivity puzzle. Working Paper CEPREMAP.

Bai J, Perron P (1998) Estimating and testing linear models with multiple structural changes. Econometrica 66(1): 47-78.

Baldwin R, Teulings C (2014) Secular stagnation: facts, causes, and cures. London: Centre for Economic Policy Research-CEPR.

Banerjee A, Dolado JJ, Mestre R (1998) Error-correction mechanism tests for cointegration in a single-equation framework. Journal of Time Series Analysis 19(3): 267-284.

Barro RJ, Lee JW (2013) A new data set of educational attainment in the world, 19502010. Journal of Development Economics 104(C): 184-198.

Beffy PO, Fourcade N (2004) Le ralentissement de la productivité du travail au cours des années 1990: l'impact des politiques d'emploi. (The slowdown in labour productivity in the 1990s: the impact of employment policies). Économie et Statistique 376(1): 323.

Benati L (2007) Drift and breaks in labor productivity. European Central Bank Working Paper Series, No. 718.

Bergeaud A, Cette G, Lecat R (2015) Productivity trends from 1890 to 2012 in advanced countries. Review of Income and Wealth 62(3): 420-444.

Bernanke BS, Gurkaynak RS (2001) Is growth exogenous? Taking Mankiw, Romer and Weil seriously. NBER Working Paper, No. 8365, NBER Program(s): Economic Fluctuations and Growth.

Biesebroeck JV (2015) How tight is the link between wages and productivity? A survey of the literature. Conditions of Work and Employment Series, No. 54. International Labor Organization. 
Bosquet C, Fouquin M (2008) Productivité du travail: la fin du processus de convergence? (Labor productivity: the end of the convergence process). Économie et Statistique 419(1): 125-142.

Botev J, Égert B, Smidova Z, Turner D (2019) A new macroeconomic measure of human capital with strong empirical links to productrivity. Economics Department Working Papers, No. 1575.

Bruneau C, Girard PL (2020) Etude de l'évolution tendancielle de la productivité en France sur les quarante dernières années. (Analysis of the trend evolution of French labor productivity over the last four decades). Document de travail France Stratégie.

Cahuc P, Carcillo S, Zylbergerg A (2014) Labor economics. $2^{\text {nd }}$ Edition. Cambridge, MA: The MIT Press.

Canarella G, Pollard SK (2003) The augmented SOLOW model and the OECD sample. International Business \& Economics Research Journal 2(7): 89-102.

Cette G, Lopez J (2012) ICT demand behaviour: an international comparison. Economics of Innovation and New Technology, Taylor and Francis Journals 21(4): 397-410.

Cette G, Corde S, Lecat R (2017) Stagnation of productivity in France: a legacy of the crisis or a structural slowdown? Economie et Statistique (494-496): 11-36.

Crépon, B., Deniau, N. and Pérez-Duarte, S. 2004. Wages, productivity and worker characteristics: a French perspective. NBER Working Paper, No. w6696.

Daniels GE, Kakar V (2017) Normalized CES supply-side system approach: how to replicate Klump, McAdam, and Willman. (Review of Economics and Statistics, 2007), Economics Discussion Papers 2017-70. Kiel Institute for the World Economy (IfW).

Engle R, Granger CWJ (1987) Cointegration and error correction: representation, estimation, and testing. Econometrica 55(2): 251-276.

Eyraud L (2007) Guide pratique des comptes chaînés. (Practical Guide for Chained Accounts). Document de travail de la DGTPE, $n^{\circ}$ 2007/04.

Feldstein M (2008) Did wages reflect growth in productivity? Presentation before American Economic Association. DOI=https://doi.org/10.1016/j.jpolmod.2008.04. 003.

Fournier JM, Koske I (2010) A simple model of the relationship between productivity, saving and the current account. OECD, Economics Department Working Papers No. 816.

Gordon RJ (2012) Is U.S. economic growth over? faltering innovation confronts the six headwinds. NBER, Working Papers 18315, National Bureau of Economic Research, Inc.

Gordon RJ (2013) US productivity growth: the slowdown has returned after a temporary revival. International Productivity Monitor, Centre for the Study of Living Standards 25(Spring): 13-19.

Gordon RJ (2014) The demise of U.S. economic growth: restatement, rebuttal, and reflections. NBER, Working Papers 19895.

Gordon RJ (2015) Secular stagnation: a supply-side view. American Economic Review, Papers Proceedings 105(5): 54-59.

Goujon A, Lutz WKC, Stonawski M, Stilianakis N (2018) Demographic and human capital scenarios for the $21^{\text {st }}$ Century: 2018 assessment for 201 countries. Publications Office of the European Union, European Commission, Joint Research Centre.

Ivanic M, Martin W (2018) Sectoral productivity growth and poverty reduction: national and global impacts. World Development, Volume 109(C): 429-439.

Jimeno JF, Moral E, Saiz L (2006) Structural breaks in labor productivity growth: the United States vs. the European Union. Working Papers 0625. Banco de España. 
Johansen S (1988) Statistical Analysis of Cointegration Vectors, Journal of Economic Dynamics and Control 12(2-3): 231-254.

Johansen S (1995) Likelihood-based inference in cointegrated vector autoregressive models. NewYork: Oxford University Press.

Johansen S, Juselius K (1990) Maximum likelihood estimation and inference on cointegration with application to the demand for money. Oxford Bulletin of Economics and Statistics 52(2): 169-209.

Jones CI (1995) R \& D-based models of economic growth. Journal of Political Economy 103(4): 759-784.

Koen V, Asada H, Habeeb Rahuman MR, Bogiatzis A (2004) Boosting productivity and living standards in Thailand. OECD, Economics Department Working Papers No. 1470.

Lee JW, Lee H (2016) Human capital in the long run. Journal of Development Economics 122(C): 147-169.

Lequien M, Montaut A (2014) Potential growth in France and the euro area: an overview of the estimation methods. Documents de travail INSEE $\mathrm{N}^{\mathrm{o}} \mathrm{G} 2014 / 09$.

Lucas RE (1988) On the mechanics of economic development. Journal of Monetary Economics 22(1): 3-42.

MacKinnon JG (2010) Critical values for cointegration tests. Working Paper 1227, Economics Department, Queen's University.

Mankiw NG, Romer D, Weil D (1992) A contribution to the empirics of economic growth. Quarterly Journal of Economics 107(May): 407-437.

Mokyr J, Vickers C, Ziebarth NL (2015) The history of technological anxiety and the future of economic growth: is this time different? Journal of Economic Perspectives 29(3): 31-50.

Perron P (1990) Testing for a unit root in a time series with a changing mean. Journal of Business and Economic Statistics 8(2): 153-162.

Perron P (1994) Trend, unit root and structural change in macroeconomic time series. In BB Rao (ed), Cointegration for the Applied Economist, 113-146. Basingstoke: Macmillan Press.

Phillips PCB, Hansen BE (1990) Statistical inference in instrumental variables regressions with I(1) processes. Review of Economic Studies 57(1): 99-125.

Summers L (2014) U.S. economic prospects: secular stagnation, hysteresis, and the zero lower bound. Business Economics 49(2): 65-74.

Thévenon O, Ali N, Adema W, Salvi del Pero A (2012) Effects of reducing gender gaps in education and labour force participation on economic growth in the OECD. OECD Social, Employment and Migration Working Papers, No. 138, OECD Publishing.

Van Ark B, Erumban A, Corrado C, Levanon G (2016) Navigating the digital economy: driving digital growth and productivity from installation to deployment. The Conference Board, New York, May.

Wickens MR (1996) Interpreting cointegrating vectors and common stochastic trends. Journal of Econometrics 74(2): 255-327. 
Appendix 1. Augmented Solow Growth Model with Human Capital, Derivation of the Long Run Equilibrium Productivity

We consider a standard Cobb-Douglas production function $Y(t)=(K(t))^{\alpha}(Q(t))^{\beta}\left(A(t) h^{\rho} L(t)\right)^{1-\alpha-\beta}$

With the notations of the main text.

where $Y(t)$ is the total production, $K(t)$ the stock of productive physical capital, $Q(t)$ the stock of human capital, $A(t)$ the Harrod neutral technical progress, $h$ the number of hours worked per worker and $L(t)$ the labor. We assume that we have decreasing returns to reproducible factors, i.e. $\alpha+\beta<1$. Indeed, a more generic model:

$Y(t)=(K(t))^{\alpha}(Q(t))^{\beta}\left(A(t) h^{\rho} L(t)\right)^{\theta}$

does not have a unique steady-state without other assumptions on the parameters $\alpha, \beta$ and $\theta$.

We assume there are two sources of exogenous growth in our model, workforce and technical progress. Both of them grow at a rate of $g_{A}(t)$ and $g_{L}(t)$ respectively such that:

$$
\begin{aligned}
& L(t)=L\left(t_{0}\right) \exp \left(\int_{t_{0}}^{t} g_{L}(s) d s\right) \\
& A(t)=A\left(t_{0}\right) \exp \left(\int_{t_{0}}^{t} g_{A}(s) d s\right)
\end{aligned}
$$

Evolutions of the physical and human capitals are described by the equations: $\dot{K}(t)=I_{K}(t)-\delta K(t)$

$\dot{Q}_{t}=I_{Q}(t)-\delta Q(t)$

where $I_{K}$ and $I_{Q}$ are investments in productive physical capital and human capital respectively. For simplicity, we assume that the depreciation rate $\delta$ is identical for the two types of capital, which does not change the main results.

A share of the outcome $Y(t)$ is invested in the two types of capital, such that $I_{K}(t)=s_{K} Y(t)$ and $I_{Q}(t)=s_{Q} Y(t)$

To derive the steady-state equilibrium, we define each variable in intensive terms, i.e., $y(t)=\frac{Y(t)}{A(t) L(t)}, k(t)=\frac{K(t)}{A(t) L(t)}$, and $q(t)=\frac{Q(t)}{A(t) L(t)}$.

The production function in intensive terms becomes: $y(t)=(k(t))^{\alpha}(q(t))^{\beta}\left(h^{\rho}\right)^{1-\alpha-\beta}$

The accumulation equations for productive physical capital in intensive terms are:

$$
\begin{aligned}
& \dot{k}(t)=s_{K} y(t)-\left(g_{A}(t)+g_{L}(t)+\delta\right) k(t) \\
& \dot{q}(t)=s_{Q} y(t)-\left(g_{A}(t)+g_{L}(t)+\delta\right) q(t)
\end{aligned}
$$

We can rearrange the two last equations so to have the growth rates of the two types of capital: 


$$
\begin{aligned}
& \frac{\dot{k}(t)}{k(t)}=s_{K} h^{\gamma} e^{-(1-\alpha) \ln (k(t))} e^{\beta \ln (q(t))}-\left(g_{A}(t)+g_{L}(t)+\delta\right) \\
& \frac{\dot{q}(t)}{q(t)}=s_{Q} h^{\gamma} e^{\alpha \ln (k(t))} e^{-(1-\beta) \ln (q(t))}-\left(g_{A}(t)+g_{L}(t)+\delta\right)
\end{aligned}
$$

Moreover, taking the logarithm of the production function in intensive terms and differentiating yield the growth rate of the output as a weighted average of the two capitals:

$$
\begin{aligned}
& \ln (y(t))=\alpha \ln (k(t))+\beta \ln (q(t))+\gamma(1-\alpha-\beta) \ln (h) \\
& \frac{\dot{y}(t)}{y(t)}=\alpha \frac{\dot{k}(t)}{k(t)}+\beta \frac{\dot{q}(t)}{q(t)}
\end{aligned}
$$

We then replace the two inputs growth rate by their expression obtained from the accumulation equations and we assume constant population and technological growth rates for simplicity:

$$
\begin{aligned}
\frac{\dot{y}(t)}{y(t)}=\alpha\left(s_{K} h^{\gamma} e^{-(1-\alpha) \ln (k(t))} e^{\beta \ln (q(t))}-\left(g_{A}(t)+g_{L}(t)+\delta\right)\right) . \\
+\beta\left(s_{Q} h^{\gamma} e^{\alpha \ln (k(t))} e^{-(1-\beta) \ln (q(t))}-\left(g_{A}(t)+g_{L}(t)+\delta\right)\right)
\end{aligned}
$$

Taking a two-dimensional first-order Taylor expansion gives:

$$
\begin{aligned}
\frac{\dot{y}(t)}{y(t)}=- & (1-\alpha-\beta) \alpha s_{K} h^{\gamma} e^{-(1-\alpha) \ln \left(k^{*}\right)} e^{\beta \ln \left(q^{*}\right)}\left(\ln (k(t))-\ln \left(k^{*}\right)\right) \\
& -(1-\alpha-\beta) \beta\left(s_{Q} h^{\gamma} e^{\alpha \ln \left(k^{*}\right)} e^{-(1-\beta) \ln \left(q^{*}\right)}\left(\ln (q(t))-\ln \left(q^{*}\right)\right)\right.
\end{aligned}
$$

Now, the steady state conditions derived from the two accumulation equations can be used:

$$
\begin{aligned}
& s_{K} h^{\gamma} e^{-(1-\alpha) \ln \left(k^{*}\right)} e^{\beta \ln \left(q^{*}\right)}=g_{A}^{*}+g_{L}^{*}+\delta \\
& s_{Q} h^{\gamma} e^{\alpha \ln \left(k^{*}\right)} e^{-(1-\beta) \ln \left(q^{*}\right)}=g_{A}^{*}+g_{L}^{*}+\delta
\end{aligned}
$$

and we get:

$$
\begin{aligned}
& \frac{\dot{y}(t)}{y(t)}=-(1-\alpha-\beta)\left[\alpha\left(g_{A}^{*}+g_{L}^{*}+\delta\right)\left(\ln (k(t))-\ln \left(k^{*}\right)\right)\right. \\
& \left.\quad+\beta\left(g_{A}^{*}+g_{L}^{*}+\delta\right)\left(\ln (q(t))-\ln \left(q^{*}\right)\right)\right]
\end{aligned}
$$

We can rearrange the equation and multiply both sides by $e^{\lambda t}$ and we finally find:

$$
\frac{d\left(\ln (y(t)) e^{\lambda t}\right)}{d t}=\ln \left(y^{*}\right) \frac{d\left(e^{\lambda t}\right)}{d t}
$$

Thus,

$\ln (y(t)) e^{\lambda t}=\ln \left(y^{*}\right) e^{\lambda t}+K$ 
Moreover, we can deduce a value for $K$ from any arbitrary period $s$ such that: $K=\ln y(s) e^{\lambda s}-\ln \left(y^{*}\right) e^{\lambda s}$

Which gives:

$\ln (y(t))-\ln (y(s))=-\phi(\lambda)\left(\ln (y(s))-\ln \left(y^{*}\right)\right)$

Where $\phi(\lambda)=1-e^{-\lambda(t-s)}$. This relation can be estimated for any time interval.

Estimating the two equations of capital accumulation in steady-state, i.e. without growth dynamics, yields:

$\dot{k}=0$ and $\dot{q}=0$

$$
\begin{aligned}
& s_{K}\left(k^{*}\right)^{\alpha}\left(q^{*}\right)^{\beta}\left(h^{\gamma}\right)^{1-\alpha-\beta}=\left(g_{A}{ }^{*}+g_{L}{ }^{*}+\delta\right) k^{*} \\
& s_{Q}\left(q^{*}\right)^{\alpha}\left(k^{*}\right)^{\beta}\left(h^{\gamma}\right)^{1-\alpha-\beta}=\left(g_{A}{ }^{*}+g_{L}{ }^{*}+\delta\right) q^{*} \\
& k^{*}=\left(\frac{s_{K}}{g_{A}{ }^{*}+g_{L}{ }^{*}+\delta}\left(q^{*}\right)^{\beta}\left(h^{\gamma}\right)^{1-\alpha-\beta}\right)^{\frac{1}{1-\alpha}} \\
& q^{*}=\left(\frac{s_{Q}}{g_{A}{ }^{*}+g_{L}{ }^{*}+\delta}\left(k^{*}\right)^{\alpha}\left(h^{\gamma}\right)^{1-\alpha-\beta}\right)^{\frac{1}{1-\beta}}
\end{aligned}
$$

Replacing one partial definition into the other allows to deduce the steadystate expression of the two types of capital and yields to the usual output equation in intensive terms in steady state:

$$
y^{*}=h^{\gamma}\left(s_{K}^{*}\right)^{\frac{\alpha}{1-\alpha-\beta}}\left(s_{Q}^{*}\right)^{\frac{\beta}{1-\alpha-\beta}}\left(g_{A}{ }^{*}+g_{L}{ }^{*}+\delta\right)^{\frac{\alpha+\beta}{1-\alpha-\beta}}
$$

As a function of propensities to invest in the two types of capital and working age population growth rate.

Yet, from an empirical point of view, we can better approximate the stock of human capital with educational variables rather than the propensity to invest in this type of capital (Arnold et al. (2007)). Therefore, from the steady-state accumulation equations, we only consider the level of the productive physical capital, as a function of the investment rate $s_{K}$, the population growth rate $g_{L}$ augmented with the depreciation rate $\delta$ and the technological process growth rate $g_{A}$, and the stock of human capital $q^{*}$.

$k^{*}=\left(\frac{s_{K}}{g_{A}{ }^{*}+g_{L}{ }^{*}+\delta}\left(q^{*}\right)^{\beta}\left(h^{\gamma}\right)^{1-\alpha-\beta}\right)^{\frac{1}{1-\alpha}}$

We replace $k^{*}$ by this expression in the production function in intensive terms to have its expression in terms of human capital stock,

$$
y^{*}=\left(\frac{s_{K}}{g_{A}{ }^{*}+g_{L}{ }^{*}+\delta}\left(q^{*}\right)^{\beta}\left(h^{\gamma}\right)^{1-\alpha-\beta}\right)^{\frac{1}{1-\alpha}}\left(q^{*}\right)^{\beta}\left(h^{\gamma}\right)^{1-\alpha-\beta}
$$

That is, by regrouping terms,

$$
y^{*}=\left(\frac{s_{K}}{g_{A}{ }^{*}+g_{L}{ }^{*}+\delta}\right)^{\frac{\alpha}{1-\alpha}}\left(q^{*}\right)^{\frac{\beta}{1-\alpha}}\left(h^{\gamma}\right)^{\frac{1-\alpha-\beta}{1-\alpha}}
$$


Finally taking the logarithm gives:

$$
\begin{gathered}
\ln y^{*}=\frac{\alpha}{1-\alpha} \ln \left(s_{K}\right)+\frac{\beta}{1-\alpha} \ln \left(q^{*}\right)+\gamma \frac{1-\alpha-\beta}{1-\alpha} \ln (h) \\
-\frac{\alpha}{1-\alpha} \ln \left(g_{A}{ }^{*}+g_{L}{ }^{*}+\delta\right) \quad\left(2^{\prime}\right)
\end{gathered}
$$

Substituting (2') in (1'), considering the effective hourly labor productivity, developing $A(t)$ as a piecewise linear trend, and adding lags of the variables to account for short-run components gives the following error correction equation

$$
\begin{aligned}
& \Delta \ln \left(\frac{\tilde{y}(t)}{h(t)}\right)=-\phi\left[\ln \left(\frac{\tilde{y}(t-1)}{h(t-1)}\right)+\theta_{1} \ln (h(t-1))-\theta_{2} \ln \left(s_{K}(t-1)\right)\right. \\
& -\theta_{3} \ln (q(t-1)) \\
& +\theta_{4} \ln \left(g_{L}(t-1)+g_{A}+\delta\right)-\ln \left(A\left(t_{0}\right)\right)-\sum_{k=1}^{K} a_{k} \mathbb{1}_{t \geq t_{k}}-g_{A}\left(t-t_{0}\right) \\
& \left.-\sum_{k=1}^{K} b_{k} \mathbb{1}_{t \geq t_{k}}\left(t-t_{0}\right)\right]+\sum_{i=1}^{p-1} \kappa_{1 i} \Delta \ln \left(\frac{\tilde{y}(t-i)}{h(t-i)}\right)+\sum_{i=1}^{p-1} \kappa_{2 i} \Delta \ln (h(t-i)) \\
& +\sum_{i=1}^{p-1} \kappa_{3 i} \Delta \ln \left(s_{K}(t-i)\right)+\sum_{i=1}^{p-1} \kappa_{4 i} \Delta \ln (q(t-i)) \\
& +\sum_{i=1}^{p-1} \kappa_{5 i} \Delta \ln \left(g_{L}(t-i)+g_{A}+\delta\right)++\sum_{i=1}^{p-1} \kappa_{6 i} \mathbb{1}_{t=t_{k}}+U_{t}
\end{aligned}
$$

Where the $\left(\theta_{j}\right)_{j \in \llbracket 1 ; 4 \rrbracket}$ are function of the parameters of the model and $\tilde{y}(t)=\frac{Y(t)}{L(t)}$.

\section{Appendix 2. Derivation of the Variables for Human Capital}

We use two databases to approximate Human capital, as measured by its educational component only, by Barro and Lee (2013) and Goujon et al. (2016). Both of them provide harmonized data for many countries over long-term periods based on UNESCO classification (ISCED) for five-year age categories over total population (with a breakdown between male and female). They provide five-year data from 1950 to 2010 and from 1950 to 2020 respectively. Yet, the way of defining levels of education differs from one database to the other.

Barro and Lee (2013) consider four different levels of education, "no schooling", "primary", "secondary" and "tertiary". "Primary" level aggregates incomplete and complete primary education (which mainly covers the first level of the ISCED); "secondary" aggregates the two levels of secondary educations (that is middle school and high school or equivalent, or, equivalently, the second and third levels of ISCED); and tertiary aggregates short cycle higher education, bachelor, master and $\mathrm{PhD}$ (the level four and over of ISCED). Every level can be 
decomposed between "incomplete" and "complete" education. Moreover, the database provides detailed data on both total years of schooling and years of schooling per level of education ("primary", "secondary" and "tertiary").

Goujon et al. (2016) provides data for six different levels of education, "no education", "incomplete primary", "primary" (level 1 of ISCED), "lower secondary" (level 2), "upper secondary" (level 3) and "post-secondary" (level 4 and over), which overlap. For instance, "lower secondary" level aggregates the share of people who completed lower secondary schooling and the share of people who attained upper secondary schooling without completing. Goujon et al. (2016) also provides data for the total years of schooling.

We focus on the adult population, that is the 25-64 year - old population. Let us denote $a$, the five-year age category such that $a=25-29, \ldots, 60-64, j$ the highest educational level completed which takes the value "primary", "secondary" and "tertiary" for the database by Barro and Lee (2013), and "primary", "lower secondary", "upper secondary" and "tertiary" for Goujon et al. (2016). $t$ denotes the period. $b$ the database (i.e., either Barro and Lee, denoted "BL" or Goujon et al. (2016) denoted "W", in reference to the Wittgenstein Centre for demography and human capital).

We denote $q_{j, t}^{a, b}$ the share of the age category $a$ of the total population whose highest level of education completed is $j$ at time $t$ from database $b$. The sum of all the shares over the different levels of education is always equal to 1 such that $\sum_{j} q_{j, t}^{a, b}=1$. Similarly, year tot,$t^{a, b}$ is the total years of schooling and $\operatorname{year}_{j, t}^{a, B L}$ the years of schooling for the level $j$, from the Barro and Lee (2013) database, such that the sum over all educational levels is always equal to the total years of schooling, year $r_{t o t, t}^{a, B L}=\sum_{j}$ year $_{j, t}^{a, B L}$. Finally, we denote $l_{t}^{a, b}$ the share of total population which is in the age category $a$.

We consider two categories of variables, the total years of schooling and the share of adults with at least secondary schooling. For the two databases, we define

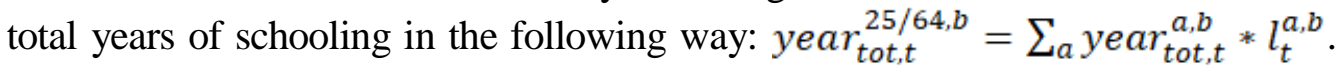
For the educational level of the adult population, we first define $q_{j, t}^{25 / 64, b}=\sum_{a} q_{j, t}^{a, b} * l_{t}^{a, b}$ the share of adult population with educational level $j$. Then, from Barro and Lee (2013), we have the following variable $q_{t}=q_{\text {sec,t }, B L}^{25 / 64, B L}+q_{\text {ter, }, \text { }}^{25 / 64 L}$ and, from Goujon et al. (2016), we test two different variables: $q_{t}=q_{\text {lsec, },}^{25 / 64, W}+q_{\text {upsec }, t}^{25 / 64, W}+q_{\text {ter, } t, W}^{25 / 6, W}$ and $q_{t}=q_{\text {upsec }, t}^{25 / 64, W}+q_{\text {ter, } t}^{25 / 64, W}$. The second variables from Goujon et al. (2016) allow to focus on upper secondary and tertiary levels more precisely. 


\title{
The Never-Ending Quest for the European Fiscal Policy's Objectives: Stability vs. Convergence or Stability and Convergence?
}

\begin{abstract}
By Carlo Klein*
The aim of this paper is to analyse the permanent struggle to define European fiscal policy objectives, hence to define the corresponding structure of such a policy. To discuss the objectives of fiscal policies in the European context our starting point will be the idea that politics has to define clear objectives, then economic policies, fiscal policies included, should be designed to attain the fixed objectives. In the European context, the Economic and Monetary Union (EMU)'s main objectives have been restated in 2015: "balanced economic growth and price stability, a competitive social market economy, aiming at full employment and social progress" for all member states. Our conclusion, based on these objectives, will be that the EMU needs a fiscal policy as well to cope with asymmetric shocks as to foster real convergence among member states. Therefore, a clearer presentation of the corresponding policies with the expected outcomes on the member state level has to be added. This has to be achieved through an improved communication policy to convince European citizens that the European integration is not just about maintaining peace in Europe but that a real improvement in living conditions can be achieved. (JEL E61, E62, F15, F55)
\end{abstract}

Keywords: Economic and Monetary Union, Optimum Currency Area, Real Convergence of European Economies, Common Fiscal Policy, Interventionist Supply Side Policies.

\section{- Introduction}

To discuss the objectives of fiscal policies in the European context, our starting point will be the idea that politics has to define clear objectives, and then economic policies, fiscal policies included, should be designed to attain the fixed objectives.

In the European context, the EMU's main objectives have been restated in the 5 Presidents' Report (European Commission 2015a): "balanced economic growth and price stability, a competitive social market economy aiming at full employment and social progress" for all member states. Fiscal policy should then be one of the available means to achieve these goals. The classical textbook definition of fiscal policy simply refers to governments' choices regarding levels of spending and taxation without referring to any objective of these policies. Thus, two questions have to be addressed: In the context of a lack of real convergence, should fiscal policy be used for potential bailouts as well as to achieve real convergence and what should be the structure of such a policy? Or, despite the lack of real convergence, should a European fiscal policy, whatever its structure, be designed with the sole objective to organize bailouts of national economies in case of emergencies? The answers should be based on the analysis of fiscal policies as

${ }^{*}$ Lecturer, Miami University Dolibois European Center (MUDEC), Luxembourg. 
means to improve real convergence and hence the resilience of the EMU's national economies.

Answers to these questions have been formulated over time, mainly through the theoretical analysis of a monetary union, based on the discussion about Optimum Currency Areas (OCA hereafter) and through the corresponding political decisions taken in Europe.

A known major criticism addressed at the EMU structure is the lack of a common fiscal policy in case of asymmetric shocks hitting the euro area. Discussions about potential fiscal policy in the euro area almost exclusively refer to these cases of "shock-contingent bailouts" (Brunnermeier et al. 2016; BénassyQuéré et al. 2018, for example), not mentioning the potential need for a structural fiscal policy to foster real convergence.

This discussion can be found in some official documents established by the European Commission (2017a, 2017b, for example) but the mainstream theoretical point of view is that fiscal and monetary policies have no impact on real economic variables in the long run (De Grauwe 2016, for example). Consequently, mainstream theory suggest that the needed structural reforms should be marketoriented to make the economies of the euro area more efficient and thus more resilient in case of asymmetric shocks.

We consider that the discussion on fiscal policy objectives should make a clear distinction between the consequences of asymmetric shocks and those of a potential lack of real convergence of the economies of the euro area, and at the same time, the interaction between real convergence and asymmetric shocks also has to be considered. Then, the question arises if market-oriented structural reforms will be enough to make euro area economies more resilient in case of asymmetric shocks and if they will contribute to real convergence among member states.

The aim of this paper is not to develop new theories of fiscal policies or to assess empirically the effects of the existing policies, but to analyse the permanent struggle to define European fiscal policy objectives, hence to define the corresponding structure of such a policy. Based on these reflexions this paper will be organized as follows.

In section 2, we will present a literature review about economic and political conditions that should be fulfilled to build a monetary union with a specific focus on fiscal policy. In section 3 we will refer to the fact that apart from OCA considerations, long term objectives of the EMU have to be considered: real convergence of member states' economies and sustainable and inclusive growth when fiscal policy objectives are defined. In section 4, we will have a closer look at the indicators used to evaluate the economic situation within the EU and the EMU, then, in section 5 we will discuss the need for a supranational fiscal policy based on the main results of the preceding sections. Finally, we will conclude in a last section.

The focus of our paper clearly lies on fiscal policy in the EMU, even if we cannot neglect potential consequences of such policies on the EU, hence on future EMU members. 


\section{Literature Review}

\section{Economic Theory: No Monetary Union without a Common Fiscal Policy}

The discussion about the need of a common fiscal policy has to be seen in the context of the analysis of monetary unions, based on OCA theory. This discussion was already launched during the sixties with Mundell's seminal paper (1961) about optimum currency areas, and then completed by McKinnon (1963), Kenen (1969) and later by Tavlas (1993), for example.

The reasons for joining a monetary union should be obvious from an economic point of view: the benefits for a joining country should be larger than the costs. According to De Grauwe (2016) these benefits will be the reduction of transaction costs, reduced uncertainty, increased economic growth and benefits due to the international use of the common currency. The corresponding economic costs are the acceptance of sovereignty losses due to the loss of the country's national monetary and exchange rate policies. Non-economic costs could be the loss of national symbols, national currencies.

Furthermore, member states have to accept structural adjustments to foster real convergence within a monetary union and so fulfil the conditions of an OCA.

The main theoretical conditions that should be fulfilled for an economic area to become an OCA are:

the optimum currency area should have perfect factor mobility (capital and labour) which means geographical and professional mobility for workers (Mundell 1961) and an integrated financial market for capital (Mundell 1973 and McKinnon 2004) even if improved capital mobility may cause a volatility paradox as described by Brunnermeier et al. (2016): "Counterintuitively, financial deepening via a partial removal of financial frictions may actually increase financial instability by facilitating excessive capital flows";

$>$ linked to this mobility condition is the condition that prices and wages in such an area should be flexible (Friedman 1953, p. 165);

$>$ the different economies of an OCA should have highly integrated markets for goods and services and free factor mobility across industries (McKinnon 1963) with the risk that this deeper integration may lead to divergent specialisations depending on national comparative advantages but may make national economies more vulnerable to asymmetric shocks (Krugman 1993);

the different economies of an OCA should be diversified in production and in consumption to "dilute" the impact of economic shocks (Kenen 1969);

an OCA should have common policies: a supranational fiscal policy ("fine-tune shock-contingent bailouts" [Brunnermeier et al. 2016]; Kenen 1969) and, a logical consequence of a single currency, a common monetary policy;

then, Baldwin and Wyplosz (2015) have restated the fact that citizens' political preferences should be homogeneous within the OCA. People 
living in a currency union should have a sense of solidarity and a belief in a common destiny. This need for political integration was already highlighted by Mintz (1970) and Haberler (1970) when the discussion about monetary integration started.

The respect of these conditions should allow the different economies within a monetary union to reduce the risks of asymmetric shocks and to face easier and faster market and/or policy adjustments in case of economic shocks.

This need for economic convergence has been restated by Tavlas (1993) for joining countries, especially the convergence of inflation rates and the need for real exchange rate variability which refers to price and wage flexibility.

A second set of theoretical analyses about the consequences of a deeper international integration focusses on the trade-off between integration and national sovereignty. Agreeing on a common currency, thereby abandoning a floating exchange rate system among member states of a monetary union, leads us directly to the monetary trilemma (based on Fleming 1962 and Mundell 1963) that states that a country or geographical area, can only achieve two out of three objectives:

stable exchange rates (or adopting a common currency);

a nationally oriented monetary policy;

international capital mobility.

Padoa-Schioppa (2004) considered that free trade has to be added so that the trilemma became an "inconsistent quartet". According to Padoa-Schioppa, the introduction of a common currency is the logical consequence of the "inconsistent quartet". The European Union, based on the four freedoms of free movements of goods, services, capital and people, needs to become a EMU.

Additionally, to that first trilemma or quartet, Europe has been and is still facing a financial trilemma (Schoenmaker 2011): if we have capital mobility as well as economic and financial integration, national macroprudential policies will be insufficient to limit financial crises. As for the monetary trilemma, national policies have to be replaced by supranational policies, hence by deeper integration.

Finally, from a political point of view, Rodrick $(2000,2017)$ highlighted "the political trilemma of the world economy" which also applies to the EMU: integrated national economies can only function either with a supranational democracy and fading nation-states or with strong nation-states and a fading democracy! So, during all these years, at least since the signing of the Maastricht Treaty, it should have been quite clear that some national sovereignty has to be abandoned if European integration was to be deepened through common policies and if democracy was to be maintained as a fundamental European value. Rodrick's trilemma simply restates the need for homogenous political preferences within a monetary union.

A logical consequence of these analyses, be that an analysis in terms of the trilemmas and/or based on OCA conditions, is that the EU needs a more deeply integrated economic region to attain its general objectives through the EMU. 
If we agree with these theoretical analyses, then a second point has to be discussed which is whether these conditions should be fulfilled by a member state before joining a monetary union or if member states' economies converge further after having joint a monetary union. This "OCA theory in reverse" (Mongelli 2008) can arise from two situations: a situation of an endogenous OCA (Frankel and Rose 1997), where market forces bring member states closer to the expected OCA conditions or an exogeneous OCA where institutions and peer pressure force member states to adjust their economies to come closer to the OCA conditions.

This distinction between endogenous and exogeneous OCAs was and still is important to understand two points of view of how a monetary union should be achieved: the economist and the monetarist views (James 2012; Mongelli 2008; Masini 2014).

According to James (2012; p. 93) "European 'monetarists' believed that the establishment of a series of monetary rules might create the framework for general economic convergence, whereas 'economists' stressed that convergence needed to precede the imposition of a single monetary framework".

A similar statement can be found in Mongelli (2008): the monetarist view considers that "nominal convergence was not indispensable as EMU represents a change in policy regimes: a new common central bank will shape future expectations while past expectations become irrelevant", whereas the economist view considers that "convergence of economic performances is a precondition for EMU".

The monetarist view, suggesting that internal changes bring the economies closer to an OCA, can also be linked to Frankel and Rose's (1997) hypothesis that "more integration can be expected to lead to more trade; and more international trade will result in highly correlated business cycles, ..., while integration is also affected by policy". This hypothesis was then challenged by Eichengreen (1992), Kenen (1969) and Krugman (1993) stating that a deeper integration leads to more specialized economies based on comparative advantages and so making different economies more exposed to asymmetric shocks.

These theoretical considerations will be the basis of our discussion about indicators to assess the EMU. Are these indicators designed to assess the endogeneity of OCA, the exogeneity of OCA or even an OCA theory in reverse (Mongelli 2008)? Then, when we discuss fiscal policy, should we focus either on its links with asymmetric shocks, or on the question of real convergence or possibly on both problems?

Before we address these questions, we will firstly summarize how these issues have been considered from a political point of view and what the consequences for a supranational fiscal policy were and still are.

\section{The Political Debate about Fiscal Policies in a Monetary Union}

As OCA theory has developed over time, so have the political considerations about how to organize a monetary union in Europe. Major political documents have been produced to justify and to prepare the introduction of the euro. 
In 1969, the Council of the European Communities decided to create a committee to present a report giving guidelines for an EMU within the European Communities. The "Werner report" (Council of the European Communities, 1970) implicitly refers to the OCA theory by mentioning the existence of structural differences between member states and by suggesting that factor mobility has to be improved, that a common monetary and fiscal policy, tax harmonization included, will be needed and that, hence, the integration of member states' economies has to be deepened, with fiscal transfers as a consequence. Apart from these common policies, national policies, mainly fiscal policies, should be better coordinated. Hence, the idea of achieving real convergence of national economies through supranational policies, structural fiscal policies included, was present right from the beginning when the political idea of a monetary union was developed.

The authors of the report also added that political problems to reach these aims should be expected and that the creation of a common currency should be discussed with social partners to work out a consensus and to generate a convergence of political preferences.

Almost 20 year later, in 1989, a second report, the "Report on the Economic and Monetary Union in the European Community" or Delors report, was published (Committee for the Study of Economic and Monetary Union, 1989). Again, the report referred to OCA conditions without naming them explicitly and insisted on the "need to achieve a substantial degree of economic union if monetary union is to be successful, and given the degree of monetary coordination already achieved, it is clear that material progress on the economic policy front would be necessary for further progress on the monetary policy front". The report favours an exogeneous approach to OCA, as the authors insisted on the fact that some conditions have to be fulfilled before the creation of the EMU, even if the process of convergence and integration has to continue after the launch of the EMU.

Nevertheless, the report insists that the EMU remains a market-oriented environment and highlights the need for a more effective coordination of national policies through the transfer of the decision-making power to the Community level but based on the subsidiarity principle (art. 5 of the Treaty on the European Union; Official Journal of the European Union 2016). The two objectives of real convergence and countercyclical interventions were mentioned when the authors recommended common structural and regional policies based on interventionist supply side policies and cyclical adjustments through coordinated national fiscal policies based on fiscal rules.

Three stages to achieve the EMU were defined: a first stage where all the participant member states had to commit to the EMU, a second transitionary stage and finally the adoption of the common currency accompanied by a strengthening of the regional and structural policy and compulsory fiscal rules. Again, the need for common policies, apart from defining simple fiscal rules, were highlighted.

At the same time a more theoretical paper was published by the Commission of the European Communities (1990): "One Market, One Money" highlighting the same objectives for fiscal and market-oriented structural policies as the Delors report: real convergence of member states and the treatment of asymmetric shocks. 
The paper recommends common rules for national budgets and recognizes shock-absorbing functions of budgets. To satisfy both aims, the authors expected disciplined national budgets and a coordination of budgetary policies. The overall gains of such a structure of fiscal policies should be a catch-up effect of backward areas and recoveries of areas hit by shocks which clearly refers to the two policy goals, real convergence and a better higher resilience in case of economic shocks.

Even if there were no explicit references to a supranational fiscal policy, the authors recognized that economic policies should be assigned to the community level if economies of scale or externalities were to be observed. Two major domains have been mentioned: R\&D and environmental investments, two major types of investments nowadays.

These reports then led to the Maastricht Treaty signed in 1992 and ratified in 1993 (Commission of the European Communities, 1992). This treaty fixed, from an EMU point of view, the three stages to the common currency mentioned in the Delors report, the statute of the European Central Bank (ECB) as well as the conditions that have to be fulfilled to adopt the euro even if these criteria were not based on OCA theory. The Maastricht nominal convergence criteria are more about financial stability to avoid excessive fiscal deficits and to limit inflation in member states than about creating an OCA even if these criteria were assumed to contribute to the convergence of the EMU towards an OCA. A timid incentive for labour mobility was introduced through the definition of a European citizenship allowing free circulation within the European Union. The basic idea of national responsibility of member states clearly dominated compared to the idea of solidarity between member states in cases of economic shocks.

Nevertheless, the Treaty of the Functioning of the European Union (TFEU; Official Journal of the European Union, 2012) synthetizing the major European Treaties, gives a framework of how real convergence should be achieved within the $\mathrm{EU}$ and $\mathrm{EMU}^{8}$ : the Treaty clearly refers to shared competence for economic, social and territorial cohesion, mentions actions to foster these cohesions and refers to the need for coordination of national policies (employment and social policies included) and to the need for supplementary actions by member states. This means that a close coordination of national economic policies with common objectives should be achieved, but no bailouts and no monetary financing through central banks will be allowed. Therefore, fiscal rules have to be developed and to be accepted by member states. The European Social Fund; Structural Funds (European Agricultural Guidance and Guarantee Fund, Guidance Section; European Social Fund; European Regional Development Fund), the European Investment Bank and other existing financial instruments should distribute financial resources available for economic, social and territorial cohesion policies and thus contribute to real convergence within the EU in general. Implicitly clear distinctions between the two major objectives of fiscal policies are made in this Treaty: asymmetric shocks should be treated on the EMU level mainly through monetary policy and accessorily through a disciplined fiscal policy. The achievement of long-run objectives should be fostered through mainly market-

${ }^{8}$ The basic idea is that all EU member states should join the EMU, except Denmark and of course the United Kingdom. 
oriented supply-side policies and accessorily through an interventionist supplyside policy with a strictly limited supranational budget as we will see.

The definition of these interventionist policies clearly refers to the fact that the EU remains a market based economy despite limited public interventions either on the European level or on the national level: "The Member States and the Union shall act in accordance with the principle of an open market economy with free competition, favouring an efficient allocation of resources, and in compliance with the principles set out in Article 119". (TEU; Official Journal of the European Union, 2016).

The sole reference to solidarity between member states mentioned in the Treaties are the cases of important energy crises or natural disasters hitting individual member states.

In general, the need for common policies has been highlighted in all the documents leading to the EMU. A combination of a common fiscal policy combined with national and rules based fiscal policies were recommended, apart from common structural (supply-side) policies. The decision if a policy should be led on the supranational level or on the national level is based on the subsidiarity principle: the policy should be executed on the most efficient level depending on the existence of economies of scale or on externalities, even if these explicit economic criteria are not mentioned in the final version of the Treaty on the European Union (TEU; Official Journal of the European Union, 2016), neither in its article 5, nor in protocol $\mathrm{n}^{\circ} 2$. The Treaty of the Functioning of the European Union (TFEU; Official Journal of the European Union, 2012) only defines areas where the Union has exclusive competences and areas where the Union and member states have shared competences without specifying any economic criteria to justify this split of competences.

\section{Combining the Objectives of the Emu and OCA Theory: The Need for Convergence and Sustainable Growth}

As the aim of the European integration is to improve the standards of living, apart from the broader aim of keeping peace in Europe, the EMU's structure needs to be adjusted to the conclusions of OCA theory so that the expected gains for member states become larger than their costs. Therefore, there is still a need for real convergence, even after twenty years of a common currency. But this concept of convergence has to be clarified, as even the European Commission considers different concepts.

\section{The EMU's Objectives and the Need for Convergence}

The achievement of real convergence has always been a concern during the different steps of monetary integration in Europe.

In a Reflexion Paper on the Deepening of the EMU (European Commission 2017a), three types of convergence are mentioned and presented as conditions to be fulfilled to attain the EU's general objectives. 
The first and most important concept mentioned is real convergence defined as "moving towards high living standards and similar income levels" which is considered as "key to achieving the Union's objectives". This type of convergence suggests that the EMU is not an objective in itself, but a means to achieve the EU's objectives.

To improve the functioning of the EMU, nominal convergence is defined by its "nominal indicators, such as interest rates, inflation and exchange rates, government deficit and debt ratios, [that] have been used since the Treaty of Maastricht. Fulfilling essential nominal targets is a prerequisite to becoming a member of the euro area". These indicators still refer to financial stability, without referring to OCA theory, but through these criteria the EMU is expected to contribute to real convergence of member states' economies.

An implicit reference to OCA theory can be found, when the document defines cyclical convergence: "Cyclical convergence means that countries are in the same stage of the business cycle, such as an up or down swing. This is important for EMU because conducting a single monetary policy is harder and possibly less effective if countries are in very different stages of the economic cycle - some will need a more restrictive/expansionary policy stance than others". here, the authors clearly refer to the problem of asymmetric shocks that may affect economies of member states differently and complicates the task of policymakers. This definition implicitly suggests again the need for real convergence of national economies in a broader sense than just convergence of real income per capita.

How are Short-run Macroeconomic Stability and Long-run Sustainable and Inclusive Growth Linked?

If we reconsider the EMU's objectives as formulated by the European Commission, it becomes obvious that after having respected the nominal criteria to join the EMU, member states should benefit from the EMU through real convergence which means that disadvantaged economies should catch up with the advantaged economies in the EMU, whatever the criteria considered to define this real convergence. Studies have summarized the empirical evidence showing that we cannot observe real convergence within the EMU (ECB 2015, Demertzis et al. 2019 and Coudert et al. 2019, Aiyar et al. 2019, for example).

To achieve real convergence, measured by real GDP per capita, the ECB (2015) recommends that three conditions for sustainable and inclusive convergence should be fulfilled:

macroeconomic stability which means the reduction of imbalances and of the risks of asymmetric shocks;

increased economic flexibility to avoid further misallocation of resources;

$>$ and higher productivity growth, measured by Total Factor Productivity (TFP), through improved quality of labour and capital and a better support to innovation in businesses. 
Demertzis et al. (2019), who have a broader definition of real convergence, add that a "euro area-level budget will contribute to investment and should become supportive of macroeconomic management". A major argument for this more interventionist view is the existence of positive externalities of interventionist policies that are often neglected when analysing the question of real convergence, but this fact had already been recognized by the European Commission in 1990 (see paragraph 2.2.). These positive externalities can mainly be generated through investments in human capital, in $\mathrm{R} \& \mathrm{D}$, in infrastructure, and through industrial policies.

The Eurostat Sets of Indicators: an Evaluation of the Convergence and of the Level of Attainment of the EMU's Objectives

To evaluate these levels, Eurostat ${ }^{9}$ has established a series of indicators that can be more or less directly linked to the different concepts of convergence defined by the European Commission:

the Europe 2020 indicators that refer directly to sustainable growth and social cohesion;

> the UN Sustainable Development Goals (SDGs) also refer directly to sustainable growth and social cohesion;

D the European Pillar of Social Rights; a set of indicators referring directly to social cohesion through the structure of labour markets and social protection.

$>$ The remaining sets of indicators focus more directly on the structure of the European economy, but also consider some broader objectives:

$>$ the circular economy indicators reflecting structural changes in member states' economies with links to sustainable growth and development;

the Macroeconomic Imbalance Procedure (MIP) Scoreboard; a set of indicators considered as the main surveillance mechanism to guide economic policies in the EU on all levels. We will have a closer look at these indicators in a specific paragraph;

and finally, the Principal European Economic Indicators (PEEIs); a set of general indicators about the economy of the EU on all levels.

\section{Should Other Indicators Be Considered?}

Masuch et al. (2018), in an ECB Occasional Paper, focus on market-oriented structural policies that should improve the functioning of the EMU and the effectiveness of monetary policy. The authors refer to the quality of the institutional framework (quality improvements of public institutions, law enforcement, transparency and accountability, reduced corruption and tax evasion), to more flexible labour markets (adjustments of relative prices and wages, less regulations, improved active labour market policies, higher mobility), to more competitive

${ }^{9} \mathrm{EU}$ policy Indicators can be accessed on Eurostat's Home page: https://ec.europa.eu/eurostat/ accessed on 15.04.19. 
product markets (lower administrative and market entry costs), to a more efficient financial sector (development of the banking and capital market union), and finally to improved fiscal structural policies (improved functioning of tax administrations, reduced tax biases against equity financing, lower tax burden on labour, higher retirement age).

Demertzis et al. (2019), in a Bruegel Policy Contribution, consider fewer indicators to assess "sustainable and inclusive growth and convergence in the European Union":

Standard economic indicators, GDP growth rate and GDP per capita, should be used to assess the present state of convergence between member states. Then Total Factor Productivity (TFP) and the number of European universities in international rankings should be used to evaluate efforts in R\&D. Gini coefficients and trust in institutions should be used to evaluate social cohesion and finally $\mathrm{CO}_{2}$ emissions should be considered to evaluate green goals.

Alesina, Tabellini and Trebbi (2017) consider similar indicators that should be observed and improved to achieve an optimal political area, a broader concept than the EMU. They group the indicators into three categories:

economic convergence (of member states' GDP per capita, income inequality and the business cycles stages of their economies);

cultural convergence (of citizens' religiosity, sexual morality, gender equality, cultural capital and their appreciation of the role of governments);

and institutional convergence (of different indicators of quality of government and public administrations, governance, quality of legal institutions, educational outcomes and regulatory environment).

Finally, their approach follows the same logic as the previously mentioned studies, as most of the policy recommendations focus on a deeper integration to improve the functioning of the EMU and hence achieve the Union's objectives. This deepening should lead the EMU towards an optimal policy area that can and must be considered as the logical consequence of monetary integration.

Considering the different concepts of convergence and the different sets of indicators developed by European institutions to evaluate real convergence within the EMU, it should become obvious that achieving and maintaining the levels attained of these objectives cannot be obtained by sole bailout mechanisms or market-oriented structural policies within the EMU. The same remark will also be valid for the EU in general.

\section{Imbalances in the Euro Area: OCA Indicators and/or Structural Indicators?}

The next paragraph focusses on two major sets of indicators, the MIP scoreboard $^{10}$ and the cohesion indicators.

\footnotetext{
${ }^{10}$ The scoreboards can be accessed on Eurostat's website: https://ec.europa.eu/eurostat/web/macro economic-imbalances-procedure/publications; accessed on 30.06.19.
} 


\section{The MIP Scoreboard}

The MIP scoreboard should be considered as the basic statistical tool to guide national and supranational policies based on a two-step procedure: first, the Alert Mechanism Report (AMR) to detect imbalances and then the In-depth Reviews (IDR) in case of severe imbalances (European Commission 2012) to reduce the risks of symmetric shocks and of the need for bailouts.

Economic imbalances can be defined as "situations where stock and flow variables are out of equilibrium for an extended period of time, which is manifested through protracted savings-investment imbalances, losses of competitiveness accompanied by excessive credit and house price growth, and accumulation of debt" (Pierluigi and Sondermann 2018).

The selection of MIP indicators has been mainly based on empirical studies on financial crises and business cycles (European Commission, 2012). These indicators, designed to guide economic policies, do not represent any policy thresholds considered as objectives to be attained, but they are based on simple statistical regularities. The threshold levels for each indicator have been determined by "the upper quartile of the historical distribution" for most indicators. One exception is the national public debt indicator of $60 \%$ of national GDP defined by the Maastricht Treaty. This at best implicit reference to policy objectives is clearly a different approach compared to the main objective of the EMU's monetary policy where a precise policy objective has been defined ${ }^{11}$.

This ambiguity is confirmed by the fact that the MIP scoreboard indicators "are neither policy targets nor policy instruments" (European Commission 2012) and was restated in 2015, when the number of indicators was increased from 10 to 14: "The inclusion of these variables into the scoreboard shall not have legal implications nor change the focus of the MIP, which remains aimed at preventing the emergence of harmful macroeconomic imbalance and ensuring their correction. ... Flashes of the new indicators would not be read as implying, by themselves, an aggravation of macro-financial risks, and consequently will not trigger further steps in the MIP" (European Commission 2015b). This vague statement about the use of these indicators suggests that there are no clear and precise policy objectives defined on how to achieve real convergence within the EMU.

This set of 14 main indicators has been completed, first by 18 , then by 28 supplementary auxiliary indicators without thresholds ${ }^{12}$ but, again, these indicators are not binding for any policy recommendation (European Commission 2018a). Nevertheless, this increase in indicators gives a broader view of the economic development of member states than the sole main indicators.

If we are looking for improvements in real convergence and in the attainment of the EU's general objectives, it is less obvious that these indicators will be helpful. They give us information of a certain number of imbalances, if we agree

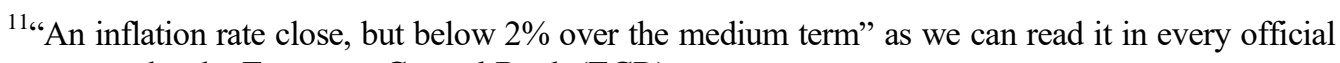
statement by the European Central Bank (ECB).

${ }^{12}$ These indicators can be accessed on Eurostat's website at: Eurostat (2019): https://ec.europa. eu/eurostat/cache/metadata/en/mips_sa_esms.htm; accessed on 29.06.19.
} 
on the thresholds as policy objectives, but is it enough to become aware of these potential imbalances to generate real convergence and to reach the EU's goals? None of these indicators allow a direct assessment of the state of the EMU as an OCA as there is no information about market integration, factor mobility, structures of national economies or price flexibility ${ }^{13}$ in the sense of OCA theory.

Nevertheless, we have to admit that macroeconomic stability is a prerequisite for sustainable real convergence. From this point of view, the main condition that member states should fulfil is the avoidance of asymmetric shocks during the business cycle. This approach, based on a national responsibility approach, considers as given, that the EU or EMU has no supranational fiscal policy and a very limited budget for structural and cohesion interventions within the Union (ECB 2015).

Cohesion Indicators 2014-2020 14

A broader approach to assess the EU's objectives is the cohesion indicators 2014-2020 published by Eurostat. These indicators assess the state of smart, sustainable and inclusive growth in the member states, linked to the Europe2020 strategy. It is hardly imaginable that these objectives could be solely achieved through market-oriented supply-side policies without complementary interventionnist policies. The EU's view is that these polices should be achieved on the regional level in cooperation with national organizations. They are considered as "the necessary investment framework to meet the goals of the Europe 2020 Strategy for smart, sustainable and inclusive growth in the European Union". Five targets have been defined: an increase in the employment rate, higher investment in R\&D, climate change and energy sustainability objectives, higher efficiency in educational systems and fighting poverty and social exclusion (Eurostat, 2018b).

The supported projects are financed by different European funds: the European Regional Development Fund (ERDF), the European Social Fund (ESF) and the Cohesion Fund (CF) for a total amount of $€ 351.8$ billion for 2014-2020. This amount was expected to be completed by $€ 100$ billion of national contributions ${ }^{15}$.

Cohesion Indicators 2021-2027

For the period 2021-2027, new priorities have been defined (European Commission 2018b):

\footnotetext{
${ }^{13}$ Export market shares, FDI flows and stocks indicators are computed based on Member states' world exchanges and not on intra-EMU exchanges.

${ }^{14}$ These indicators can be accessed on Eurostat's website: https://ec.europa.eu/eurostat/web/ europe-2020-indicators/europe-2020-strategy/publications; accessed on 29.06.19.

${ }^{15} \mathrm{https} / / /$ ec.europa.eu/regional_policy/en/policy/what/investment-policy/; accessed on 12.05.19.

${ }^{16}$ These indicators can be accessed on Eurostat's website: https://ec.europa.eu/eurostat/web/co hesion-policy-indicators/cohesion-indicators; accessed on 30.06.19.
} 
1. A smarter Europe, through innovation, digitization, economic transformation and support to small and medium-sized businesses.

2. A greener, carbon free Europe, implementing the Paris Agreement and investing in energy transition, renewables and the fight against climate change.

3. A more connected Europe, with strategic transport and digital networks

4. A more social Europe, delivering on the European Pillar of Social Rights and supporting quality employment, education, skills, social inclusion and equal access to healthcare.

5. A Europe closer to citizens, by supporting locally-led development strategies and sustainable urban development across the EU.

The corresponding resources will be allocated depending on GDP per capita levels combined with social and climate change indicators (youth unemployment, low education level, climate change, and the reception and integration of migrants). For this new period with its ambitious priorities, a total European budget of $€$ 461.117 billion will be available with expected national contributions of $€ 200$ billion (European Commission 2019).

\section{A Need for a Supranational Fiscal Policy based on OCA Theory and European Objectives}

This brief overview shows that the awareness of the structural adjustments needed was present right from the naissance of the idea of monetary integration in Europe and that these problems should be addressed either through marketoriented policies (more flexibility) or through interventionist supranational or common policies, fiscal policies included. Nevertheless, the concept of common policies was not and is still not very clear. Should it be policies decided on the EU level for all and/or specific member states or should it be a sole coordination of national policies with a more or less important part of autonomous decisions by national governments? The concept of subsidiarity has been defined as the guideline for these questions. Again, political preferences of governments and citizens of the different member states are not homogenous, as they should be for an OCA. This fact is the basic problem when the need for and the design of fiscal policies should be discussed, not just for the EMU, but for the EU in general. Based on Musgraves' classification of economic roles for governments, Buti (2019) clarifies these problems when he states that "the Maastricht Treaty leaves the cure of inequality fully in the hands of EU member states, focuses on granting efficiency of markets with the one-market project (even if certain aspects, such as policies to support productivity and structural reforms, are fully decentralized) and sustainability with the fiscal rules, and gives a small weight to stabilization, which is based on monetary policy and automatic stabilizers". This reflects the traditional idea of European integration, that political decisions will be followed by economic adjustments which is the "OCA theory in reverse" approach mentioned by Mongelli (2008). 
We will just recall that, from a theoretical point of view, an OCA needs a common fiscal policy in case of economic shocks, but a common fiscal policy, apart from market-oriented policies, will also be needed to reduce economic divergences between member states. Monetary policy, automatic stabilizers and decentralized structural policies seem not to be enough to address both problems.

Fiscal Policy and Asymmetric Shocks

\section{The Need for a Common Countercyclical Fiscal Policy}

As we have seen, there is a theoretical consensus that in case of asymmetric shocks countercyclical fiscal policy should be used to limit the impact of such shocks if factor mobility and/or price flexibility are insufficient.

The Commission of the European Communities (1990) has defined a shock as "any unanticipated event which has a direct or indirect impact on endogenous variables of the reference system" (member states). Nevertheless, we have to be more precise about the definition of shocks and about which shocks should be treated through countercyclical fiscal policies and which ones should be treated through structural adjustments.

These shocks may be either country-specific or common to the EMU, but they may have differentiated impacts on countries of a union depending on the initial conditions (economic structure, economic agents' behaviour, policy preferences) of these countries. If these conditions are different from one country to another, then common shocks, like country specific shocks, will be considered as asymmetric shocks with either temporary or permanent consequences.

\section{How to Finance a Common Fiscal Policy?}

To limit the negative consequences of asymmetric or endogenous shocks (De Grauwe 2016), OCA theory suggests that a budgetary union with a supranational budget should operate as an insurance mechanism for those economies suffering from asymmetric shocks. These fiscal interventions should be based on public investment programmes, less on simple public consumption (Drèze and Durré 2014). In this sense, the countercyclical policy could at the same time contribute to real convergence by investing in domains fostering positive externalities and economies of scale.

This missing insurance mechanism in the EMU design can be explained again by a lack of homogenous political preferences summarized in the opposition between a responsibility (market discipline) approach, dominating mainly in northern European countries, and a solidarity approach (risk sharing) dominating more in the southern European countries (Brunnermeier et al. 2016). The sovereign debt crisis has nevertheless generated instruments to cope with future crises: the European Financial Stability Facility (EFSF) and then the European Stability Mechanism (ESM), funds that provide conditional loans to member states facing mainly asymmetric shocks. 
A lot of discussions on how to improve these mechanisms are led and a general proposal for a euro area reform, including fiscal policy, can be found in the so-called $7+7$ report (Bénassy-Quéré et al. 2018). According to the authors, the report aims at presenting recommendations for financial stability, incentives for domestic, hence national reforms, and at generating a consensus in the responsebility (market discipline) vs. solidarity (risk sharing) controversy.

The authors recognize the need for a deeper (political) integration for viable supranational fiscal policy but avoid the debate due to a lack of political consensus on this topic: "A proper budget could only grow out of political decisions to finance defined common public goods and to design an institutional framework ensuring adequate accountability to a legislative body".

Therefore, the authors mention a limited focus of their contribution on "macroeconomic, financial and fiscal stability" considered as a public good (Bénassy-Quéré et al. 2018) for all European citizens. This public good should generate obviously positive externalities and hence be financed by a common budget.

The resulting recommendations of their analysis of fiscal policy can be summarized as a call for an improved coordination of national policies through simplified fiscal rules: "nominal expenditures should not grow faster than longterm nominal income ... and they should grow at a slower pace in countries that need to pay down their debts". This process should be monitored by "an independent, national-level fiscal council" that would report to the "euro area fiscal watchdog". The advantage of this system still based on national responsibilities is clearly simpler fiscal rules. This simpler structure will not avoid Eurosceptics' criticism of European elites if an independent council of experts monitors national budgets even if the authors suggest that the EMU also needs an overhaul of its institutional structure. Still, a lack of accountability will immediately be highlighted by Eurosceptics'.

For large asymmetric shocks, the authors refer to the existing ESM which should provide conditional loans to member states and euro area safe bonds could be issued. A system of junior sovereign bonds issuing should be developed to finance any excessive spending by member states. Again, complicated solidarity mechanisms are recommended that need to be explained to the public to avoid new criticism of the EMU structure.

\section{OCA Theory and Interventionist Supply Side Policies}

\section{$\underline{\text { The Need for Interventionist Supply-Side Policies }}$}

The theoretical discussion on structural adjustments mainly focusses on capital, labour and product markets adjustments to increase flexibility on these markets.

Pierluigi and Sondermann (2018) suggest that structural policies should improve the functioning of economic institutions, labour market structures and product market regulation should become more flexible. A similar approach can be found in Masuch et al. eds. (2018). The authors define structural policies as 
"efficient labour, product and financial market regulations, ..., good governance and efficient institutions, ..., the rule of law and the control of rent-seeking".

Even if De Grauwe (2016) mainly recommends increased market flexibility to solve structural problems, except in the case of exogenous shocks considered as permanent shocks due to facts that they cannot be controlled by the EMU (oil price changes, for example). In such a case he suggests that policy answers could either be more flexible labour and products markets or temporary supranational budgetary means to generate convergence.

These permanent shocks; "events that remain present over a time period considered (this does not preclude that it eventually disappears)"; may again be common or asymmetric due to structural differences (differences in domestic natural, human and capital resources) among member countries.

Nevertheless, more interventionist approaches have been developed, partly influenced by the low interest rates environment.

To achieve the EU/EMU's objectives through interventionist policies, we can refer to Mazzucato's (2013) suggestions that there should not be a discussion about the size of the public deficit, but about its composition. The author recommends defining strategic domains where governments should invest to foster "smarter (innovation-led)", more inclusive and sustainable growth. A similar idea is presented by Drèze and Durré (2014) when they suggest that growth should be stimulated through "public investments and selective private investments".

Pisani-Ferry (2019) presents a similar argument, referring to the present low interest rates. Governments should take "advantage of persistently low interest rates to finance economically sound investments that will benefit future generations".

Blanchard (2019) also considers fiscal policy, mainly its consequence, the public debt level, in the context of low interest rates. His position is less straightforward than the previous authors' position as he asks the question: even if fiscal costs of high debt levels have been low and so debt rollovers are feasible, are they desirable? Welfare effects have to be considered linked to the fact that public investment was too low in the past. His conclusion is that we should accept certain levels of public debt if they are due to sound investment policies by governments even if his conclusion is based on assumptions that can be challenged as recognized by the author himself.

To foster sustainable and inclusive growth, Demertzis et al. (2019) recommend public intervention to stimulate productivity and innovation. This type of policy should address the problems of climate change and of social cohesion in Europe at the same time. The authors implicitly refer to equity arguments (Rosen and Gayer, 2014) in favour of a centralized budget when they mention that this policy should also be a policy to reduce divergences between member states and regions within the EMU.

In this context the Commission of the European Communities (1990) has defined four levels of macroeconomic policy coordination without referring to a common policy. A degree zero where "each government acts independently taking all its external environment as given"; a degree one where each government leads a "non-cooperative isolationist policy" taking into account potential spill-overs on 
other member states; a degree two where governments lead "optimal noncooperative policies with full information exchange"; a degree three where governments accept "full coordination. Governments jointly set their instruments in order to maximize welfare". The major difference between the levels of coordination resides in the importance of information exchange between member states without being more precise on the objectives of such a coordination.

So, what should be considered as sound investments or investments fostering smart, inclusive and sustainable growth? In general, public investments are suggested in four domains that we mentioned already previously: investment in human capital, R\&D, infrastructure and industrial policy.

The theoretical justification for public investment is that the four domains are considered as generating public goods with positive externalities, hence corrections of market imperfections (Romer 2001). As we have already stated before, these standard arguments had been retained by the Commission of the European Communities (1990) in its "One Market, One Money" report to define criteria to justify supranational policies: existence of positive externalities on the community level due to supranational policies, indivisibilities and economies of scale. To define the optimal level of intervention, the subsidiarity principle should then be applied, based on these economic criteria.

\section{How to Finance These Interventionist Supply-Side Policies?}

The introduction of a European tax, which is not the most popular proposal, could have three advantages: transparency, simplicity and acceptability.

The structure of the system should be clear so that taxpayers would know the tax base and the use of the tax. Then, the system should be simple so that taxpayers would understand how the system works and the cost of the system should be minimized. Consequently, we could expect a greater acceptance of European taxes, especially if the aims of the EMU were formulated in a more precise way than at the moment. Therefore, a better communication will be needed to increase the acceptability of such a tax system. This point will be developed further at the end of our paper.

This basic description of a potential European tax system is probably overoptimistic so that alternatives should be considered. Mazzucato's suggestions (2013) seem to be very useful in this context:

royalties and the setting up of a European investment funds: when the EU or member states invest in R\&D generating returns, then they should get royalties;

income-contingent loans and equity; depending on the level of returns on publicly financed investments, the EU and member states should be considered like shareholders and get a return on the amounts invested (also in the case of public-private partnerships). In these two cases, these financial resources should be used to service the sovereign debt contracted to finance the corresponding investments; 
development banks: public investment banks should help finance structural projects like the European Investment Bank (EIB) does whereas other public financial institutions, like the ESM, should help finance countercyclical interventions in member states under the assumption that a consensus on a commitment to this policy can be obtained.

\section{The Present Instruments for European Interventionist Policies}

The major instruments are the EU budget and the InvestEU initiative ${ }^{17}$.

\section{The EU Budget}

The EU budget is an investment budget that has to be balanced every year. The annual amounts available are defined by the Multiannual Financial Framework (MFF) for a period of seven years (European Commission 2019b).

Different policy domains corresponding to the general aims of the EU are covered by this budget. The financing covers measures to foster smart and inclusive growth (subdivided in measures in favour of competitiveness for growth and jobs and for economic, social, and territorial cohesion); sustainable growth; security and citizenship; foreign policy and a final part of the budget finances the European administration.

For 2018, a total amount of $€ 160.114$ billion has been allocated which corresponds to about $1 \%$ of EU's gross national income (GNI) which is less than Belgium's or Denmark's national budgets.

The main resources are provided by the member states (76\% for 2019) and the management of the budget is organized as follows: direct management by the European Commission 18\%, shared management with member states $74 \%$, indirect management $8 \%$ of the available resources.

\section{The InvestEU Initiative}

The InvestEU initiative, an extension of the Investment Plan for Europe or the so-called Juncker plan, relies on the idea that European financial resources combined with financial guaranties given by the EU will trigger a multiplier effect and will generate even larger privately financed investments than the initial European resources. Again, the domains benefiting from these initiatives should correspond to the EU's general objectives: investments in sustainable infrastructure, in research, innovation and digitalization, in small businesses, and in social investments and skills.

The InvestEU fund will manage $€ 15.2$ billion of financial resources from the EU budget; then EU budgetary guarantees combined with private partners' resources for investment projects should reach $€ 47.5$ billion and the total

\footnotetext{
${ }^{17} \mathrm{We}$ will only refer to the EU in this paragraph as there are no specific budgets or other financial resources for the EMU. We will not consider the ESM because this mechanism only intervenes in case of financing problems resulting from countercyclical interventions.
} 
multiplier effect is estimated at $€ 650$ billion for the period between 2021 to 2027 (European Commission 2019a).

This very brief description of the EU's financial resources clearly shows that an annually $1 \%$ budget, compared to the EU's GNI, even combined with a still lower annual percentage InvestEU programme cannot be enough to foster real convergence within the EMU and even less in the EU. This fact is the logical consequence of the responsibility or market discipline approach that dominates the political debate in Europe. This approach relies on the idea that real convergence should be achieved through market-oriented policies, but we cannot expect an important impact of these amounts on the future development of the EU and not just for the left behinds.

\section{What Should Be a Future Fiscal Policy in the EU and/ or the EMU?}

As we have de facto two levels of economic integration in Europe, the European budget should be separated into an EMU and a non-EMU part. We will now only refer to the EMU part in this paragraph.

\section{The Structure of Public Budgets Matters}

European financial resources available for EMU member states should be grouped in a countercyclical and in a structural component (Drèze and Durré 2014). A deeper integration for these member states needs a more developed budget, even if there will be a risk that real convergence between EMU member states and non-member states might become more complicated.

The countercyclical component should be considered as an insurance instrument in case of asymmetric shocks (De Grauwe 2016) and should be financed by national and ESM resources. This structure should take into account the two dominant approaches to public intervention in Europe: the ESM resources are based on a risk- sharing or solidarity approach between member states and above a certain threshold of sovereign debt, member states should issue junior sovereign bonds at market conditions, which refers to the market rules or responsibility approach. The advantage of such a structure is that the government bond market's fragility will be considerably reduced (De Grauwe 2016).

For the structural component of a European budget, the EU/EMU's objectives have to be defined first of all in a more precise way, then, the corresponding objectives for member states should be defined based on the initial European objectives. Finally, indicators with defined thresholds should be established. Based on this clarification of objectives, policy means have to be defined. Then, the financial needs for these different polices have to be evaluated, hence a structural component of a European budget will be defined. An agreement needs to be found how to combine this European budget with national budgets and private investment initiatives.

This structure does not really need new institutions, but the existing elements should be used (EU budget, EIB and European Fund for Strategic Investments (EFSI), for example), but a clearer commitment to the objectives, to how to reach 
these objectives and to what to do in case the objectives are not attained will be needed. The sole change that we recommend is to separate the budget in two parts one for the EMU and one part for the remaining member states with a remaining question if the remaining member states need or want to have an insurance mechanism in case of asymmetric shocks.

The major difficulty to build up such a system is the lack of homogenous political preferences in the EMU/EU. This structure clearly pleads for a deeper political integration within the EMU and in the ideal case even within the EU. Then, a supranational fiscal policy based on a broader European tax and on common decisions on how to use these financial resources could be developed. Apart from taxes, the issuing of European bonds, guaranteed by all member states could be another source of financial resources to finance these European development programmes. These bonds would be repaid by the future taxes generated by the investment programmes or by other revenues generated by public investments.

Each investment project should be evaluated based on a cost/benefit analysis: the expected social benefits need to be larger than the expected social costs (Drèze and Durré 2014). The selected projects should mainly be decided in domains with market imperfections, that are labour intensive and should be distributed among member states in a way to foster real convergence (Drèze and Durré 2014).

\section{$\underline{\text { Rules Based }}$}

The remaining problem for all kinds of fiscal policies is the potential sovereign debt that will appear due to public intervention, either on the European level (which is not allowed for the moment) or on the national level.

The existing rules have been criticised for their complexity and measurement problems (Darvas et al. 2018) and also for their pro-cyclical structure and their problems of enforcement (Bénassy-Quéré et al. 2018). These inefficiencies explain their limited acceptance by policymakers and the wider public and why more and more discussions come up on how to make these needed rules more efficient and less complex.

Reports by Bénassy-Quéré et al. (2018) and Darvas et al. (2018) suggest that nominal public expenditures should not grow faster than the nominal growth rate to avoid further increases of debt-to-GDP ratios. At the same time, the levels of nominal expenditure should be compatible with debt reduction targets for those member states presenting unsustainable levels of debt. Finally, an escape clause from these rules should exist if very large shocks appear.

The theoretical link between deficits and debt has to be taken into account when a fiscal policy will be designed. A crucial point is the beforementioned relationship between a country's growth rate and the interest rate on sovereign debt (European Commission 1990, De Grauwe 2016; pp. 218-220; Blanchard 2018). When the interest rate exceeds the growth rate, then the increase of the sovereign debt-to-GDP ratio runs out of control and will cause financial instability. If the interest rate is lower than the growth rate, then this risk will not appear, as long as the relationship will not be reversed. A logical consequence will be that the 
definitions of fiscal rules to be applied to national and a supranational budget should be based on this relationship as suggested by Bénassy-Quéré et al. (2018).

\section{$\underline{\text { A Need for a Better Communication Policy in Europe }}$}

The previous developments clearly suggest that there is a need for an improved and simpler communication by European institutions to increase the transparency of the EU/EMU's objectives and its corresponding policies. Much clearer statements should be made about the corresponding advantages for member states, about the indicators used to assess improvements in member states and about how to adjust policies in cases where the objectives have not been attained.

Especially simplified rules should be explained to all citizens and how and why European programmes contribute to the defined objectives and why they are the better solution compared to national solutions. Finally, a clearer statement should also be made about short-term vs. long-term improvements for member states.

\section{Conclusion}

The process of monetary integration in Europe has generated an everlasting discussion about the need for a fiscal policy and about the definition of the aim(s) of this policy. The theoretical and political statements presented different conclusions from those that were considered to create the incomplete monetary union that we know today.

These limits of monetary integration become even more obvious in the aftermath of the financial and the sovereign debt crises between 2008 and 2011.

The structure of monetary, economic and political integrations in Europe, hence the role of a European fiscal policy, have been reconsidered since then, but the theoretical framework of a monetary union suggests just one solution: a deeper integration. A deeper integration means a political union allowing a budgetary union, so a need for more homogenous political preferences which can only be achieved through a deeper commitment to the EU/EMU by its citizens.

The following quote summarizes the political change and the corresponding change in communication that will be needed in the future to achieve our common goals in Europe: "Words matter: we need a new vocabulary for policymaking. Policy is not just about 'intervening'. It is about shaping a different future: cocreating markets and value, not just 'fixing' markets or redistributing value. It's about taking risks, not only 'de-risking'. And it must not be about levelling the playing field but about tilting it towards the kind of economy we want" (Mazzucato 2018, Penguin edition p. 19).

Therefore, more precise definitions of the objectives of European integration and of the advantages for member states are needed. As a consequence, a clearer presentation of the corresponding policies with the expected outcomes on the member state level has to be added. This has to be achieved through an improved 
communication policy integrating all the previously mentioned elements to convince European citizens that the European integration is not just about maintaining peace in Europe but that a real improvement in living conditions can be achieved.

If these adjustments cannot be realized, then the common currency risks failing and, with this purely economic aspect, the whole European idea.

\section{References}

Aiyar S., Bluedorn J., Duval R., Furceri D., Garcia-Macia D., Ji Y., Malacrino D., Qu H., Siminitz, J. and Zdzienicka A. 2019. Strengthening the Euro Area: The Role of National Structural Reforms in Enhancing Resilience. IMF Staff discussion note. June 2019 SDN/19/05.

Alesina A., Tabellini G., Trebbi F. 2017. Is Europe an Optimal Political Area? Brookings Paper on Economic Activity. DOI= https://www.brookings.edu/wp-content/uploads/ 2017/03/3_alesinaetal.pdf.

Baldwin R. Wyplosz C. 2015. The Economics of European Integration, $5^{\text {th }}$ edition. McGraw-Hill Education, Maidenhead.

Bénassy-Quéré A., Brunnermeier M., Enderlein H., Farhi E., Fratzscher M., Fuest C., Gourinchas P.-O., Martin P., Pisani-Ferry J., Rey H., Schnabel I., Véron N., Weder di Mauro B., Zettelmeyer J. 2018. Reconciling Risk Sharing with Market Discipline: A Constructive Approach to Euro Area Reform. Policy Insight $N^{\circ}$ 91. Center for Economic Policy research.

Blanchard O. 2019. Public debt and Low Intertest Rates. American Economic Review. Vol. 109, no. 4, April 2019 (pp. 1197-1229).

Brunnermeier M., James H., Landau J.-P. 2016. The Euro and the Battle of Ideas. Princeton University Press, Princeton.

Buti M. 2019. Fiscal Policy in the European Economic and Monetary Union: An Evolving View. In Blanchard O., Summers L., eds. (2019): Evolution or Revolution? Rethinking Macroeconomic Policy After the Great Recession. Peterson Institute for International Economics. The MIT Press. Cambridge, MA.

Commission of the European Communities 1990. One Money, One Market. An Evaluation of the Potential benefits and Costs of Forming an Economic and Monetary Union. European Economy, $\mathrm{N}^{\circ} 44$.

Commission of the European Communities 1992. Maastricht Treaty. Treaty on the European Union by Council of the European Communities. DOI= https://europa.eu/ european-union/sites/europaeu/files/docs/body/treaty_on_european_union_en.pdf.

Committee for the Study of Economic and Monetary Union 1989. Delors Report. Report on the Economic and Monetary Union in the European Community. DOI= http://ec. europa.eu/economy_finance/publications/pages/publication6161_en.pdf.

Coudert V., Couharde C., Grekou C., Mignon V. 2019. Heterogeneity within the Euro Area:New Insights into an Old Story. CEPII Working Paper No 2019-05 - March.

Council of the European Communities 1970. Report to the Council and the Commission on the realisation by stages of economic and monetary union in the Community. "Werner Report" (definitive text).

De Grauwe P. 2016. Economics of Monetary Union, $11^{\text {th }}$ edition. Oxford University Press, Oxford.

Demertzis M., Sapir A., Wolff G. 2019. Promoting Sustainable and Inclusive Growth and Convergence in the European Union. Policy Contribution Issue n ${ }^{\circ}$ 7. Bruegel. 
Darvas Z., Martin P., Ragot X. 2018. European Fiscal Rules Require a Major Overhaul. Bruegel Policy Contribution ${ }^{\circ} 18$. October 2018.

Drèze J., Durré A. 2014. Fiscal Integration and Growth Stimulation in Europe. Recherches économiques de Louvain; 2014/2 Vol. 80; pp. 5 - 45.

Eichengreen B. 1992. Should the Maastricht Treaty Be Saved? Princeton Studies in International Finance, $\mathrm{N}^{\circ} 74$, International Finance Section, Princeton University.

European Central Bank 2015. Real Convergence in the euro area: evidence, theory and policy implications. ECB Economic Bulletin, Issue 5/2015 - Article.

European Commission 2012. Scoreboard for the Surveillance of Macroeconomic Imbalances. European Economy. Occasional paper 92.

European Commission 2015a. Completing Europe's Economic and Monetary Union. Report by Jean-Claude Junker in close cooperation with Donald Tusk, Jeroen Dijsselbloem, Mario Draghi and Martin Schulz.

European Commission 2015b. Adding Employment Indicators to the Scoreboard of the Macroeconomic Imbalance Procedure to Better Capture Employment and Social Developments. Ref. Ares (2015) 5426195 - 27/11/2015

European Commission 2017a. Reflection Paper on the Deepening of the Economic and Monetary Union; DOI= https://ec.europa.eu/commission/sites/beta-political/files/ref lection-paper-emu_en.pdf.

European Commission 2017b. Reflection Paper on the Future of EU Finance. DOI= https://ec.europa.eu/commission/sites/beta-political/files/reflection-paper-eu-finances _en.pdf.

European Commission 2018a. Report from the Commission to the European Parliament, the Council, the European Central Bank and the European Economic and Social Committee Alert Mechanism Report 2019. SWD (2018) 466final.

European Commission 2018b. EU Budget for the Future. Regional Development and Cohesion. DOI= https://ec.europa.eu/commission/sites/beta-political/files/budget-may 2018-new-framework-glance_en.pdf.

European Commission 2019. The EU Budget at a Glance. DOI= https://ec.europa.eu/in fo/sites/info/files/about_the_european_commission/eu_budget/budget-brochure-a517-05_interactive.pdf.

European Commission 2019a. EU Budget for the future. What is the InvestEU Program$m e$ ? DOI= https://ec.europa.eu/commission/sites/beta-political/files/what_is_investe u_mff_032019.pdf.

European Commission 2019b. What is the Investment Plan for Europe? DOI= https://ec. europa.eu/commission/priorities/jobs-growth-and-investment/investmentplan-europe -juncker-plan/what-investment-plan-europe_en.

Eurostat 2018. Smarter, greener, more inclusive? Indicators to support the Europe 2020 strategy. DOI=https://ec.europa.eu/eurostat/statistics-explained/index.php?title= Euro pe_2020_indicators_-_executive_summary.

Fleming J. 1962. Domestic Financial Policies Under Fixed and Under Floating Exchange Rates. Staff Paper (International Monetary Fund), Vol. 9, No. 3; pp. 369-380.

Frankel, J., Rose, A. 1997. The Endogeneity of the Optimum Currency Area Criteria. Economic Journal, 108.

Friedman M. 1953. The Case for Flexible Exchange Rates in Essays in Positive Economics, University of Chicago Press, Chicago.

Haberler G. 1970. The International Monetary System: Some Recent developments and Discussions, In George Halm (ed.) Approaches to Greater Flexibility in Exchange Rates. Princeton University Press, pp. 115-123.

James H. 2012. Making of the Monetary Union. The Belknap Press of Harvard University Press, Cambridge, Massachusetts. 
Kenen, P. 1969. The theory of optimum currency areas. An eclectic view, in Mundell, R. and Swoboda, A. (eds.) Monetary Problems of the International Economy, Chicago, Chicago University Press.

Krugman P. 1993. Lessons of Massachusetts for EMU, in Giavazzi F. and Torres F. eds., The Transition to Economic and Monetary Union in Europe, Cambridge University Press, New York, pp. 241-261.

Masuch K., Anderton R., Setzer R., Benalal N. (editors) 2018. Structural policies in the euro area. European Central Bank Occasional Paper Series $\mathrm{N}^{\circ} 210$.

Masini F. 2014. A History of the Theories on Optimum Currency Areas. European Journal of Economic Thought, Vol. 21, $\mathrm{N}^{\circ}$ 6, pp. 1015-1038.

Mazzucato M. 2013. The Entrepreneurial State. Debunking Public vs. Private Sector Myths. Republished by Penguin Books in 2018.

Mazzucato M. 2018. The Value of Everything. Making and Taking in the Global Economy. Republished by Penguin Books in 2019.

McKinnon R. 1963. Optimum Currency Areas. The American Economic Review, Vol. 53, No. 4 (Sep. 1963), pp. 717-725.

McKinnon R. 2004. Optimum Currency Areas and Key Currencies: Mundell I versus Mundell II. JCMS 2004 Volume 42. Number 4. pp. 689-715.

Mintz N.N. 1970. Monetary Union and Economic Integration, The Bulletin, New York University.

Mongelli F. P. 2008. European Economic and Monetary Integration and the Optimum Currency Area Theory. European Economy; Economic Papers 302; European Commission.

Mundell R. 1961. A Theory of Optimum Currency Areas. The American Economic Review, Vol. 51, No. 4 (Sept. 1961), pp. $657-665$.

Mundell R. 1963. Capital Mobility and Stabilization Policy under Fixed and Variable Exchange Rates, Canadian Journal of Economics and Political science, 29, pp. 475485.

Mundell R. 1973. Uncommon Arguments for Common Currencies. In H.G. Johnson and A.K. Swoboda (eds.), The Economics of common currencies, London: Allen and Unwin, pp. 114. 132.

Official Journal of the European Union 2012. Consolidated Version of the Treaty on the Functioning of the European Union. DOI= https://eur-lex.europa.eu/legal-content/ EN/TXT/PDF/?uri=CELEX:12012E/TXT\&from=EN.

Official Journal of the European Union 2016. Consolidated Version of the Treaty on the European Union. DOI= https://eur-lex.europa.eu/legal-content/EN/TXT/PDF/?uri= CELEX:12012E/TXT\&from=EN.

Padoa-Schioppa T. 2004. The Euro and Its Central Bank. Getting United After the Union. The MIT Press. Cambridge, Massachusetts.

Pierluigi B., Sondermann D. 2018. Macroeconomic Imbalances in the Euro Area: Where Do We Stand? European Central Bank Occasional Paper Series; № 211, June 2018.

Pisani-Ferry J. 2019. When Facts Change, Change the Pact. DOI= http://bruegel.org/20 19/05/when-facts-change-change-the-pact/?utm_source=GDPR\&utm_campaign=5e 994e6458-EMAIL_CAMPAIGN_2019_05_02_08_31\&utm_medium=email\&utm_ term=0_7c51e322b7-5e994e6458-278663049.

Rodrik D. 2000. How far will international economic integration go? Journal of Economic Perspectives 14, pp. 177-186.

Rodrik D. 2017. Straight Talk on Trade. Ideas for a Sane World Economy. Princeton University Press.

Romer D. 2001. Advanced Macroeconomics. International Edition. Singapore. McGrawHill. 
Vol. 7, No. $1 \quad$ Klein: The Never-Ending Quest for the European Fiscal Policy's...

Rosen H.; Gayer T. 2014. Public Finance. Global Edition. Maidenhead. McGraw-Hill Education.

Schoenmaker D. 2011. The financial trilemma. Economic Letters; 111 (2011), pp. 57-59.

Tavlas G. 1993. The "New" Theory of Optimum Currency Areas. The World Economy Review; pp. 663-685. 


\title{
Sustainable Governance and Knowledge-based Economy - Prerequisites for Sustainable Development of the Developing and Transitional Economies
}

\begin{abstract}
By Kristina Jovanova*
Economic globalization results in unbalanced development and growing inequality between the centre and the periphery of the global economic map. This process is driven by the expansionist policies of the corporations and the financial capital, being in collision with the social protection system. Markets are good for wealth creation, but they fail to take care of the citizens' social needs. Social justice is a public good that can be provided for only by means of the political process. Globalization fails to meet the needs of the ultimate beneficiary of the development processes - the citizen. The modality in which economic localization foundations were set in the development and transitional economies, did not exhibit clear development capacities in order to improve the global position of these countries. Alternative development strategies are required in order to keep the territorial integrity of the nation-state and radical reforming of the central government role in the process is a prerequisite. The main driving force of the sustainable governance concept refers to the participation, knowledge and information distribution and cooperation among stakeholders. Economic prosperity is dependent on the effectiveness in production, collection and use of knowledge in the economic processes. Economy converts into a hierarchy of networks and what comes out as a result is a network society in which individual or corporative capacity for participation and networking determines the socio-economic position. Knowledge - Based Economy (KBE) refers to an economy that applies information resources, technology and knowledge into the economic development processes. Innovations entail increased communication intensity and feedback among companies, academic institutions, laboratories, consumers. They are a result of a number of interactions and synergies of specific innovative systems that tend to expand outside national borders, ideally becoming global, incorporating numerous global-local connections. (JEL Q01, F60, F00)
\end{abstract}

Keywords: Globalization, localization, sustainable development, knowledge based economy, governance

\section{The Root of the Problem}

The paper is exploring the modalities of sustainable governance and economic activities that would counterbalance the demonstrated deficiencies of the global economic order dominated by mega - capitalism and would improve the position

*National Programme Officer, Organization for Security and Co-operation in Europe (OSCE) Mission to Skopje, North Macedonia. 
of the developing and transitional economies on the global economic map (Dicken, 2007).

The first introductory section penetrates into the root of the problem, casting light on two major segments: 1) the combination of unbalanced distribution of production factors, knowledge and technology and 2) the presence of corruption, captured state by corporative capital and lack of sustainable governance instruments.

The research develops into a presentation of literature reviewed in order to develop the thesis and elaborate the main starting points, followed by a methodological approach for proving the existent discrepancies on the global economic map, projected in the centre-periphery theory.

Discussions, findings and conclusions follow as a result of the elaborated thesis and starting premises.

\section{Marginal Productivity Factor}

The capitalism driving force is profit maximization that is realized by means of accumulating extra value incorporated into the goods and services traded and the underpaid labour force. This system functions either by intensification of labour exploitation or by expanding production and introduction of more efficient and technologically innovative methods that are increasing the trade value for greater profit. The contradiction inherent to the process is the following - the more reduced labour time, the less labour value traded goods incorporate.

According to the theory of marginal productivity, in a modern high tech economy not all labour market participants are able to valorise their labour. Labour market puts on the surface only those who possess specific skills and knowledge. The rest are out on the margins of the system. Moreover, digitalization and robotics enable for production without human input. Unprecedented in the history of mankind, production without human labour input is possible. Hence, technological development appears to be the main factor for the rising inequality, while labour supply needs to correspond to the labour demand in order to avoid it.

If goods and services cannot result in profit without their realization on the market and unpaid labour force excluded from the production system cannot consume the rising supply in goods and services, does this mean the end of mass production is announced? Definitely not, as the financial sector takes over by opening credit lines and upbringing the capital on the throne of the mega capitalist order (Stiglitz, 2015). In the long run, labour factor position additionally worsens by falling down into the spiral of indebtedness under the mercy of the financial institutions lead by the individual need for profit. The pattern reflects from individual to national level in most of the transitional and developing countries (Bartlett and Uvalić, 2013).

\section{Asymmetry of Information, Non-Transparency, Corruption and Speculative Capital}

The imperfections of the market mechanisms are not properly treated by national policies. A major percentage of the inequality also results from inactivity and lack of adequate government policies, selective and not transparent decision- 
making, corruption and breaking the rules of the system, even more, producing rules as per the preferences of the ruling political and financial elites (Ceriani and Dávalos, 2014). The situation worsens when governments are controlled by financial oligarchs interested in the less transparent market. The practice is not exclusively applicable to developing and transitional countries, but also takes place globally and in rather developed economies. Yet, the instruments and tools are different and extend from non-objective and hidden information to using financial market derivatives that create fabricated reality on the real values of assets. The last was one of the main reasons for the 2008 financial crisis. Stiglitz rightfully calls them 'financial weapons for mass distraction' in his 2008 book 'The Price of Inequality'. When these financial derivatives that denominate virtual and speculative capital are subject to trade, asymmetry of information between buyer and a seller allows seller (financial institution) to extract extra profit. This is a pure speculative transaction.

Capital, in its nature, needs to circulate. Yet, not all capital transactions lead towards creating added values. When capital rather accumulates due to the payment of credit interest, it is called speculative capital. The mass expansion of speculative capital in a form of financial derivatives and their subsequent trade on the financial market overpassed the amount of trade transactions in goods and services. Even though of suspicious nature, financial derivatives normally tend to be backed up by real assets and value by borrowers on the market, shifting the risk of failure on the account of citizens' budgets, thus paving the road to a long-term economic instability. Moreover, government policies are inclined towards bailing out corporative failures on the financial market (for example, financial crisis 2008).

The inherent tendency of the speculative capital to move from highly developed towards underdeveloped countries, that is, from countries with low towards ones with high interest rates, constitutes a potential threat for developing and transitional economies of irreversibly falling into the spiral of indebtedness. Financial industry exercises high pressure on these countries by using speculative capital for financing trade balances with one final goal - realization of goods and services on the market and creating profit.

\section{Economic Globalization - Irreversible Trend that Fails to Meet Global Social Needs: A Review}

The evident exponential rise of the financial derivatives in the past decades ${ }^{18}$ in combination with the politico-economic approach in defining the process, leads to the conclusion that economic globalization is a process of privatization of the world economic resources by the owners of capital, very often virtual and hybrid capital. Under the same logic, it represents a process of transformation of the territorial (national) state into a market-corporate state, a new stage in the

\footnotetext{
${ }^{18}$ The activity of global financial derivatives reached 457 trillion euros in 2007 and 553 trillion in 2015, according to the Statistical Release, OTC Derivate Statistics at End-June 2015, Monetary and Economic Department, Bank for International Settlements, November 2015, retrieved from https:// www.bis.org/publ/otc_hy1511.pdf.
} 
development of capitalism called mega - capitalism, which (dialectically) equals to the stage of capitalist development that precedes post - capitalism and post market society, as seen by Marx (Shachtman, 1962), Keynes in his book 'Economic Possibilities for our Grandchildren', Hilferding in 'Finance Capital', or from the latest history, by Peter Drucker in 'Post-Capitalist Society' and Robin Hahnel in 'Of the People, By the People: The Case for a Participatory Economy, from 2012. The free capital movement is the basic characteristic of the economic globalization. Countries compete to attract capital, a fact that limits their own sovereignty and power to tax it. In the meantime, the movement of the labour force is strictly regulated. Hence, globalization radically modifies economic and societal arrangements in a direction of decreasing the state control over the economy. The effect is accelerated by the activities of neoliberal politicians and economists that act as corporative capital agents with a final goal of decreasing the power of the state over its national economy and opening the road to an expansion of capital and profit accumulation.

There is an evident political trend that creates extra profit for elite structures not due to their objective productivity and contribution towards social welfare, but due to corruptive connections with the ruling power, called 'rent seeking' (Stiglitz, 2012). This phenomenon is a very common practice in the transitional and developing economies and is very far away from a state of optimal and equitable distribution of the social wealth where the personal reward should correspond to the benefit delivered to the society. Literature offering solutions for the distribution of resources is immense. Market fundamentalists (Adam Smith, Milton Friedman) suggest that distribution of resources is most effectively and efficiently achieved within the market mechanisms system and that each intervention into the system would decrease the overall efficiency of the economy. From that perspective only, economic globalization is ultimately a successful project - free competition on a global level incites inventive and entrepreneurial talents and fosters technological development processes. But, the economic globalization is in a collision with the social protection system. As John Maynard Keynes, Joseph Stiglitz and Paul Krugman imply, markets are good for wealth creation but fail to serve the social needs of citizens. While market functions blindly in accordance with individual interests not giving moral judgement of correctness, society cannot function without differentiating between right and wrong. The collective distinction between right and wrong is up to politics that fails to bring societally acceptable decisions in a world that lacks strong moral platform (Soros, 2011). Political action is necessary even for creation and maintaining the market per se. The global crisis in 2008 demonstrated that markets are truly volatile; they possess internal power but lack inherent system moral (Down, 2008).

Profit dominates moral values. Underdeveloped and transitional countries remain affected by the unbalanced distribution between private and public goods with the mega - capitalist trends working in favour of accumulating private goods in the hands of few political elites (Mason, 2015). As financial markets are subject to crises, they do not strive towards equilibrium, but facilitate the free trade of goods and services between voluntary participants in favour of their individual needs, rather neglecting the collective needs of people, such as order, law 
enforcement and social justice. These "public goods" can be provided for with political process only. If the main advantage of the markets is considered the efficiency (situation when supply equals demand in quality and quantity) and their inefficiency is obvious (inability to absorb the available human resources and labour potential) than logical conclusion prevails that globalization without adequate coordination and strengthening of the international political and societal arrangements, leads to inequality. If citizens' welfare is the imperative of the democratic systems, we cannot afford to maintain a kind of globalization system that appears to be the main reason for the ever-growing inequality due to unfair rules of the game or even the absence of them.

The positive sides of the economic globalization per se are not contested, but the manner in which globalization is managed. Globalization trend cannot and should not be stopped. Yet, the main challenge remains: how can we direct the process towards achieving win-win outcome for all involved stakeholders. Nobel Prize winner Amartya Sen (Sen, 1999) claims that GDP quantitative indicator is not an appropriate measure of human welfare and that globalization 'winners' might compensate the 'losers' and yet gain. The problem is the absence of legitimate international equivalent of the political processes conducted at the national level. Market challenges became global and politics remains deeply rooted in the sovereignty of the national states. This contributes to increasing the gap between rich and poor countries.

According to the latest World Bank indicators (World Bank Group, 2015 and 2019), the wealthiest 1 per cent of the citizens on Earth earns as much as the poorest 57 per cent together and 10 percent of the world's population lived in 2015 on less than US $\$ 1.90$ per day. This type of system functions in favour of the top level and is so inefficient that the profit of the top is smaller than the loss of the bottom in the societal pyramid. The biggest loss appears to be the trust - lost trust in the democracy and justice.

Technological development is advancing at a very high speed the humankind has never seen before the twenty-first century and it is very hard to predict the future. Same technology can create very different kinds of societies. For example, South and North Korea have had access to exactly the same technology but have chosen to employ it in very different ways (Harari, 2017). Yet, the latest technology development trends leave open space for one very obvious move eliminating the role of the central governments (nation-states) as a direct economic development factor and opening space for networking on a global-local level, creation of knowledge clusters and developing of Knowledge-Based Economy.

\section{Knowledge-Based Economy: A Counterbalance to the Mega Capitalism}

Knowledge, as an integral part of the so-called 'human capital' and technology, has always been the driving force of the economic development, but only as far as in the last couple of decades its importance has been recognized as a growing crucial development factor. Knowledge-Based Economy (KBE) refers to an economy that applies information resources, technology, specific skills and knowledge for achieving economic development. The idea of knowledge playing a 
key economic role is not new. Adam Smith referred to "new type of specialists that bring an important contribution in creating economically useful knowledge" (Mueller, 2015). Friedrich List (List, 1841) acknowledged "institutions that contribute to the development of productive forces by means of creation and distribution of knowledge". The idea of Schumpeter (McCraw, 2007) on innovations as important economic dynamics factor was followed by students such as Galbraith, Goodwin and Hirschman.

The notion of KBE is closely linked to the work of the management theorist Peter Drucker and the sociologist Daniel Bell, (Drucker, 1959 and Bell, 1973). Yet, the term 'Knowledge Economy' and its synonym 'Knowledge-Based Economy' was not widely spread up to the early 90-ties of the last century. Since then, the development of KBE turned into the leading principle of the economic development policies in the developed countries, despite its incomplete definition and attempt to be contested as a development concept. The term 'KnowledgeBased Economy' resulted in total recognition of the role of knowledge and technology in economic growth and development. For example, OECD countries from the beginning of this millennium are increasingly dependent on production, distribution and use of knowledge in the context of economic processes. Economic output and employment in the technological intensive sectors have increased in the countries from the global centre with the fastest rate ever noted. In the last decade, the proportion of high technology in the industrial production of OECD has doubled and is estimated that in the biggest number of developed countries, more than 50 per cent of GDP is knowledge-based.

The definition of KBE combines the approach of the World Bank and OECD: 'Knowledge-Based Economy is the type of economy based on economic incentives and institutional regime which stimulates acquiring, creation, dissemination and use of knowledge and flow of information for increasing the growth and welfare, as well as effective educational systems for development of skills, ICT, research, development and innovation'. According to Ian Brinkley, former director of Knowledge Economy Programme of Work Foundation, the $\mathrm{KBE}$ idea may be operationalized by 1) defining the knowledge industries (for example, knowledge based services); 2) knowledge intensive labour force (example, holders of certificates in most contemporary professional codes); 3) knowledge sources and assets (research and development) and 4) knowledge based services (volume of trade in knowledge - based industries).

These are narrow approaches in defining KBE. Alternatively, KBE can be defined as a concept that incorporates complex processes of socio-economic restructuring, followed by growing importance of information flow and processing and creation of knowledge though the entire economic activities' process. This concept involves investment in science, technology, engineering and maths (Science, Technology, Engineering and Mathematics - STEM), increased number of educated workers and consumers and the development of new industry sectors.

The Knowledge-Based Clusters and similar instruments that constitute an integral part of the KBE concept is presented in Table 1. 
Table 1. Knowledge Clusters and Similar Instruments

\begin{tabular}{|l|c|c|}
\hline Concept & Short definition & Quantification (example) \\
\hline $\begin{array}{l}\text { K-cluster } \\
\text { knowledge cluster) }\end{array}$ & $\begin{array}{c}\text { Agglomeration of } \\
\text { institutions where } \\
\text { knowledge is input and/or } \\
\text { output }\end{array}$ & $\begin{array}{c}\text { Number of organizations per } \\
\text { location }\end{array}$ \\
\hline $\begin{array}{l}\text { K-hub } \\
\text { knowledge hub) }\end{array}$ & $\begin{array}{c}\text { Local innovation system, } \\
\text { centre of network } \\
\text { production and } \\
\text { distribution of knowledge }\end{array}$ & $\begin{array}{c}\text { Number of human resources } \\
\text { and labour force focused on } \\
\text { knowledge and their output } \\
\text { (patents, software, } \\
\text { documents produced) }\end{array}$ \\
\hline K-architecture & $\begin{array}{c}\text { Structures and institutions } \\
\text { for communication and } \\
\text { knowledge flow }\end{array}$ & $\begin{array}{c}\text { ICT management, regular } \\
\text { meetings and knowledge } \\
\text { exchange initiatives }\end{array}$ \\
\hline Epistemological relief & $\begin{array}{c}\text { Locations with high or } \\
\text { low knowledge intensity }\end{array}$ & $\begin{array}{c}\text { Regional R\&D, costs, } \\
\text { location of K clusters and } \\
\text { knowledge centres }\end{array}$ \\
\hline
\end{tabular}

Source: Dev Singla, Chandan, (2008) Knowledge-Based Cluster Development in India, Opportunities and Challenges, Massachusetts Institute of Technology.

These trends necessarily lead to the revision of the existing theories and models. Traditional production factors based on labour, capital, material and energy where knowledge and technology are external factors are replaced with a new concept where knowledge represents direct productivity factor.

For the purpose of measuring and monitoring the KBE development, World Bank developed Knowledge Economy Index (KEI), using a four pillars framework: 1) economic initiative, incentive and an institutional regime in support of KBE; 2) educated population ready to create, disseminate and use knowledge; 3 ) efficient system of companies ready to absorb innovation and technology created, research centres, universities, consultancies ready to contribute to the global knowledge aggregate development and 4) information and communication infrastructure for facilitation of effective creation and processing of knowledge and information. According to the World Bank data for 2012, the highest KEI has been calculated for Sweden and Scandinavian countries, EU, USA, Switzerland, Australia and New Zeeland.

Developing and transitional economies lack the majority of all the KEI indicators.

\section{Methodology: Center vs. Periphery on the Global Economic Map - The Unsustainable Reality and the Need for Localization}

For the purpose of achieving the defined goals, the paper uses classical research methods, such as analysis, synthesis, induction, deduction, description, comparing, abstraction, historical method and similar. The theoretical component includes contemporary literature in the field of global and local economy, quotations from renowned authors from journals, statistical data from reports published by international governmental and nongovernmental organizations and 
internet pages. However, the main methodological platform for analysing the problem of the developing and transitional economies is the centre-periphery theory.

According to the centre-periphery theory, global capitalism has contradictory structure. It is developing into dominating socio-economic system based on the appropriation of the extra value by means of monopolistic instruments. The monopolistic position of the centre (countries that enjoy control over information, technology and knowledge) enables accumulation of the added extra value from the countries satellites in the periphery of the global economic map, later on, used for augmentation and centralization of the capital. Instruments of this process are the prices of products and services on the market in the economic branches with a greater organic composition of the production factors (greater technology versus labour). Respectively, the unbalanced territorial distribution of such economic branches creates unbalanced development and inequality among territories on the global economic map. This is the inherent discriminatory practice of mega capitalism, based on the exclusive right over contemporary technology, the latter being a factor of above average productivity of the centre. Contrary to the interests of the periphery, globally speaking, the technological advantage of the centre has been internalized as a cost on the global level directed towards the disadvantaged on the periphery. Moreover, the periphery is unable to compete structurally with the centre, as in the era of financial capital domination, the contemporary economic reforms offered by the global financial institutions are of a rather monetary character causing damage to the production infrastructure of the periphery and opening financial channels for crediting the mass consumption of products created in the centre. The interventionist instruments used thereby are so untypical for the neoliberal economic provenience, as great paradox has been created: by state interventions from the centre promoted is a capital-labour model in which periphery countries would ultimately lose their power over labour in favour of the Transnational Corporations (TNC) and ultimately eliminating the nation - state and converting it into corporate state with an eliminated social component.

These policies enjoy strong support from the global centre, USA, the only country with a veto right in the IMF and lead to a rise of speculative financial assets detrimental to the development of entrepreneurship and structural reforms in the periphery countries (developing and transitional). This results in unproductive spending, unemployment and inefficiency. By owing monopolistic position over highly technology intensive production and offering it to the periphery, the centre pumps out the accumulation of capital from the periphery deepening the development gap. Explained in this manner, the centre-periphery theory refutes western theories according to which centres are sources of development trends for the developing and transitional economies (the periphery). To the contrary, periphery corporate state capitulated before capital itself, eliminating the need for its taxation just to be able to attract it.

This type of capitalist order that takes its major driving force from the technological supremacy of one global centre (the Silicon Valley) backed by the voluntarism of the speculative capital and cultural individualism is politically, societally and first of all, economically unsustainable. When speculative financial 
capital is the only binding mechanism between centre and periphery, there is an open space for expansion of corruptive, corrosive and criminal structures, distorting the system of universal human values.

The postulates of a contemporary understanding of a democratic society are in collision with the practical tendencies of the global economy functioning. If we assert that democratic government belongs to citizens and exists for citizens then it would be very hard to assert that the current political system trends in developing and transitional economies are democratic. The power remains with the rich financial elites that have captured the corporate state and spread towards the lowest society cell in the local communities, using mass and sophisticated public political campaigns. If the government is, in fact, functioning for improving the welfare of citizens, they must be allowed to smoothly participate in the decision making on issues of their direct interest. Citizens' participation in decision making processes can only be done efficiently at the local level of government, at the level of their communities, exactly where resources come from, where challenges are felt and where common goals and interests are shared among community members.

In the rapidly changing global economic environment, the shift in perceptions and understanding of the economic processes leads to a transition from economic globalization to economic localization and ultimately, glocalization. This process needs to be followed by a subsequent shift in policies and politics at the national and international level. The political focus needs a shift from protecting to limiting the power of TNC (Transnational Corporations).

The new technological era of the K5 wave (Quigley, 2012) has the potential to end the destructive trend. Yet, this requires strong political will for decentralization of the global economy into polycentric local structures with fair game rules and economic inclusion of the periphery countries. There is no need for choosing between unlimited mega - capitalism and the opposite - back to communism, as both are unsustainable. Fruitful interaction between the power of knowledge and social welfare is imperative.

Local initiative need to be given a space for action and realization, currently being suffocated by the immense state subsidies the corporate state offers to the powerful business elites. Global economic entities do not approach local territories in order to improve them or create businesses and jobs. They come in order to extract profit as fast as possible and as much as possible. Creating jobs makes sense to them only if they can reduce their labour costs. The goal of a typical TNC is to be anywhere in terms of their own benefit and nowhere in terms of responsibility; Mander and Goldsmith (2005). Hence, the knot between central corrupted government and financial elites from TNC must be broken and the power of decision making redirected towards local communities by means of building strong local government that would provide for democracy and economic freedom of the community members in the developing and transitional economies. Such a decentralized system of sustainable local communities must be built gradually. Economic localization needs to be preceded by political decentralization and economic democracy built through political democracy that would enable economic governance at the local level. The newly created environment would open space for local ideas, flow on incentives for innovations, knowledge and 
information and knowledge-based economy can start to be developed by combined top down and bottom up approach.

Economic theory has developed attempts to measure the local development, but no single theory gives a precise definition. Common explanations of some of them can be mathematically expressed as follows:

Local Development $=\mathrm{CxR}$, where $\mathrm{C}$ refers to the capacity of a local territory (economic, social, technological and political) and $\mathrm{R}$ indicates the resources (natural, human resources, locational advantage, capital investments, entrepreneurship culture, transport and communications, technology and industry, market and export potentials). If the value of $\mathrm{C}$ equals 1 , the capacity is neutral, which neither adds up nor takes out value from the resources of the local community. Value higher than 1 indicates strong capacity able to multiply local resources and value lower than 1 refers to low capacity and bad quality of social, organizational and political leadership where corruption, cronyism and interests of a narrow group of people degrade the potential of the local resources and hinder sustainable development. Traditional economic theories focus on the $\mathrm{R}$ part of the equation (resources), neglecting the capacities. Yet, contemporary sustainable development cannot be imagined without a close correlation between the two segments-the more differentiated capacities local community possess, the probability for putting resources in function of sustainability is higher.

In the context of the transitional economies development, both segments need institutional support: 1) improvement of the political, technological, social and overall economic environment for sustainable development and 2) initiating a process of strengthening the resource base, replacing traditional materialistic resources with the creation of knowledge, innovation, connectivity and clustering.

The striking differences between traditional mainstream development and development based on localization (economy of local communities) are presented in Table 2.

Table 2. Contradicting Characteristics between Mainstream and Local Economics

\begin{tabular}{|ll|}
\hline Mainstream economy & Economy of local communities \\
Global & Location based \\
Specialized & Diversified \\
Singular & Multifaceted \\
Broad scope & Narrow scope \\
Competitive & Cooperative \\
Centralized & Decentralized \\
Counter cultural & Culture - specific \\
Non local ownership & Local ownership \\
Short term profit & Long term investment \\
Growth oriented & Sustainability oriented \\
Ecologically unsustainable & Ecologically sustainable \\
Amoral & Ethical \\
\hline Source: Gibson-Graham, J.K. (2006) & Post-Capitalist Politics. Minneapolis, MN: Minnesota \\
University Press. &
\end{tabular}




\section{Results: In Pursuit of Alternatives}

Transitional and developing economies are in an urgent need of alternative capital sources in order to quit the doomed indebtedness. The corporate state has not seemed to be able to support the creation of sustainable economic entities that would lift the countries from the periphery towards the centre of the global economic map, but rather declared itself as the major capitalist that centralized and sterilized economic vividness, putting the private sector in a position of an instrument of achieving short term political goals of the elites. In support of the thesis, the total external debt stocks of developing countries and economies in transition reached $\$ 6.7$ trillion in 2014, an increase of 5.2 per cent compared with 2013 stocks (World Bank data). Hence, radical moves are necessary for fighting the neo-colonial lock: 1) economic localization (using internal resources and capacities); 2) economic glocalization (establishment of local-global connections); 3) redefinition of the central government function; 4) introduction of sustainable governance principles, Knowledge-Based Economy and change in the general mentality matrix of the citizens. In view of the latter, as per the theory of the Dutch social phycologist, Gerard Hendrik Hofstede ${ }^{19}$, the average mentality in the postcommunist transitional economies is prone to hierarchy, avoidance of risk and entrepreneurship, centralization, politicization, intolerance towards novelties and unconventional ideas, non-participatory decision making and an overall absence of motivation - lacking all that is needed for rising productivity in the era of info and mega - capitalism.

Turning Inwards: Economic Sovereignty of Local Governments a Precondition for Economic Localization

Developing and particularly transitional economies inherited very centralized administrative structures that exercise state intervention into all economic segments. This in combination with the overwhelming global financial capital pressures and converted central state from de jure democratic to de facto corporative provides an unfavourable platform for developing and transitional economies in terms of the ability to improve their geo-strategic position on the global economic map. From a purely economic perspective, the basic platform for exit scenario is maximized employment of domestic economic capacities, available human resource capital, knowledge, skills and information.

Economic localization would be the most logical way out of the negative scenario. This process starts with decentralization of power, transfer of functions and decision making and shifting the focus of economic activities from central to the local level of government. Bottom-up approach is crucial for ensuring economic efficiency and growth via establishing of direct links between local needs and service delivery to citizens and businesses. Decentralization in decision making, as the first step towards economic localization, would open space for

\footnotetext{
${ }^{19}$ Hofstede is a Professor Emeritus of organizational anthropology and international management from the University of Maastricht. He is a former IBM employee, where he has implemented extended researches related to cultural behaviours.
} 
effective and efficient use of local resources. Economic activities have to be dismantled at the lowest level of government for giving space to local initiatives, decreasing the distance between supply and demand, the creation of local production systems, trade and participative local government. Local comparative advantages need to be properly advertised and thus create positive competition. The concept of territorial marketing enables these centripetal forces that attract capital at the local level, contrary to the centrifugal forces of the technological development that creates divergences. Economic success is due to an optimal combination of both development forces. Polycentric development policies will further contribute to elimination of disparities, incite internal migration and stimulate growth in less developed regions.

The model of localization implemented in most of the transitional economies is not based on clear economic sovereignty and does not provide for a development platform and benefit for the ultimate beneficiaries, ordinary citizens. De jure, legislation is in place, but de facto, no political will exist for enforcement, all this in combination with the high frequency of corruption practices. Local governments are still very much dependant on the central and the latter does not seem to be interested in giving up power in favour of real growth. Instead, clientele approaches are still maintained for the benefit of the corporate sector. Enabling economic sovereignty at the local level also needs clear fiscal independence, which again is not a case.

\section{Creation of Global-local Connections}

Contrary to the traditional policies and practices in developing and transitional economies, development is no longer directly connected to the functions of the nation-state in rather developed economies. The ultimate responsibility for citizens' welfare is transferred to local level governments in their capacity of important subsystems of the global politico-economic system. Yet, localization does not mean complete isolation from the global economic scene, to the contrary, it paves the way to glocalization, a sustainability model where local communities, businesses, economic subjects in general, establish direct links with other localities on the global map, thus creating local-global connections. The key element is their complete independence in decision making, a factor crucial for sustainability.

Interactions between economic actors on the global scene vary in the span from cooperation to competition and rivalry. This evident paradoxical behaviour depends on the type of interactions and the final objective of the process. For example, TNC in one industry are fierce rivals, but at the same time cooperate when about to build joint position before the domicile country that would work in favour of both. In the era of info capitalism, capital is super mobile and economic activities are de-territorialized. They can be easily moved from one location to another, yet the inherent connection to the geographical location does not decrease in importance - each economic function is enrooted in a specific location defined by national legal environment, political structure and macroeconomic parameters.

This set-up of global-local production networks dominates the global economic map with clear tendencies towards concentration or dispersion, blurring 
the traditional national frontiers and integrating national and local economies in ways that exert power over the economic development trends. These processes produce disproportional results in different territories. The contemporary world is different than the one in the $60 \mathrm{~s}$ and $70 \mathrm{~s}$, even though not more inclusive than before, yet more dependant.

\section{Redefining of the Central Government Function}

Developing and transitional economies are faced with radical transformations in view of the socio-economic and political aspects such as decreased power of syndicates and collective bargaining, deficit in democracy, eroded legitimacy of state institutions, diminished power of non-governmental organizations, while neglecting the needs of local businesses and citizens. Economic localization must proceed from radical changes that give a brand new role to central government authorities and would convert them into catalyser and development agent for the local economic subjects. The primary role of the central government needs to be confined to maintaining a stable macroeconomic environment and promoting local economic development policies that would serve as alternative sources for financing debts. This would limit the impact of speculative capital as its import would be reduced.

The new, modern central government and state powers need to work in partnership with the local and create joint policies that ultimately support local community members according to the principle of subsidiarity. The process is multidimensional and certainly two-way. Local community members also need to take direct responsibility and leadership in the local economic development processes (OSCE Mission to Skopje, 2013). All these factors lead to improvement not only in government models, but also the establishment of new governance practices - participatory, democratic and inclusive.

\section{Implementation of the Democratic Governance Concept via ICT Systems}

ICT development and the overall global economy changes have a major impact on the organization and the implementation of the central and local government functions (Asian Development Bank, 2014). The fast info technologies modify the fashion in which governments implement their functions and create instruments for strengthening local democracy by the inclusion of citizens into decision making at the lowest level of government. The transformation of public administration from traditional to contemporary model of governance and the affirmation of the ideas of innovation, effectiveness and efficiency constitute a basic platform for entirely new organizational model of government that is bound to respond to the contemporary needs of citizens. The new model of functional decentralized and socially responsible state directs its policies towards local governments and citizens.

The democratic, good governance concept is as old as the human civilization itself. Landell Mills and Serageldin (Diouf, 1991) treat governance aspects such as political responsibility and effective public administration and define governance 
as "use of political authority and exercising control over for social and economic development", putting the main emphasis on the political and administrative aspects of the governance, but do not explain the complete connection between government and the citizens.

Governance is a system of values, policies and institutions by which government (central and local) influences the economic and the overall human development of the community members and citizens in general. It represents the manner in which government organizes itself for making and implementation of decisions. It includes mechanisms and actions of citizens and communities for identification of their needs and interests, harmonization of their differences and exercising their legal rights and responsibilities. Rules, institutions and practices are those that set boundaries and provide for benefits for individuals, organizations and corporations. Governance, including its social, political and economic dimensions, functions on each and every level, regardless if micro local (household), local (municipality, settlement), regional, national or global. The main driving force, instrument and medium for the functionality of the democratic governance concept are participation, active involvement in its processes with a special accent on the distribution of relevant knowledge and information across the stakeholders' networks. The cooperation is paramount; it is more efficient than competition, a thesis successfully promoted by the Nobel Prize Winner Dr John F. Nash, from Princeton University. The point is as follows: there is a need for maximum cooperation between the government and the service beneficiaries. They are subjects striving towards same goal, they are not competitors. This principle is the main difference between corrupted from one side and transparent and accountable governments on the other (Tremlett, 2013). The most convenient level of government that is capable of enforcing an effective governance process in line with the community member needs is the local government. This is the starting point in creating contemporary economic development policies. However, practices in developing and transitional economies showcase a high level of political corruption where central government networks by exercising political power force local ones to deviate from fulfilling their basic goal - meeting the different needs of community members. In such a situation, local governments lose their basic function and turn into an extended instrument of the central government in support of the corporative and financial elites' interest.

Contemporary ICT represents a coordination agent among local, regional and central governments, but only if political will exists (Hamnond, 2009). Even though in theory the process seems viable, in practice extra efforts are necessary in order to achieve such a synergy, including distinction among different levels of government and combination of the top down and the bottom - up approach. Central governments cannot just transfer resources, functions and power to local ones, without first clearly determining their own new functions and local governments cannot undertake, without policy and legal support from the central governments. Similar to this, e-government cannot isolate itself from the general context of the e-governance. This is a test for the developing and transitional countries of their readiness to position themselves under the supervision of the citizens. Democratic governance needs to be participative, transparent and 
responsible. Simultaneously, it needs to promote the rule of law in an equitable and effective manner. This ensures that political, social and economic priorities are consensus - based and citizens' orientation principle implemented in the developed and EU countries, fully adopted.

\section{Conclusions}

Central governments need to retain their basic security, defence, macroeconomic and legislative functions for protecting primarily domestic capital and production resources and building basic infrastructure. All direct economic governance processes need to be decentralized to a lower level of government. This repositioning of the central government is a paramount for building protective mechanism against the destructive global economic effects that affect the central government budgets and national policies and are expanding the indebtedness down to the final consumers - the citizens.

The process need not result in isolation of the local communities but to the contrary, need to create a favourable environment for creating new, effective and efficient local-global connections that would benefit the final consumers-citizens, without direct and evident interference of the central government. This process would enable substitution of the formal with informal innovative methods of economic development in line with the authentic needs of the local community members and their local resource potentials. Endogenic local sources are the new driving force and the focus is re-shifted towards sustainability vis-s-vis ever changing global environment.

The new economic concept of sustainable development is based on the role of informal rather than formal institutions, where nation - states and central governments recognize the economic sovereignty of the local governments. Each contrary policy potentially leads to disintegration proportionally to the degree of exhaustion of the local economies and the transfer of profit to the financial elites via the corporate state mechanisms. Informal institutions are networks, partnerships, clusters that mobilize local sources based on trust and partnership. Informal communication based on trust lead to a decreased transaction costs, sustainability and external influences immunity.

Knowledge, information, innovations and building of innovative systems and networks undertake the primary role in the newly created environment, contrary to the old traditional theories and practices that put the accent on the national economic strategies and budget policies, submitting the local economy to the mercy of the central fiscal transfers. The traditional ineffective and outdated relation: global financial elites - central governments - local governments - citizens is unsustainable and leads to the scenario of "economic secession" of the local territory from the national and represents a bad medium with the global economy.

The sustainable development of developing and transitional economies has to be based on knowledge - based industries that tend to group into Knowledge Based Clusters, local innovation systems organized around universities, research 
centres and companies that produce innovation. These processes require restored trust among economic stakeholders.

Finally, enhanced social relations among local community members and local public-private partnerships are basic economic development factors of the new technological era, while the local - global networking into industrial, production, trade, service and research and development clusters represent the future of economic sustainability in the changing global environment.

\section{References}

Asian Development Bank (2014). Innovative Asia: Advancing the Knowledge-Based Economy: The Next Policy Agenda, retrieved from http://adb.org/sites/default/files/ pub/2014/innovative-asia-knowledge-based-economy.pdf.

Bartlett, W., \& Uvalić, M. (2013). The social consequences of the global economic crisis in South East Europe, Research Paper on South Eastern Europe, London School of Economics and Political Science, LSEE.

Bell, D. (1973). The Coming of Post - Industrial Society, A Venture in Social Forecasting, New York.

Ceriani, L., \& Dávalos, M.E. (2014). First insights into promoting shared prosperity in South East Europe, South East Europe Regular Economic Report No.5., The World Bank Group, Europe and Central Asia Region.

Dev Singla, C. (2008). Knowledge-Based Cluster Development in India, Opportunities and Challenges, Massachusetts Institute of Technology.

Dicken P. Global Shifts (2007). Mapping the Changing Contours of the World Economy, 5th Edition, Oxford Academic Journal of Economic Geography, Volume 7, Issue 6, Paperback, London: Sage 2007. ISBN 978-4-129-29554.

Diouf, J. (1991). Comment on "Governance and the External Factor," by Landell-Mills and Serageldin, and "The Cultural Dimensions of Governance," by Martin, The World Bank Economic Review, Volume 5, Issue suppl_1, December 1991, Pages 321-324, Retrieved from https://doi.org/10.1093/wber/5.suppl_1.321.

Down, K. (2008). Moral Hazard and the Financial Crisis, Centre for Risk and Insurance Studies, Nottingham University Business School, CRIS Discussion Paper Series2008.VI.

Drucker, P.F. (1959). The Landmarks of Tomorrow, Harper \& Row, University of Virginia.

Drucker, P.F. (1993). Post Capitalist Society, ISBN 0887306616, ISBN 0750620250.

Gibson-Graham, J.K. (2006). Post-Capitalist Politics. Minneapolis, MN: Minnesota University Press.

Hahnel, R. (2012). Of the People, By the People: The Case for a Participatory Economy, ISBN-10: 0983059764, ISBN-13: 978-0983059769.

Hammond, G.W. (2009). The Impact of local decentralization on economic growth: evidence from U.S. Counties, (West Virginia University) Mehmet S. Tosun (University of Nevada), Discussion Paper No. 4574.

Harari, Y.H. (2017). Homo Deus: A Brief History of Tomorrow, HarperCollins Publishers, 195 Broadway, New York, NY.

Hilferding, R. (1981). Finance Capital, A Study of the Latest Phase of Capitalist Development Retrieved from https://www.marxists.org/archive/hilferding/1910/finkap/index.htm.

Keynes, J.M. (1932). Economic Possibilities for our Grandchildren, New York: Harcourt Brace, 1932. 
Krugman, P. (2017). Globalization: What Did We Miss? Retrieved from: https://www.gc. cuny.edu/CUNY_GC/media/LISCenter/pkrugman/PK_globalization.pdf.

List, F. (1841). The National System of Political Economy, Retrieved from https://archi ve.org/details/NationalSystemOfPoliticalEconomyFriedrichList.

Mander, J., \& Goldsmith, E. (2005). Globalization, Arguments Against, ISBN-10: 087156 3525.

Mason, P. (2015). The end of capitalism has begun, Retrieved from https://www.theguar dian.com/books/2015/jul/17/postcapitalism-end-of-capitalism-begun.

McCraw, T.K. (2007). Prophet of Innovation: Joseph Schumpeter and Creative Destruction, Retrieved from https://www.questia.com/read/120038465/prophet-ofinnovation-joseph-schumpeter-and-creative.

Mueller, P. (2016). Adam Smith's Criticism of Government: Knowledge, Retrieved from https://www.libertarianism.org/columns/adam-smiths-criticism-government-knowle dge.

OSCE Mission to Skopje (2013). Implementing Citizens Participation in Decision Making at Local Level, Retrieved from https://www.osce.org/mission-to-skopje/231356?Do wnload=true.

Quigley, C. (2012). Kondratieff Waves and the Greater Depression of 2013-2020, Retrieved from http://www.financialsense.com/contributors/christopher-quigley/kon dratieff-waves-and-the-greater-depression-of-2013-2020.

Sen, A. (1999). Development as Freedom (New York: Alfred A. Knopf.) ISBN 0-375-406 19.

Shachtman, M. (1962). Introduction to Franz Mehring's Karl Marx, Retrieved from https:// www.marxists.org/archive/shachtma/1962/xx/mehring.html.

Soros, G. (2011). On Globalization ISBN-13: 978-1586482787.

Stiglitz, J.E. (2012). The Price of Inequality: How Today's Divided Society Endangers Our Future, W. W. Norton \& Company.

Stiglitz, J. (2015). How I Would Vote in the Greek Referendum, The Guardian article, Retrieved from https://www.theguardian.com/business/2015/jun/29/joseph-stiglitzhow-i-would-vote-in-the-greek-referendum.

Tremlett, G. (2013). Mondragon: Spain's giant co-operative where times are hard but few go bust, Retrieved from http://www.theguardian.com/world/2013/mar/07/mondra gon-spains-giant-cooperative.

World Bank Group (2019). Retrieved from https://www.worldbank.org/en/topic/poverty/ overview.

World Bank Group (2015). Doing Business: Going beyond Efficiency, Economy Profile 2015, FYRoM, Flagship Report.

World Bank Group (2015). FYRoM Public Expenditure Review Fiscal Policy for Growth, Report No. 93913, Macroeconomics \& Fiscal Management. 



\title{
Outcomes from Building Transparency in Governance in a Smart City Project in India: A Case Study of Panaji, Goa
}

\author{
By Mridula Goel* \& Sheetal Thomas ${ }^{\dagger}$
}

\begin{abstract}
The Government of India is trying to tackle the challenges of rapid urbanization through the Smart Cities Mission, launched in 2015. This paper discusses a case about the development of a smart city under this initiative, which exhibits exemplary governance practices while improving developing infrastructure and technological solutions to solve critical problems of the city, e.g., Solid Waste Management. It addresses the question whether building good governance practices results in successful achievements of a public policy program and aimed at infrastructure development along with best practices in governance. This paper attempts to assess whether the Panaji Smart city project is in line with purpose of the Smart Cities Mission to create model cities which can be triggers for planned and rapid urban development on desired lines'. Information for the case study was collected through published data and personal site visits, interviews and discussions with senior officials of the project team and stakeholders. The findings are useful not only in portraying the Smart City of Panaji with respect to citizen engagement, transparency and accountability but also in evaluating the outcomes of the project. It is interesting to note that the 'model' framework adopted to implement the project appears to be filled with good governance but has till date not made much impact on lives of residents of the smart city and as yet does not appear to be creating desired networks that would be connecting to urbanization in the region. (JEL G30)
\end{abstract}

Keywords: Engagement, Governance, Smart City, Technology, Transparency

\section{Introduction - Designing Cities to tackle the Challenges of Rapid Urbanization}

India's Gross Domestic Product (GDP) has been steadily increasing, showing an annual growth of more than $7 \%$. This increase has placed India into the fast paced developing countries of the world, but this economic growth is challenged with ever increasing population. In 2014, the population of India's Cities was 410 million and as per the world urbanization report it is likely to reach to 600 million by 2030 and grow to 800 million in another 20 years (World Urbanization Prospects: The 2014 Revision, 2015). Thus, $40 \%$ to $50 \%$ of India's population will be residing in urban cities of India by 2030 and 2050 respectively.

Currently almost $30 \%$ of India's population lives in urban cities and contributes $63 \%$ of India's GDP (Census 2011). With increasing urbanization, the urban population will contribute $75 \%$ of India's GDP by 2030 (Facts:

\footnotetext{
*Associate Professor, Birla Institute of Technology \& Science, India.

†Doctoral Fellow, Birla Institute of Technology \& Science, India.
} 
Urbanisation in India, 2011). As the degree of urbanization has grown, the needs of providing critical infrastructure to the growing urban population have also increased (India: Degree of urbanization from 2007 to 2017, 2018).

India has, however, not been able to effectively tap on the development potential of its urbanisation process as the existing urban infrastructure is not adequate to accommodate the extensive growth of its cities. The problem of rapid urbanization, which is not supported with suitable infrastructural developments, tends to create negative externalities even in the rural areas. It is expected that almost 25-30 persons from rural areas move every 60 seconds to major cities in India for better economic opportunities (Vajda, 2017). The problem is compounded by a proliferation of informal settlements (slums) in urban areas. It is important to take care of these issues; otherwise India's cities will become increasingly chaotic and difficult to manage (Phua, 2007). Furthermore, rural poverty will simply be converted to urban poverty, with little improvement in standards of living (Twelfth Five Year Plan, (2012-2017) Faster, More Inclusive and Sustainable Growth, 2013).

Consistently high population growth and rural-urban migration have posed serious challenges of urbanization in the country. As cities sprang up and expanded on a need basis they contributed to growing urban problems of congestion, sanitation, lack of access to basic amenities and overall poor quality of life. To combat this and to create 'drivers of change' the government has set up the 'Smart Cities Mission' to create model cities which can be triggers for planned and rapid urban development on desired lines. Government of India has taken up with urgency the ever increasing needs of urbanization and launched the Atal Mission for Rejuvenation and Urban Transformation (AMRUT) Mission and the '100 Smart Cities' program in June 2015 to support the process of urbanization (Tripathi, 2018). These initiatives aim to stimulate the State governments and Urban Local Bodies (ULBs) to implement the urban sector reforms. Ultimately, the restructured and enriched governance in cities would sustain the urban transformation.

The AMRUT Cities Program aims to enhance the basic infrastructure (water, sanitation, open spaces and public transportation) of 500 cities in India, with the Government of India looking to invest $\$ 7.5$ billion over next four years. The Program intends to provide suitable training to members of the urban local bodies (Charles, 2015). On the other hand, under the '100 Smart Cities Mission' Program the government is committed to develop satellite towns of larger cities and modernize existing midsized cities. Within the framework of the Program, the aim is to pursue such information and communication technology (ICT) initiatives that improve livability, investment and service opportunities, and facilitate the achievement of growth in an environmentally sustainable manner (Vajda, 2017).

The Indian Central Government has committed INR 480 billion $(\sim 6$ billion Euros) to finance the Smart Cities Mission, with a condition that the State Government should also spend an equivalent amount for the smart city project (Hoelscher, 2015). This core funding is supposed to attract funds from other sources, including domestic and foreign private investors, development banks and bilateral donors. 
Smart Cities need smart governance and smart regulation (Dewi Mutiara, 2018) and urgent reforms are required at the institutional and policy level in order to ensure that these Programs do not fall victim to the errors of the past. Our study attempts to analyze whether adoption of new governance models, incorporating transparency in institutional processes in case of a smart city project, has helped to achieve desired outcomes of the public policy program (Babita Jangra, 2016) of urban transformation in India.

\section{Concept of a Smart City}

An extensive literature review points out to the following definitions, processes and challenges of the smart city initiative taken up by Government of India. Neirotti et al (2014) has identified the importance of smart use of technology to provide improved services to the citizens and thus improve their life quality. A smart city is one which has the potential to incorporate and efficiently use the latest technology to provide better services (Paolo Neirotti, 2014). 'A smart city is a system of systems - water, power, transportation, emergency response, built environment, etc. - with each one affecting all the others' (Pratap Podode, 2016). During the last twenty years, the world has emerged as a competitive stage to usher developments into its cities, countries have come out to improve their infrastructures, providing the best services concerning environment, social and economic conditions (Freeman, 2017).

These efforts brought up the concept of intelligent cities (Komninos, 2009) that is the predecessor of Smart Cities (Yigitcanlar, 2015). According to Mark Deakin \& Husam Al Waer, Smart Cities are those which are made up by intelligent usage of latest information technology, in areas like health management, transportation and mobility, use of efficient power and energy, knowledge creation and knowledge transfer in terms of education and local governance (Mark Deakin \& Al Waer, 2011). Camboim et al 2019 studied the development of several smart cities in Europe like Amsterdam, Barcelona, Lisbon, Vienna and conceptualized a smart city as an urban innovation ecosystem, where knowledge easily flows among different stakeholders to create value, supported by suitable institutions and governance, a digital-green infrastructure and urban planning to provide various facilities according to functional requirements (Guilherme F Camboim, 2019).

According to the Smart Cities Council, a smart city is one that uses information and communications technology (ICT) to create a more livable and sustainable urban environment. The Smart City approach is not 'one-size-fits-all'; each city assesses local resource availability and strengths and identifies its priorities to formulate its own concept, vision, mission and plan (proposal) for development.

The Urban Development and Services initiative of the World Economic Forum helps governments to address major urban challenges. In 2015, their focus was on India (World Economic Forum; Future of Urban Development and Services, 2015). They provided recommendations that focused on institutional reforms to accelerate the delivery of Smart Cities and support urban development. Their recommendations included strengthening city administration, putting 
suitable user charges for service delivery, while stipulating that subsidized user costs should be funded by the state, helping to ensure the financial independence of the city. They recommended collaborating with the private sector and improving the system of resolution of disputes, good citizen engagement and feedback mechanisms and improving the permit process. India's three tier governance structure, Central, State and local, often involves liaising with multiple departments. This makes obtaining permits a lengthy process, but several state governments have enacted reforms to optimize the process. Goa has also, done so in 2019.

The Urban Development and Services initiative stated that by developing Smart Cities, countries will create a welcoming environment for foreign investment flows, resulting in industrial growth and higher GDP. Smart solutions in key areas of environmental protection, health, transport and waste management can contribute to sustainable growth and better quality of life. It is forecast that a smart city project may generate a $10-15 \%$ rise in employment, especially jobs in information technology and information systems (Smart cities: The future of Digital India, 2018).

The focus on smart city development as a way to urbanize in an efficient manner is a strategy that has also, been adopted in other places of the world. Smart City concept is on the agenda of countries such as UK (Caprotti F, 2016), Singapore (Sang Keon Lee, 2016), Spain (Martín García Vaquero, 2016) and many others. The development of automation devices for smart homes supports the development of smart cities and these in turn create infrastructure that creates effective use of smart home devices (Rita Yi, 2013). Smart technology can even be an important part of the solution to city food challenges (Maye, 2019) but perhaps it is more important for developing countries like India. Developing nations face greater exacerbated challenges of urbanization such as lack of infrastructure, population growth in urban areas, poor urban services such as drinking water, sanitation, health or education.

Spearheading urbanization through smart city concept has nuances of the Chinese strategy of using SEZs to lead development in the country. The infrastructural development in these SEZs showcased the intensive modernization and growth of the region. It enabled the growth of manufacturing led development process (Susanne A Frick, 2019; Madakufamba, 2015). As in case of China the success factors for India also include a resilient commitment for transformation from the country's top leadership, favorable policies and regulations, autonomy to institutions that encourage them to take developmental steps, along with strong support of Government (Zeng, 2012).

\section{Channelizing Development through Decentralized Governance Mechanisms}

However, in a country as vast and diverse like India, in terms of geography and people, the understanding and connect of policy requires reaching to the grassroots. Realizing the need to decentralize and gain advantage of closer interaction and better accountability between public and government, there is 
considerable emphasis on reviving and/or strengthening local institutions and mechanisms.

To strengthen local governance in the rural areas, the 73rd Constitutional Amendment in 1992 was carried out to give Constitutional status to the 'Panchayats' ${ }^{20}$ as institutions of local governance for promoting economic development by strengthening local governance at the rural level (Ananth, 2014). The Panchayati Raj Institution (PRI) is government by itself and acts as an agency of the state government (Tame, 2014). The objective of PRIs is to understand the problems at the ground level and put in place both acceptable and feasible solutions. However, in the urban areas such functions are done by the urban local bodies (ULB), the municipalities and city corporations, which have been operating to tackle common problems in their municipality, using traditional mechanisms that prioritize according to expression of public need and grievance.

The nature of administration depends on severity or impact of the problem. For instance while fighting the high level of air pollution in the Indian capital, the Delhi government authorities hiked the parking fees by four times to dissuade people from use of private cars and thereby reduce vehicular emissions (Karelia, 2017).

To rationalize local government functioning in the urban areas the government through the 74th Constitutional Amendment of 1992, attempted to decentralize urban governance by entrusting power to the ULB (Hussain, 2007). Yet, the negative public perception about ULBs functioning mechanisms is so deep rooted that such amendments and other directives fail to create a positive impact.

The Smart Cities Mission is based on 'bottom-up' methodology. Processes, proposals and projects are conceptualized locally through early citizen stakeholder engagement. This is in line with Government of India's commitment not only to build inclusive and livable cities but also to fulfill its vision of achieving more decentralized and collaborative decision-making (Hoelscher, 2015).

One fundamental objective of the 100 Smart Cities scheme is to reinforce the ULBs' capability to create cash for themselves through user costs, as the smart city has its own independent identity that is free of the perception about existing municipalities and city corporations (Gordon Falconer, 2012). However, service delivery institutions often suffer from limited autonomy, accountability and incentives, and an overall lack of consumer focus. This makes it difficult for them to recover user costs.

Along with such limitations faced by ULBs, there are problems created by deep-rooted corrupt practices in several places. Use of latest technological developments in the working of municipal corporations is low, not only due to limited access to funds but also more often due to traditional, well entrenched bureaucratic systems.

Thus, some features that should be present in a smart city include:

- Development of city into a urban hub with best infrastructural amenities

- Focused approach to bring inclusiveness in social and economic conditions

\footnotetext{
${ }^{20}$ Panchayats are an elective council of about five members organized in the Republic of India as an organ of village self-government.
} 
- Planned long term growth strategy

- Use of technology to enhance governance and administrative efficiency

- Sustainable development and livable environment

In our discussion of the case of Smart City development of Panaji, we attempt to assess the presence of the above features. It is important to know whether the adoption of smart city measures the city has created employment, implemented sustainability of public policy projects and above all has it been able to promote the key objective of the Smart Cities Mission : as 'driver of change' that can then be a trigger for planned and rapid urban development on desired lines.

\section{Methodology}

The paper aims to assess the developments in governance, infrastructure and technology under Smart City initiative, these discussions are presented in the form of a case. The data was collected through both primary and secondary sources; primary data was obtained by meeting different officials and employees directly engaged with activities under Smart City Project. Interview method was used to understand and extract relevant information related to practices and governance styles of smart city initiative. Observation method was used to identify the benefits of smart city initiative on infrastructure and technology along with published data available through government body. The secondary data was also collected from newspapers apart from government publications like tenders, agenda's, detailed project reports, and focused group discussion transcripts.

\section{A Case Study of Panaji as a Smart City}

The Government selects cities in India as part of the Smart Cities Mission through a 'City Challenge Competition', which creates identity association and bonding for the local community. The public, the ULBs and state government work as one team to apply for the competitive process and get the resource support, they then have a more developed sense of ownership of the program and related projects.

The Smart Cities Mission objective is to develop at least two Smart Cities in each of 29 states of India, where cities with a population of over 1 million may become potential Smart Cities; besides which State capitals, cultural heritage cities and the agglomerates of cities are also, considered to have the potential to be Smart Cities. The focus of the Smart City Mission is on sustainable and inclusive development and the idea is to look at compact areas, with the objective of creating a replicable model which will act like a light house to other aspiring cities.

The selection of Panaji fit the choice criterion on account of being a State capital and a cultural heritage city. There are close to 900 heritage structures in and around Panaji, as per the statistics revealed by the Goa heritage action group (Heritage Conservation Phase 1- Listing and grading of heritage structures in Panaji, 2014). The population of the city is, however, only 114,759 persons in the 
metropolitan area as per 2011 Census of India (Provisional Population Totals, 2011) (www.censusindia.gov.in, 2011). Also, it is a compact area and its development can be 'with the objective of creating a replicable model which will act like a light house to other aspiring cities'.

\section{Key Priorities of Smart City Development}

An interaction of the goals of Smart Cities Mission along with requirements and priorities of the state of Goa on the one hand and the desired objectives for Panaji as gathered through citizen engagement, determined the focus areas for implementation (Figure 1).

As per the Smart Cities Mission, Smart Cities should contain at least one pancity feature. The idea is to incorporate 'smart planning' in infrastructure for enhancing inclusiveness and creating better environmental outcomes (Kok Siew $\mathrm{Ng}, 2019)$. In case of Panaji, Intelligent Transport System for Eco Mobility and Information Communication Technology (ICT) enabled Municipal Services have been identified as two priority areas for intervention on a city wide basis. Our focus is on studying the latter: Use of ICT to improve service delivery with respect to solid waste management (SWM) in case of the smart city of Panaji.

Solid waste management in India is largely inefficient and ineffective, due largely to the absence of a sustainable business model covering the full spectrum of waste management activities (Annepu, 2012; Rajkumar Joshi, 2016; Harshit Khandelwal, 2019). In case of Goa, and most other states in India, the problem exists right from inadequate coverage of waste collection, to segregation and right down to the fact that collected waste is rarely disposed of in a controlled, hygienic and environmentally sensitive way.

To tackle this situation the model SWM plant in Saligao was set up on May 30, 2015, even before the selection of Panaji as a smart city. The SWM plant is 9 kms from Panaji and had started generating electricity for captive use in just seven months of set up (The Times of India, Saligao Garbage Treatment Plant begins generating power, 2017).

Municipal service level benchmarks in the city of Panaji already indicated robust service provision in the basic sectors - water supply, waste water, solid waste management and storm drainage. The focus after the smart city project was on improving the efficacy and efficiency of these systems. It is therefore proposed to upgrade the quality and levels of municipal service delivery through process reengineering and embedding of ICT solutions. RFID readers to monitor litter bin evacuation and GPS tracked waste transport vehicles will give the solid waste management cell the advantage of real-time and remote monitoring. Solid waste collection systems are well planned, but monitoring of these systems leaves much to be desired. 
Vol. 7, No. 1 Goel \& Thomas: Outcomes from Building Transparency in Governance...

Figure 1. Factors Determining Panaji Smart City Objectives

\section{Goa Facts and Challenges}

- Urbanization level is 60-70\%

- Deterioration of heritage buildings and aging infrastructure

- Waste management issues

- Lack of public transport

National Objectives of Smart City Plan

- Improved infrastructure and quality of life

- Clean and sustainable environment

- Sustainable and inclusive development

- Replicable model

\section{Citizen Stakeholder} Engagement

- Public consultation meetings

- Focused group discussions

- Road shows and workshop

- Zone wise ideation session

\section{Goa State Objectives}

- To be well governed state of India

- To preserve natural beauty of state

- To increase GDP substantially

- Become knowledge centric destination

- Enhance quality of life

- Promote heritage and cultural diversity

- Progress in productive knowledge and economic status

- Introduce environmentally sustainable methods
Panaji Facts and Challenges

- Informal settlements of urban poor

- Dilapidating heritage infrastructure

- Lack of public spaces and transport

- Environmental degradation

Source: Compiled by researchers from various sources.

The story of waste management in Panaji is a best practice that is talked of in India and abroad. The effectiveness of waste management department in the 
municipal arm, the City Corporation of Panaji (CCP) is challenged by a dearth of adequate staff to monitor waste management. With system efficiencies being rolled in, Panaji can move towards the realization of its goal of a zero waste city.

Proposed e-governance measures enable linkage of these systems to city administration. Currently service provision in the city is through multiple departments. The e-governance platform will ensure a unified database for revenue and service provision. Data analytics possible through the proposed MIS system will enable informed decision making and have a significant bearing on city planning and citizen engagement. Given that the basic infrastructure was already in place, using technology to improve efficiency in SWM in Panaji was a low hanging fruit.

However, the development of smart cities is not only about making improvements within that city, but to also, create triggers for development in surrounding regions. Unfortunately, that appears to remain a challenge. The adoption of SWM systems, supported by ICT has yet failed to create desirable benefits for other parts of the state.

\section{Transparency at Central and State Government level}

Goa was one of the 23 states /UTs to have a second chance in 'fast track' selection process and its capital city: Panaji was selected in this round. The Director (Smart Cities), Ministry of Urban development shared some observations made by the Proposal Review Committee with the Principal Secretary (Urban Development) Goa Government. The extent of transparency in the process is obvious as this letter is available on the website of Panaji Smart City (Imagine Panaji Smart City Development Ltd., 2017) ${ }^{21}$.

For instance, one of the relevant suggestions from the Ministry related to municipal works and especially solid waste management (SWM), "the municipal services package attempts to fit in various services in a piecemeal manner. While the SWM subcomponent is relatively better worked out, components such as water meters and power grid seems loose and not integrated into the overall package'. It was recommended vide this letter to revise the details and illustrate inter linkages within the sub-components or alternatively only focus on solid waste management aspects (Imagine Panaji Smart City Development Ltd., 2017). SWM continues to be an important priority for both the city's ULBs: Panaji Smart City and City Corporation of Panaji, but integrating with other utilities has yet to be completed. Further, the transfer of good practices to surrounding areas is missing. The network effects of smart city development to improve urbanization in the region do not appear to have occurred in our case.

\section{Efficient Institutional Mechanisms for Local Governance}

100 Smart Cities initiative of the Indian government rests on four pillars related to: Physical infrastructure, Social factors, Economic factors and Institutional features (What is a smart city, 2017). The physical factors relate to infrastructure

\footnotetext{
${ }^{21}$ https://imaginepanaji.com/wp-content/uploads/2016/03/Comments-from-MOUD.pdf.
} 
in high linkage sectors like Transport, Power, Water, IT and the current globally challenging area of pollution and waste (Rita Yi Man Li, 2015). Social factors relate to the areas of education and culture, as expected, but noteworthy is their emphasis on inclusive development. The economic pillar covers skill development and entrepreneurship, which is a new policy initiative of present government, financial institutions, etc. However, it is the challenges of establishing efficient institutions and processes in government that are known to be difficult.

It is noteworthy that on several of these institutional features and mechanisms the case of Smart City of Panaji has shown positive changes, even in the short span of two years of commencement of the project. We discuss in the following sections changes related to key institutional features like: minimum government, maximum governance, citizen engagement, transparency and accountability.

Such institutional reforms are very useful in economic development as it is the institutional factors that pose an important risk to foreign investment. To boost public and private sector growth within the country and to give a positive message to the foreign investors, it is important that we have consistent and effective regulatory policies. As the multinational organizations want to do business in environments which are market friendly, it is important the country regime is open to such overseas investors (Mumtaz Hussain Shah, 2015). A study conducted by Valbona Zeneli confirmed that a strong and significant relationship existed between the quality of the reforms, the performance of the institutions in the host countries and the attraction and distribution of FDI in the region. (Zeneli, 2014). An improvement in governance can create substantial and constructive impact on the income level. Thus, development in institutional quality would increase the country's income level which has further positive effect on the level of foreign investment that comes into the country (Bissoon, 2011).

\section{Minimum Government, Maximum Governance}

A Special Purpose Vehicle ${ }^{22}$ (SPV) will execute the implementation of the Smart City Action Plan. For Smart Cities, the government will appoint CEOs, thereby restricting the autonomy of local governments. It is these CEOs who will drive the concept and execution of the project. The Imagine Panaji Smart City Development Ltd (IPSCDL) was incorporated as a limited company under the Companies Act 2013 with the State Government and City Corporation of Panaji as equal promoters of the Special Purpose Vehicle (SPV): IPSCDL.

Public policy initiatives are often managed through an SPV, as it is considered that an SPV brings independence and transparency to a project. Under the smart Cities Mission as well, it was stated that the SPV will be responsible for managing, operating, evaluating and reporting the Smart City development projects within their city. Panaji though selected after the first 20 selections in round 1 the 'fast

\footnotetext{
${ }^{22}$ A special purpose vehicle (SPV) in India is a limited company formed for a special purpose. These entities have powers limited to the execution of the specific purpose for which they have been formed, their life is limited to the completion of the purpose.
} 
track mode' as one of 13 cities, is the second smart city project, after Dharamshala $^{23}$, to set up an SPV (The Times of India, 2016).

Using an SPV brings in efficiency and speed in decision making and implementation. It also, enabled the IPSCDL team to maintain a clean image and reputation. For example, Municipal bonds which are identified by the government as a source of revenue to support funding for Smart Cities development have not yet been adopted in case of Smart City Panaji because of a fear of public negative perception (Final City Sanitation Plan - Panaji, 2015).

The organizational structure of the SPV in case of Panaji is designed for good governance. Taking along various layers of government has been facilitated through direct representation of each in the functioning of the SPV (Figure 2). The Chairman of IPSCDL is from the Ministry of Urban Development and the Managing director and CEO is from the State Government's Goa State Infrastructure Development Corporation (GSIDC). This covers representation from the Central and State levels of government. The GSIDC functions as the Project Management Unit (PMU) and provides technical staff to IPSCDL.

Figure 2. Smart City Implementation-Organizational Structure

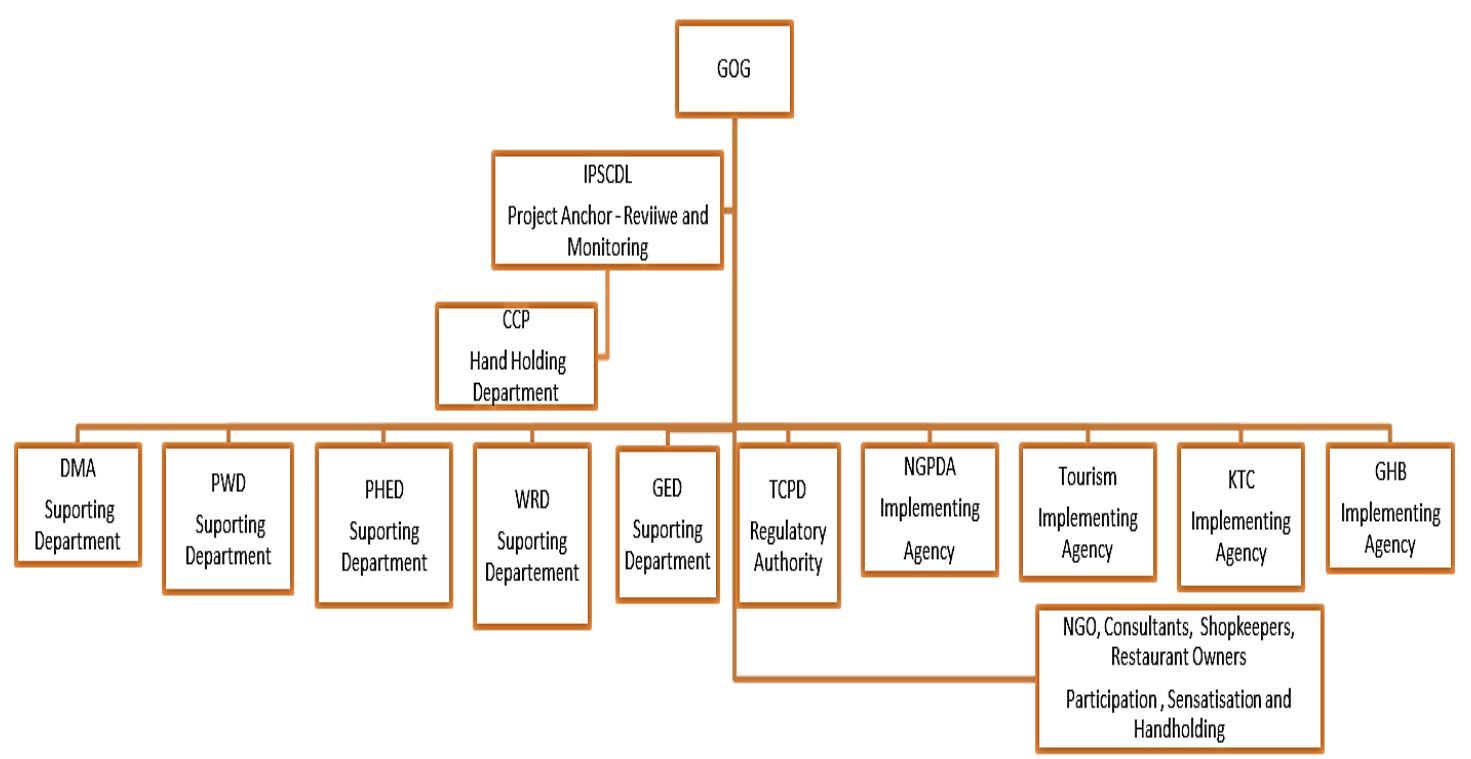

Source: Compiled by authors from inputs provided by IPSCDL, Panaji

To ensure operational independence and autonomy in decision making of the SPV, the Goa State Level High Powered Steering Committee agreed, in principle, to empower the IPSCDL by delegating the rights and obligations of the ULBs: City Corporation of Panaji (CCP), North Goa Planning and Development Authority (NGPDA) and Goa State Urban Development Authority (GSUDA) to it.

\footnotetext{
${ }^{23}$ Dharamshala is a city in the Indian state of Himachal Pradesh. Surrounded by cedar forests on the edge of the Himalayas
} 
The organizational Structure has representation from the different layers and departments that are required to implement the smart city initiatives. Further, the key thread that has bound the initiative and helped to manage conflict between the authorities has been the nature of leadership of the state. A strong and popular Chief Minister in the state helped to steer the program in a smooth manner. After his demise on 17 March, 2019 the impact on such a public policy program and its functioning would need to be to re-assessed.

Smart Functioning Office of Imagine Panaji Smart City Development Ltd.

Transparency in governance is visible in case of the Smart City Office at Panaji. The governance style adopted by this Smart City office is very distinct from that commonly associated with government office ambience and functioning in the country. A visit by the authors to the Imagine Panaji Smart City Development Ltd project office was a revelation. The office premises are housed in the Adil Shah Palace $^{24}$ which is located in the heart of the city. The sprawling high ceilinged rooms are spartanly furnished but well equipped with e-devices. There is a marked absence of the usual clutter found in most government offices in the country: in terms of storage cabinets, cupboards, files and papers.

All information asked for was searched in the laptops by the helpful staff. A unique feature was the presence of a floor printer with a box of used paper for reuse. Such a pool of used paper in a government office can be viewed as a clear sign of transparency! While most government departments hoard documents in confidential files and keep well locked in cabinets for decades, here was a government office easily putting out rejected paper for re-use.

The staff in the Imagine Panaji Smart City Development Ltd project office was refreshingly young and there were more women than men. The Managing director and CEO is in fact, less than 40 years of age. The team works cohesively and is committed to working long hours with enthusiasm.

It is however, notable that the commitment of the IPSCDL team and the independence of the SPV has yet not been able to make significant change in the lives of the residents of the Smart City of Panaji and definitely not created linkages of development in areas beyond the city.

\section{A Well-defined and Transparent Purchase Process}

In order to build the digital infrastructure required as per the concept of the Smart Cities Mission it was decided to put in place the Goa Intelligent City Management System (GICMS) in Panaji. The Smart City solutions in Goa will be integrated through an existing City Backbone Network and a Command and Control Centre is proposed to be set up at the IPSCDL office, Panaji.

\footnotetext{
${ }^{24}$ The palace of the Muslim ruler of Bijapur Yusuf Adil Shah(1450-1511), is the oldest surviving building in the city, the seat of Goan Secretariat (built around 1500). Typically colonial in design and architecture, the building once served as Adil Shah's summer palace cum fortress which has been renovated.
} 
The gamut of Smart City digital solutions includes city wide public Wi-Fi to cover access to information on the entire key services available for citizens through various apps (Smart City Proposal- Panjim, 2016). Real time monitoring and tracking will be done for waste collection bins and collection vehicles, as mentioned earlier. Smart environmental sensors will be integrated with the Command and Control Centre to capture and display/provide feed on temperature, humidity, air pollution, noise pollution, etc. Smart parking facilities will be put in place to locate empty parking spaces and mobile app based bookings.

The Smart Cities Mission recommends that the executive wing of the city needs to develop technical and management capacity to execute large urban rejuvenation Programs. However, in case of identifying a vendor for the Goa Intelligent City Management System (GICMS) the technical specifications were prepared by the team at the IPSCDL project office. While the government allows for hiring a project management consultant for such and other functions of a project, this young team along with their Managing Director \& CEO handled the task on their own.

The process of tendering a key project is well defined so that bids can be comparable on technical grounds. The technical specifications for the project were posted to invite bids for tenders to finalize the vendor to operate under the Smart City Mission. IPSCDL ensured while creating the tender document that a proof of concept was a mandatory condition for technical qualification of the vendor. IPSCDL launched its proof of concept demonstrations for the short listed leading four bidders after the first stage of bid evaluation. Four companies: Bharat Sanchar Nigam Limited (BSNL), Honeywell International Inc., Larsen \& Toubro Ltd, and NEC Technologies India Private Limited were selected for the city surveillance trial.

The criteria was to ensure that the bidders who have so far projected themselves on paper are now putting up a live demonstration of their worth and commitment. Most reasons why a large government project fails are the lack of coordination and lack of the promised delivery on paper during the bid.

The four companies were required to conceptualize a full system, including a surveillance system along with a command and control center. They were then given independent scores based on performance. On basis of an overall technical score the financial bid was opened and the work order given to the lowest bidder on July $02,2018$.

Larsen \& Toubro Ltd., which is already doing similar work on other Smart city projects in the country beat BSNL, Honeywell and NEC by emerging as the lowest bidder with their bid of Rs 180 crore ( 22.8 million Euros).

The letter of intent was issued to Larsen \& Toubro Ltd and the first phase of work has started. It covers laying of the optical fibre network, creation of Wi-Fi hotspots at key locations, setting up of the integrated command and control center. The command and control center will cover the entire city with 400-odd surveillance cameras, and will be integrated with the City Corporation of Panaji's garbage management system. It will help to inform the authorities over which areas garbage needs to be collected, which public bins are overflowing and residents through their smartphone app can also, know whether their garbage has 
been collected from their doorstep or not. "In this way, we want to increase the efficiency of municipal systems," said Commissioner of City Corporation of Panaji. The project is time bound and had to be completed in eight months, by February 2019. However, as of April 2019 the processes were not implemented. L\&T is in process of establishing the logistic infrastructure before starting operations. Mechanisms that incorporate transparency in purchase and ensuring quality at times result in unavoidable implementation delays.

\section{Citizen Stakeholder Engagement}

The state of Goa is often known in India as the 'West of the East' (Sudhir Vyankatesh Wanmali, 2018) and its citizens have a strong voice with the government and in community affairs. The Smart Cities project of the capital city is close to the hearts of the people of Goa and the media avidly follows and freely reports on the developments therein.

In the Smart Cities Mission one of the key criterion is citizen engagement, and in Goa citizen stakeholder engagement is usually intense. In case of the Smart City Panaji the public involvement has been very strong both at the stage of concept development, proposal preparation and finalization. The City Corporation of Panaji, the relevant municipality, engaged with citizens across various platforms to gather suggestions and feedback towards the smart development of Panaji City. This included public consultation meetings and focus group discussions with stakeholders, road shows, workshops and zone wise ideation sessions. Some of the key areas discussed were Transport \& Mobility, Heritage and Waste Management.

Consultations with citizens brought forth concerns of a deteriorating heritage due to factors related to development restrictions on conservation zone, lack of enforcement powers with Heritage Committee and lack of funds with owners to maintain heritage structures. Citizens expressed environmental concerns related to higher pollution emissions and adverse effect on the ecology of water bodies and even Panaji's prime hilly area of Altinho, which houses key government offices and Chief Minister of Goa's residence.

Events like celebrity meets, musical programs etc. were organized to promote and sensitize the local people even prior to the submission of Smart city proposal to the competition. Team FC Goa (Indian Super League, Football team) made an appearance to engage with the community, raise awareness and show its support for the Panaji Smart City Challenge. The Bandstand, a community event was organized by Confederation of Indian Industry (CII), Goa Chapter and the City Corporation of Panaji every Sunday evening to promote Panaji Smart City's initiative for citizen involvement.

CII also, collaborated with the Corporation of the City of Panaji, to organize a Panaji Smart City Round Table to discuss global experiences and solutions. A technical exhibition was arranged wherein proposed maps were displayed and explained to the general public, in order to gather feedback from stakeholders. Focus group discussions, press conferences, public consultation meetings were regularly organized to gather support of the community. 
While such engagement was carried out in the preparatory stages and in the initial stage of implementation of the smart city project, it does not appear to be the case at this time. This is supported by the feedback gathered from residents given below.

A similar situation prevails with respect to media reporting and public communication through IPSCDL website.

\section{Panaji Smart City Project Outcomes:}

Media reporting is an important source for assessing transparency and accountability. While information was freely available to the authors from the staff at IPSCDL project office but the best reference sources they had to offer us were the published media reports in local newspapers. Besides their website, which displays all documents and processes till award of the project there are the newspaper releases for most developments after receiving the Smart City status. The media coverage is regular and comprehensive and possibly explains why the Smart City developments are not updated on their own website. At best links to media reports are provided on the site. Hence, for purpose of this case for all developments post selection of Panaji as a Smart City we have referred to press releases in local newspapers.

However, updating of activities and progress of Smart City Projects on own website is important and necessary to maintain the quality of communication with the public. It is observed that the website is not updated for long and as the project has progressed without making big, visible changes the media coverage appears to be also slow in recent times.

As the phase wise implementation of various schemes and programs related to smart city project is going on, interviews and discussions with residents of Panaji were carried out to understand ground level realities during the period from January 2018 to January 2019. Issues of governance, technological advancements and effective solid waste management were discussed and some of the observations gathered were in contradiction to the initial stance of: active Citizen engagement and open communication.

During the implementation phase, gaps in communication were reported by the residents; the Smart City planning had emphasized on transparency in understanding the needs of resident citizens and detailed maps and plans were publicly shared, as indicated above. However, as conveyed to authors such maps are not easily accessible in public domain any longer. The implementing authorities need to be careful to sustain their initial stance of communicating information easily to the stakeholders and maintaining citizen engagement even during the implementation phase.

The garbage management system is being run efficiently along with local municipal bodies like the CCP and there is a visible improvement in cleanliness of the city as result. However, citizens expressed reservation about the operational sustainability of the projects that form the smart city development as 'user charges' recommended for sustainability have not been incorporated. Until many of the projects roll out such outcomes cannot be commented upon. However, on 
speaking to IPSCDL office it was learnt that in most cases operational maintenance costs have been built onto the L\&T project

Citizens appreciated the beautification and cleanliness of the main spine of the city but were not satisfied with the overall image of the city. They felt that while the Smart Cities Mission envisaged creating livable urban spaces leading to improvement in quality of life of its residents such change was yet to happen. Further, a key objective of the Smart Cities Mission is to bring inclusiveness in social and economic conditions of the people in the region. Herein residents stated that the project did not communicate the employment and income generation possibilities for residents. It is true that smart city developments will add to increase in land value through creating prospects of capital gains, but many residents are not satisfied with the outcomes of the investment in Panaji Smart City development as the revenue generation or employment creation in the current period is not visible.

\section{Conclusion}

Urbanization is a natural outcome of economic growth. The pace of the process of urbanization in a country with both a large and rapidly growing population is bound to present both infrastructural and governance challenges. This is more so when the government of the country adopts policies to speed up the growth in manufacturing output (Mridula Goel, 2017). The Make in India policy is bound to step up the migration of workers from rural to urban areas.

The Smart Cities Mission is an important initiative towards developing infrastructure in urban spaces in a planned way and addressing key priorities using technological solutions. The present study of the capital city of the state of Goa, best known as a popular tourist destination, offers a view of the important changes in the institutional features and mechanisms that have been identified as one of the important pillars to support urban development. Implementation and governance of the Smart City Program in Panaji exhibited the exemplary practices related to stakeholder engagement and transparency and accountability in governance. However, as the implementation of the project is proceeding there appears to be some dissonance; perceived through poor media coverage, lack of website updation of activities and progress and citizen perception. Further, the nature of the program does not incorporate any explicit, recognizable mechanisms to spread good practices. Even the specific achievement of good practices in SWM adopted in Panaji have failed to impact surrounding areas. Explicit policy directives by the state government are required and proposed in the last year for this purpose. This begets the question of how strong the network effects of smart city development are likely to be in encouraging regional urban transformation. The questions thus, that remain to be addressed are:

- How important is the design of a public policy program in achieving its goal? Is the Smart Cities Mission designed suitably for urban transformation? 
- Can governance reforms overcome the barriers of long gestation period in infrastructural development to create efficient outcomes?

- Can digitization be an adequate process improvement to tackle the challenges of urban development?

\section{References}

Ananth, P. (2014). Panchayati Raj in India. Journal of Education \& Social Policy, 1(1), 1-9. Retrieved from http://jespnet.com/journals/Vol_1_No_1_June_2014/1.pdf

Annepu, R.K. (2012). Sustainable Solid Waste Management in India. Columbia University in the City of New York. Retrieved from http://www.seas. columbia.edu/ earth/wtert/ sofos/Sustainable\%20Solid\%20Waste\%20Management\%20in\%20India_Final.pdf

Babita Jangra, J. M. (2016). Swachh bharat abhiyan (clean India mission): SWOT analysis. International Journal of Community Medicine and Public Health, 3(12), 3285-3290. doi:http://dx.doi.org/10.18203/2394-6040.ijcmph20164249

Bissoon, O. (2011). Can Better Institutions Attract More Foreign Direct Investment (FDI)? Evidence From Developing Countries. International Conference on Applied Economics - ICOAE, (pp. 59-70).

Caprotti F, C.R. (2016). Smart-Eco Cities in the UK: Trends and City Profiles. University of Exeter (SMART-ECO Project). Retrieved from http://www. smart-eco-cities.org/ wp-content/uploads/2016/08/Smart-Eco-Cities-UK-2016.pdf

CCF. (2014). Heritage Conservation Phase 1- Listing and grading of heritage structures in Panaji. Retrieved from https://charlescorreafoundation.org/2019/05/25/panajis-for gotten-resource-old-buildings/

Charles, A. (2015, November 16). How can India make smart cities a reality? Retrieved June 18, 2018, from https://www.weforum.org/agenda/2015/11/ how-can-india-ma ke-smart-cities-a-reality/

Dewi Mutiara, S.Y. (2018). Smart governance for smart city. IOP Conference Series: Earth and Environmental Science.

Facts: Urbanisation in India. (2011). Retrieved June 20, 2018, from www.worldbank. org: http://web.worldbank.org/archive /website01291/ WEB/ 0_CO-22.HTM

(2015). Final City Sanitation Plan - Panaji. Corporation of The City of Panaji. Retrieved from http://ccpgoa.com/swachhbharat/uploads/download/13_down_Final_City_Sani tation_Plan_Panaji_June_2015.pdf

Freeman, G. (2017). The Origin and Implementation of the Smart-Sustainable City Concept-The Case of Malmö, Sweden. The International Institute for Industrial Environmental Economics. Masters Thesis, Lund University. Retrieved from http:// lup.lub.lu.se/student-papers/record/8924149

Gordon Falconer, S.M. (2012, September). Smart City Framework A Systematic Process for Enabling Smart+Connected Communities. Cisco Point of View, pp. 2-9. Retrieved from https://www.cisco.com/c/dam/en_us/about/ac79/docs/ps/motm/Smart-City-Fra mework.pdf

Guilherme F Camboim, P. A. (2019). Driving elements to make cities smarter: Evidences from European projects. Technological Forecasting and Social Change, 142, 154-167. doi:https://doi.org/10.1016/j.techfore.2018.09.014

Harshit Khandelwal, H.D. (2019). Application of life cycle assessment in municipal solid waste management: A worldwide critical review. Journal of Cleaner Production, 630-654. doi:https://doi.org/10.1016/j.jclepro.2018.10.233 
Hoelscher, R. A. (2015, December). India's Smart Cities Mission:An Assessment. ORF Issue Brief(124), 1-11. Retrieved from https://www.orfonline.org/wp-content/uploa ds/2015/12/Issue-Brief_124.pdf

Hussain, M. A. (2007). Urban Governance and Politics: A case study of Tirupati. The Indian Journal of Political Science, 68(3), 509-522. Retrieved from https://www.js tor.org/stable/41856351

Imagine Panaji Smart City Development Ltd. (2017). Retrieved June 16, 2018, from https://imaginepanaji.com/: https://imaginepanaji.com/wp-content/uploads/2016/03/ Comments-from-MOUD.pdf.

India: Degree of urbanization from 2007 to 2017. (2018). Retrieved July 21, 2018, from The Statistics Portal: https://www.statista.com/statistics/271312/urbanization-in-in dia/

Karelia, G. (2017). 7 Steps Taken By Authorities To Curb Rising Air Pollution Levels In Delhi. (S. Bhaskar, Editor) Retrieved June 26, 2018, from https://swachhindia.ndtv. com/7-steps-taken-by-authorities-to-curb-rising-air-pollution-levels-in-delhi-14332/

Kok Siew Ng, A.Y. (2019). Sustainable waste management through synergistic utilisation of commercial and domestic organic waste for efficient resource recovery and valorisation in the UK. Journal of Cleaner Production, 277, 248-262. doi:https://doi. org/10.1016/j.jclepro.2019.04.136

Komninos, N. (2009). Intelligent cities: Towards interactive and global innovation environments. International Journal of Innovation and Regional Development, 1(4), 337-355. doi:https://doi.org/10.1504/IJIRD.2009.022726

Madakufamba, M. (2015). The role of Special Economic Zones in China's development Prospects for Africa. Southern African News Features.

Mark Deakin, H.A. \& Al Waer, H. (2011). From intelligent to smart cities. Intelligent Buildings International, 3(3), 140-152. doi:https://doi.org/10.1080/17508975.2011. 586673

Martín García Vaquero, J.M.-A. (2016). Smart Cities in Spain - Policy, Sustainability, and the National Plan: New Political Measures, Agents, and Sustainability. In Economic Modeling Analysis and Policy for Sustainability (pp. 266-283). IGI Global. doi:10.40 18/978-1-5225-0094-0.ch014

Maye, D. (2019). Smart food city': conceptual relations between smart city planning, urban food systems and innovation theory. City, Culture and Society, 16, 18-27. doi: https://doi.org/10.1016/j.ccs.2017.12.001

Mridula Goel, M.A. (2017). Make in India Policy of 2014 and the self reliance objective of the 1956 industrial policy. International Journal of Research in Computer application and Management , 7(1), 24-17.

Mumtaz Hussain Shah, A.G. (2015). Significance of Good Governance for FDI Inflows in SAARC Countries. Business \& Economic Review, 7(2), 31-52.

Paolo Neirotti, A.D. (2014). Current trends in Smart City initiatives: Some stylised facts. Cities, 38, 25-36.

Phua, G.L. (2007). Urbanization and Slum Formation. Journal of Urban Health: Bulletin of the New York Academy of Medicine, 84(1), 27-34. doi:https://dx.doi.org/10.1007 \%2Fs11524-007-9167-5

Pratap Podode, F.P. (2016). Smart Cities India Readiness Guide. Smart Cities Council. Retrieved from https://smartnet.niua.org/sites/default/files/resources/Smart_Cities_ Council_India_Readiness_Guide_v2016-02.pdf

Provisional Population Totals. (2011). http://www.censusindia.gov.in/2011-prov-results/ paper2-vol2/data_files/goa/Tables.pdf. Panji. 
Rajkumar Joshi, S. A. (2016). Status and challenges of municipal solid waste management in India: A review. Cogent Environmental Science, 1-18. doi:http://dx.doi.org/10.10 80/23311843.2016.1139434

Rita Yi Man Li, H. D. (2015). Sustainable Construction Waste Management in Australia: A Motivation Perspective. In R. Y. Li, Construction Safety and Waste ManagementAn Economic Analysis (pp. 1-30). Springer. doi:https://doi.org/10.1007/978-3-319-12 430-8

Rita Yi, M. L. (2013). The Usage of Automation System in Smart Home to Provide a Sustainable Indoor Environment: A Content Analysis in Web 1.0. International Journal of Smart Home, 7(4), 47-60. Retrieved from https://ssrn.com/abstract=2306 084

Sang Keon Lee, H. R. (2016). International Case Studies of Smart Cities- Singapore. Inter-American Development Bank. Retrieved from https://publications.iadb.org

Smart cities:The future of Digital India. (2018). Retrieved May 29, 2018, from https:// www.tatacommunications.com/wp-content/uploads/2017/06/Tata-CommunicationsSmart-Cities.pdf

Smart City Proposal- Panjim. (2016, March). Retrieved June 29, 2018, from https://imagi nepanaji.com/wp-content/uploads/2016/03/Panaji-Smart-City-Proposal.pdf

Sudhir Vyankatesh Wanmali, D. O. (2018, July 19). Goa State, India. Retrieved July 19, 2018, from https://www.britannica.com/place/Goa

Susanne A Frick, A. R. (2019). Toward Economically Dynamic Special Economic Zones in Emerging Countries. Economic Geography, 29(1), 30-64. doi:https://doi.org/10.10 80/00130095.2018.1467732

Tame, R. (2014). Role of Panchayati Raj Institutions in Rural Development:The Study of a Tribal Village in Arunachal Pradesh. Modern Research Studies: An International Journal of Humanities and Social Sciences, 1(3), 503-521.

The Times of India. (2016, August 18). Retrieved May 17, 2018, from https://timesofindia. indiatimes.com/city/goa/SPV-to-implement-Panaji-Smart-City-plan-announced/articl eshow/53746637.cms

The Times of India, Saligao Garbage Treatment Plant begins generating power. (2017, January 17). Retrieved June 10, 2018, from https://timesofindia.indiatimes.com/city/ goa/saligao-garbage-treatment-plant-begins-generating-power/articleshow/5660721 $8 . \mathrm{cms}$

Tripathi, P. (2018, April 10). Sustainable cities, human mobility and international migration. Commission on Population and Development. Retrieved June 18, 2018, from Sustainable cities, human mobility and international migration: http://www.un. org/en/development/desa/population/pdf/commission/2018/country/AgendaItem3/en _india.pdf

Twelfth Five Year Plan (2012-2017) Faster, More Inclusive and Sustainable Growth (1 ed.). (2013). SAGE Publications India Pvt Ltd.

Vajda, Z. (2017, November 17). Developing 100 Smart Cities in India. Retrieved June 20, 2018, from http://www.geopolitika.hu/en/2017/11/17/developing-100-smart-cities-in -indial

What is a smart city. (2017, September). Retrieved May 20, 2018, from http://smartcities. gov.in/content/innerpage/what-is-smart-city.php

World Economic Forum; Future of Urban Development and Services. (2015). Retrieved June 13, 2018, from https://www.weforum.org/events/national-strategy-day-india

World Urbanization Prospects: The 2014 Revision. (2015). United Nations Department of Economic and Social Affairs/Population Division.

www.censusindia.gov.in. (2011). Retrieved July 9, 2013, from http://www.censusindia. gov.in/2011census/dchb/goatables.html 
Vol. 7, No. 1 Goel \& Thomas: Outcomes from Building Transparency in Governance...

Yigitcanlar, T. (2015). Smart cities: An effective urban development and management model? Australian Planner, 52(1), 27-34. doi:https://doi.org/10.1080/07293682.20 15.1019752

Zeneli, V. (2014, March). The Role of Institutions and Good Governance for Attracting Foreign Direct Investments: Evidence from Southeast Europe. Business and Economics Journal, 5(2), 1-20. doi:0.4172/2151-6219.100092

Zeng, D. Z. (2012). China's Special Economic Zones adn Industrial Clusters: The Engines for growth. Journal of International Commerce, Economics and Policy, 3(3), 1-10. doi: https://doi.org/10.1142/S1793993312500160 


\title{
The Sustainable Development Goals and Leading European Retailers
}

\author{
By Peter Jones* \& Daphne Comfort ${ }^{ \pm}$
}

\begin{abstract}
The Sustainable Development Goals (SDGs) agreed at a United Nations General Assembly in 2015 embrace an ambitious and wide-ranging set of global environmental, social and economic issues designed to effect a transition to a more sustainable future; the United Nations important role of the private sector in addressing the SDGs. The majority of Europe's leading retailers have been pursuing sustainability strategies, and reporting on their achievements against their strategies, for some time and within the European retail community there is a recognition that retailers have a vital role to play in contributing to the achievement of the SDGs. This exploratory paper reviews and reflects on how seven of Europe's leading retailers claim to be committed to addressing the $S D G s$. The findings revealed that all seven retailers reported on their commitment to contributing to the achievement of the SDGs, though the scale and the extent of their commitment varied. In reviewing the retailers' approach to the SDGs, the authors drew attention to a number of issues namely, concentration on specific SDGs, issues of measurement and reporting and tensions between sustainability and economic growth.
\end{abstract}

Keywords: Sustainable development goals, retailing, Europe, economic growth, reporting

\section{Introduction}

The Sustainable Development Goals (SDGs), agreed at a United Nations General Assembly in September 2015, were described as demonstrating "the scale and ambition" of its "2030 Agenda for Sustainable Development", which is designed to "shift the world on to a sustainable and resilient path" (United Nations 2015a). The SDGs are ambitious and embrace a wide range of environmental, social and economic issues including climate change, energy, water stewardship, marine conservation, biodiversity, poverty, food security, sustainable production and consumption, gender equality and economic growth. The United Nations called on all governments to develop national strategies to pursue the SDGs but also acknowledged "the role of the diverse private sector ranging from microenterprises to cooperatives to multinationals" (United Nations 2015a) in addressing these goals, and many companies within the private sector have begun to take up this challenge (Wynn and Jones 2020).

The majority of leading retailers have been pursuing sustainability strategies and reporting on their achievements against these strategies for some time.

${ }^{*}$ Professor of Management, School of Business, University of Gloucestershire, UK. ${ }^{ \pm}$Research Associate, School of Business, University of Gloucestershire, UK. 
Leading retailers are certainly in a singularly powerful position to drive sustainable development in four ways, namely through their own actions, through their relationships with suppliers, through their daily interactions with consumers and though their wider role in society as opinion leaders. As such, large retailers seem well placed to contribute towards the achievement of the SDGs. In 2018 the British Retail Consortium (2018) launched its "Better Retail Better World initiative, designed to mobilise "the retail industry to meet some of the biggest global challenges of the coming decades". Within the European retail community there is also a recognition that retailers have a vital role to play in contributing to the SDGs. Stefan Gent, Secretary General of the German Retail Federation, for example, recognised that the "the SDGs are a milestone for sustainability' and that 'the retail sector feeds into this UN Agenda 2030 and its goal with a large number of measures and initiatives" (German Retail Federation 2018). The SDGs are, without doubt, a very complex work in progress and in sharing Appau and Mabefam's (2020) belief that "it is too early to evaluate whether the SDGs live up to their potential and promise", the authors take the view that at the present time it would be premature to undertake a detailed evaluation of the contribution of retailers to the SDGs. Rather the aim of this short exploratory paper is much more modest, in that it offers an exploratory review of how some of Europe's leading retailers publicly claim to be committed to addressing the SDGs.

\section{The SDGs}

The SDGs, described as "a plan of action for people, planet and prosperity" (United Nations 2015a) came into effect in January 2016 and they will guide the United Nations' development thinking and policy up to 2030. The SDGs are the latest in a line of global sustainable development initiatives which can be traced back to the declaration designed "to inspire and guide the peoples of the world in the preservation and enhancement of the human environment" (United Nations Environment Programme 1972), following the United Nations Conference on the Human Environment held in Stockholm in 1972. The SDGs look to build on the United Nation's Millennium Development Goals (MDGs) established in 2001. The MDGs were described as having "produced the most successful anti-poverty movement in history" (United Nations 2015b) but other assessments of the achievements of the MDGs have been more balanced. While Fehling et al. (2013), for example, acknowledged that "remarkable progress has been made" they argued that "progress across all MDGs has been limited and uneven across countries".

There are 17 SDGs and they encompass a wide range of global challenges from "the wellbeing of every individual to the health of the planet, from infrastructure to institutions, from governance to green energy and peaceful societies to productive employment" (Institute of Human Rights and Business 2015) (Table 1). In some ways, SDG 13 namely, to take urgent action to combat climate change and its impacts, "is more than just one of the 17 SDGs' in that 'it is a threat multiplier with the potential to worsen some of humanity's greatest challenges, including health, poverty and hunger" (United Nations Climate 
Change 2019). However, SDG 12, namely, to ensure sustainable consumption and production patterns, might also be seen to be fundamental to the transition to a sustainable future. Pantzar et al. (2018), for example, argued that "consumption of goods and services is at the very heart of the challenge of achieving a more environmentally, socially and economically sustainable Europe". In a similar vein, the Nordic Council of Ministers (2018), claimed that "SDG 12 is the goal most interlinked to other goals, being coupled to no less than 14 out of the 16 remaining goals". More specifically, SDG 12 seems particularly relevant to retailers who are in a powerful position to drive both production and consumption processes within their supply chains.

Table 1. United Nations Sustainable Development Goals

\begin{tabular}{|l|c|}
\hline SDG 1: & Eliminate Poverty \\
\hline SDG 2: & Zero Hunger \\
\hline SDG 3: & Good Health and Well-being \\
\hline SDG 4: & Quality Education \\
\hline SDG 5: & Clender Equality Water and Sanitation \\
\hline SDG 6: & Access to Affordable, Sustainable and Modern Energy \\
\hline SDG 7: & Decent Work and Sustainable Economic Growth \\
\hline SDG 8: & Industry, Innovation and Infrastructure \\
\hline SDG 9: & Reduced Inequality \\
\hline SDG 10: & Sustainable Cities and Communities \\
\hline SDG 11: & Sustainable Consumption and Production \\
\hline SDG 12: & Climate Action \\
\hline SDG 13: & Life Below Water \\
\hline SDG 14: & Life on Land \\
\hline SDG 15: & Peaceful and Inclusive Societies \\
\hline SDG 16: & Global Partnerships for Sustainable Development \\
\hline SDG 17: & \\
\hline
\end{tabular}

However, there is little consensus in defining sustainable consumption and it is widely recognized to be a contested concept, which embraces "competing discourses" (Hobson 2006). In looking to put some flesh on the concept, the International Institute for Sustainable Development (2017) suggested that sustainable consumption can be seen as "an umbrella term that brings together a number of key issues, such as meeting needs, enhancing the quality of life, improving resource efficiency, increasing the use of renewable energy sources, minimising waste, taking a life cycle perspective and taking into account the equity dimension". Jackson (2006) summarised a variety of definitions but noted that these adopt different positions, on whether sustainable consumption implies "consuming more efficiently, consuming more responsibly, or quite simply consuming less". Jackson (2006) further argued that "the dominant institutional consensus' is that sustainable consumption "is to be achieved primarily through improvements in the efficiency with which resources are converted into economic goods". Definitions aside, Hinton and Redclift (2009) argued that sustainable consumption "could be considered an ambivalent term: the discourse comprises many different parts, mobilised at different times and in different ways". 
In addition to the SDGs themselves, there are 169 associated targets, in "a genuinely comprehensive vision of the future" in which "little is left unaddressed" (Institute of Human Rights and Business 2015). The targets for SDG 1, for example, include eradicating extreme poverty: ensuring that all men and women, and particularly the poor and vulnerable, have equal rights to economic resources, access to basic services and ownership and control over land and property; and building the resilience of the poor and vulnerable to reduce their exposure to climate change related extreme events. The targets for SDG 12, include achieving the sustainable management and efficient use of natural resources by 2030; halving per capita global food waste at the retail and consumer levels; and encouraging companies to adopt sustainable practices and sustainability reporting.

The European Commission (2017) argued that "the scale, ambition and approach of the Agenda are unprecedented. One key feature is that the SDGs are global in nature and universally applicable, taking into account national realities, capacities and levels of development and specific challenges". All countries were seen to have a shared responsibility to achieve the SDGs, and to have a meaningful role to play locally and nationally as well as on the global scale. Further, the European Commission (2017) argued that "the 2030 Agenda integrates in a balanced manner the three dimensions of sustainable development - economic, social and environmental' and that it is 'indivisible, in a sense that it must be implemented as a whole, in an integrated rather than a fragmented manner, recognising that the different goals and targets are closely interlinked".

Lambert (2020) argued that the public sector has traditionally been seen to have the major role in promoting global development agendas but that within the last 25 years, the private sector has become an increasingly important player in the development process. The launch of the SDGs epitomises this more balanced emphasis and private businesses are seen to have a key role to play in the successful achievement of the SDGs. Scheyvens et al. (2016) claimed that the private sector had a number of assets including, innovation, responsiveness, efficiency, specific skills and a range of resources, which would be invaluable in helping to deliver the SDGs.The World Economic Forum (2018) claimed "the annual funding gap for the Sustainable Development Goals is many trillions of dollars. The only way to close that gap is with the help of the private sector - in particular, by impelling companies to account in their decision-making for environmental, social, and governance issues relevant to the SDGs". That said, the Institute for Human Rights and Business (2015) suggested that "the SDGs seem to have quietly re-imagined a new model of business, relapsed as an agent of development, harnessed and channelled by governments and set to work on alleviating poverty and fostering sustainable economic growth for all". Further, the Institute for Human Rights and Business (2015) argued that "business is not an adjunct of aid" and that "economic activity cannot easily be directed to where the need is greatest" but rather "it prospers when provided with the right conditions and the right opportunities".

More specifically, the United Nations Global Compact and KMPG (2016) argued that the SDG's provided a range of opportunities for food and consumers goods retailers to generate shared value, focused on the coming together of market potential, societal demands and policy action, around a number of themes including 
enterprise development, sustainable supply, healthy and sustainable living and product innovation. In addressing sustainable supply, for example, the United Nations Global Compact and KPMG (2016) suggested that retailers can look to increase their share of energy from renewable sources, to reduce their demands on natural resources, to ensure fair labour practices across their supply chains and to enhance climate resilience. Walmart (2019), the world's largest retailer, has acknowledged the importance of the SDG's and reported that it would be focusing on climate change, responsible supply chains, retail opportunity, inclusive sourcing, and healthier and safer food.

\section{Method of Enquiry and Frame of Reference}

In an attempt to undertake an exploratory review of how the leading European retailers publicly claimed to be committed to be addressing the SDGs, the leading ten retailers in Europe (Retail Index 2020), as measured by turnover, were selected for investigation. In selecting these retailers, to provide the framework for the study, the authors took the view that as the leading players in the European retail economy, they might be seen to reflect innovative and start of the art approaches to addressing the SDGs. Retailers have employed a range of methods to report their sustainability commitments and achievements, but publication on corporate websites is now the most popular and accessible reporting mechanism (Morhardt 2009).With this in mind, an internet search, using the key phrase "Sustainable Development Goals" and the name of each of the selected retailers, was conducted using Google as the search engine in February 2020. This search revealed that seven of the leading ten European retailers namely, Schwarz, Aldi, Carrefour, Rewe, Tesco, Auchan, and J. Sainsbury, reported on addressing the SDGs on their corporate websites. The information from this search provided the empirical information for this paper.

The specific examples and selected quotations drawn from the retailers' corporate websites are used for illustrative purposes with a view to reviewing how the the leading European retailers claimed to be committed to addressing the SDG's, rather than to offering a systematic comparative analysis of the retailers' approaches to the SDGs. The paper is based on information that is in the public realm and the authors took the view that they did not need to contact the selected retailers to obtain formal permission to use this information prior to conducting their research. When outlining the issues of reliability and validity in relation to information drawn from the Internet, Saunders et al. (2009) emphasised the importance of the authority and reputation of the source and the citation of a specific contact individual who can be approached for additional information. In reviewing the retailers' corporate material on their websites, the authors felt that the two conditions were met. However, while the authors recognise that their approach has a number of limitations, not least that it draws exclusively on corporate information posted on the Internet by just seven retailers, they believe it is an appropriate approach in a paper which looks to offer an exploratory review of 
how some of Europe's leading retailers claim to be committed to addressing the SDGs.

Schwarz, a private, family owned retail group, is Europe's largest retailer and it trades under the Kaufland and Lidl brands. Kaufland is a full-range retailer with over 1,300 stores in Germany and Eastern Europe, while Lidl is a discount operation with a limited average range of c. 3,800 products and it operates some 10,000 stores in over 30 countries. Aldi, is the common brand of two German discount supermarkets, and it trades from over 11,000 stores. Some $37 \%$ of its stores are in Germany, and while the majority of its other stores are in Europe, including in Austria, Belgium, France, Netherlands, Spain and the UK, it also has stores in Australia, New Zealand, China and the US. Carrefour is a French multinational retailer and it operates a range of retail formats including hypermarkets, warehouse clubs, superstores, supermarkets and convenience stores. In total it has over 12,300 stores in over 30 countries in Europe, Asia, Africa and Latin America, including in France, Italy, Spain, Poland, China, Indonesia, Taiwan, Tunisia, Morocco, Argentina and Brazil.

Rewe operates a diversified retail portfolio, which includes department stores, hypermarkets, home improvement stores, supermarkets and convenience stores and it has over 12,000 stores in 14 countries, principally in Germany, but also in a number of other European countries including Austria, Italy, Hungary and the Czech Republic. Tesco is the UK's largest retailer, with some 3,400 stores, and it trades from hypermarket, superstore, and convenience store formats and while its stores are almost exclusively concentrated in the UK, it has a presence in 11 other countries. Auchan is a French multinational retailer and it operates hypermarkets, supermarkets and convenience stores and it has over 3,800 stores in 12 countries including France, Austria, Italy, Poland, Hungary, Russia and China. J. Sainsbury initially founded in 1869, trades from over 600 supermarkets, some 800 convenience stores and 800 stores operating under the banner of Argos, throughout the UK.

\section{Results}

All seven of the selected leading European retailers claimed to be committed to addressing the SDGs, though the scale and the extent of their claimed commitment varied. In outlining its commitment to the SDGs, Schwarz (2018), for example, claimed "we are taking bold action to support the goals of the global agenda for 2030" and claimed "in pursuit of these goals we will set new industry standards". Further, Schwarz (2018) also formally recognised its pivotal role in pursuing such policies in that the company reported "as one of the world's leading retailers, we shape the change necessary in those places we can actively make an impact in production, in consumption and in the recycling of products."

Carrefour (2019) formally reported that the company "supports the 17 Sustainable Development Goals" that "these common goals help with the implementation of sustainable development programmes entered into jointly with other partners". In addressing the SDGs, Aldi South (2018) claimed "we promote 
the achievement of these global goals by participating in initiatives and implementing a range of sustainability practices". In his Chairman's "Introduction" to Auchan's (2018) 2017 Corporate Social Responsibility section of its Annual Report, Regis Degelcke, noted that the company was "mindful" of "the 17 sustainable development goals set by the United Nations" but the report provided no details on how they were addressing the SDGs.

Within these general commitments to the SDGs, some of the selected retailers reported on their commitment to all 17 SDGs while others concentrated their energies on specific goals. J Sainsbury, for example, provided some simple examples of its contribution to all the SDG's. In illustrating its commitment to SDG 3, J Sainsbury (2018) affirmed its belief that "more sustainable agricultural practices can provide nutritious food for our growing population and support rural development while protecting the environment". J Sainsbury's (2018) commitment to SDG 6 is grounded in the belief that "protecting water resources and maintaining water quality and availability enables us to better manage our production of food in supply chains".

In contrast, Tesco (2018) claimed to contribute "in different ways and to different degrees to all the SDGs" but "identified which goals are particularly relevant to us: where expectations, risks, and other opportunities for Tesco are greatest and where we can make the most significant contribution". Here Tesco identified eight SDGs namely SDG's 2, 3, 7, 8, 12, 13, 14 and 15. Tesco's target for SDG 2, for example, is to facilitate surplus food donation programmes in all its stores. Tesco looked to work closely with food banks and charities and it has provided support for homeless shelters, domestic violence hostels and after-school clubs. Tesco's target for SDG 14, is to sustainably source all the wild fish on sale in its stores and here the company has emphasised its commitment to support sustainable fisheries and to work to protect the marine environment.

In a similar vein, Aldi South (2018) emphasised its focus on nine of the SDGs namely, SDG's 2, 3, 5, 6, 8, 12, 13, 14 and 17. In focusing on SDG 8, which looks to promote inclusive and sustainable economic growth and to productive and decent employment, for example, the company emphasised its commitment to human rights and fair labour standards and reported that it expected all its suppliers and business partners to adhere to these standards as an integral part of all contractual relationships. The company reported monitoring working conditions and social standards at production facilities throughout its supply chain and looking to improve the health and wellbeing of its employees. Carrefour reported that it is particularly focused on seven of the SDGs namely, SDGs 2, 3, 5, 12, 13, 14 and 15 and Rewe prioritised a smaller number of the SDGs, namely SDGs 2, 7, $8,12,14$ and 15 .

In many ways, as outlined earlier, SDG 12 Sustainable Consumption and Production, is fundamental to the transition to a more sustainable future, and it is addressed, albeit in different measure, by six of the selected retailers. In providing a rationale for why it "focuses its sustainability efforts on SDG 12", Schwarz (2018) argued "transitioning to a sustainable economy and lifestyle can only work if we change our consumption habits and production methods". In looking to effect such a change, Schwarz (2018) set a number of milestones, focused upon 
sustainable raw materials, zero waste, food waste, chemicals and empowerment. Here Schwarz reported undertaking a systematic analysis to set sustainable goals for its most relevant raw materials, and looking to reuse, recycle or recover a "significant proportion" of waste generated by the company by 2025. At the same time Schwarz claimed to be empowering and supporting all employees in sustainably performing their jobs and to be providing customers with greater transparency on the social, environmental and health related impacts of its product range.

Tesco's (2018) targets for SDG 12 were to "help halve global food waste from farm to fork" and "making all packaging recyclable". In reporting on its actions to meet these targets in the UK and Central Europe, Tesco claimed to have sold some 28,000 tonnes of perfectly imperfect fruit and vegetables that previously would not have met the company's size and shape specifications. At the same time Tesco committed to remove all hard to recycle materials from its own brand packaging. Aldi North (2017) reported on 27 initiatives to illustrate how the company as contributing to SDG 12 including the company's baby body suit, animal welfare, labelling for fruit and vegetables, packaging and recycling, food losses and genetic engineering. In illustrating the sustainable consumption and production of the company's baby body suit, for example, Aldi North told the story of the suit's lifecycle from cotton cultivation in India, through the production of yarn and fabric and assembly in Bangladesh, to its sale, use and recycling in Europe.

In looking to address the SDGs, the majority of the selected retailers have focused upon their own operations but some of them also reported on the contribution to achieving the SDGs within their supply chains. Aldi North, for example, reported on the company's sustainability requirements for suppliers and production facilities across a range of the SDGs. In addressing SDG 2, for example, Aldi North (2017) reported that its "purchasing policies and other programmes allow us to exert influence indirectly on upstream processes with subsuppliers and producers" and "we are switching our range to more sustainable raw materials, where it makes sense and it is possible to do so". Further, Aldi North (2017) reported "in countries of our products' origins, we are making efforts to improve the living conditions of small holder farmers and their families" and "we provide training and workshops for small holders for this purpose". Aldi North (2017) also reported that its suppliers must comply with strict regulations for the cultivation of fruit and vegetables and that since 2016 the company had banned the use of eight active ingredients previously used in fruit, vegetable and potato production in Germany.

At the other end of the supply chain, Schwarz (2018) reported on "Bringing Sustainable Consumption to the Society at large". Mindful that the conventional processes for the manufacture of its textiles and shoes relies on the use of chemicals, Lidl and Kaufland have joined the Greenpeace Detox campaign, which aims to keep potential hazards to humans and the environment to a minimum. Schwarz (2018) also looked to respond to what it describes as "consumers' growing demands for products manufactured in a responsible and environmentally friendly manner". Such environmentally friendly products are available to 
customers in Lidl and Kaufland stores in a number of European countries. Schwarz (2018) also reported on its activities in "raising consumer awareness" by ensuring that products produced in line with environmental and social standards are clearly labelled and include brochures and packaging with information on product sustainability, in an attempt to make customers more aware of the benefits.

Some of the selected leading European retailers have looked to integrate their approach to the SDGs within their wider corporate sustainability strategies in a variety of ways. J. Sainsbury (2018) for example, mapped a number of the SDGs onto the five core values, namely, "living healthier lives, making a positive difference to our community, respect for our environment, sourcing with integrity" and "a great place to work" that provide the structure for its sustainability reporting. SDGs 2, 3, 5, 12, 13, 14, 15 and 17 were, for example mapped onto its outline report on living healthier lives, and SDG's 6, 7, 9, 1213 and 17 were linked to respect for the environment. Rewe reported comparing its corporate sustainability goals and business processes with the SDGs. As such, Rewe (2017) looked to address its priority SDGs as part of its focus on its four "pillars of sustainability", namely Green Products; Energy, Climate and Environment; Employees: and Social Involvement. Here the focus on Green Products, for example, was linked to SDGs 12, 14 and 15, while SDGs 7, 11 and 13 applied to the Energy, Climate and Environment pillar.

In "Working towards the Sustainable Development Goals" Carrefour (2019) integrated SDGs 2, 5, 12, 13, 14 and 15 within its Corporate Social Responsibility strategy criteria, namely, combatting waste; protecting biodiversity; supporting partners; and social dynamics and diversity. Further Carrefour (2019) grade the contribution of each of the four criteria to the six SDS. Thus, combatting waste, protecting biodiversity and supporting partners were all classed as making a "very strong contribution" to SDG2, protecting biodiversity and supporting partners were classes as making a "strong contribution" to SDG 13, and while social dynamics and diversity made a "very strong contribution" to SDG 5, it was classed as making a "contribution" to the other five SDGs. In addressing SDG 13 as part of combatting waste, Carrefour reported that by introducing an internal carbon price and rolling out its waste reduction policy and its energy and climate plan, the company had incorporated a key climate change goal into its investment strategy. In a similar vein, as part of its strategic commitment to protect biodiversity, Carrefour reported it was promoting agroecology and encouraging the use of resilient farming practices that will boost productivity and output, contribute to the conservation of ecosystems and gradually improve the quality of land and soil.

\section{Discussion}

A number of Europe's leading retailers have claimed to be addressing the SDGs and some of them have claimed to be looking to integrate their approach to the SDGs with their corporate sustainability strategies. In making such claims, some of these retailers reported on looking to contribute to all 17 SDGs while others concentrated on a more limited number of specific SDGs that reflected their 
business strategy and their opportunity to make a meaningful contribution. At the same time, it is important to recognise Ruiz-Real et al.'s (2018) claim that "sustainability is a key element for retailers, who have seen that sustainable development could become an important source of competitive advantage". In looking to contribute to the achievement of the SDGs, the retailers can also be seen to be driving business efficiencies, which can, in turn, offer them a source of competitive advantage. In pursuing actions to combat climate change and its impacts, by reducing carbon emissions, energy and water consumption and waste generation, for example, the retailers are also reducing costs. In a similar vein, retailers' SDG commitments to decent work, gender equality and good health and wellbeing all help to promote stability, security, loyalty, and efficiency within their workforce.

Given the importance of SDG's 12 and 13, highlighted earlier, the retailers' contribution to these SDGs', needs to be seen against the wider European background. In addressing European progress on SDG 12, for example, the European Commission (2019) focused on three sets of issues, namely, decoupling environmental impacts from economic growth, energy consumption and waste generation. The European Commission (2019) reported that while the European Union has made some long-term progress in decoupling environmental impacts from economic growth, in that resource productivity had increased by $34.7 \%$ between 2002 and 2017, the amount of waste generated per capita had increased by $3.3 \%$ from $2102-2016$ and that there had been a deterioration in the overall assessment of progress on SDG 12 compared with the previous year. In addressing SDG 13, the European Commission (2019) reported some progress on climate mitigation in the European Union, namely a $15.4 \%$ reduction in greenhouse gas emissions between 2002 and 2017 and a reduction in final energy consumption of $2.0 \%$ during the same time period, with all sectors of the economy contributing to this reduction. However, the European Commission also (2019) argued that "unfavourable trends in climate impact remained", and here, by way of an illustration the European Commission reported that mean surface temperatures had risen by 1.61-1.71 degrees Celsius between 2009 and 2018, compared to preindustrial levels.

More generally, the leading European retailers can be seen to be responding positively to the United Nations' rallying cry for private sector engagement with the SDGs. However, four sets of issues merit reflection and discussion. Firstly, there is an issue about retailers focusing upon specific SDGs. The retailers would argue that in pursuing this approach they are concentrating on where they can make their most meaningful contribution to the SDGs. This certainly resonates with the World Business Council for Sustainable Development's (2018) suggestion that a number of "companies are clearly seeing value in narrowing down the broad SDG agenda with a view to focusing their efforts on a specific sub-set of goals". However, PWC (2018) claimed that "many companies are engaging at a more superficial level" and "are failing to prioritise goals that need corporate support the most or to address those that could cause the biggest problems in the future if left unchecked". At the same time, PWC (2018) argued that prioritisation "requires a longer-term vision of, and approach to, business growth strategy and planning than 
some companies are used to employing" and that such a "longer term perspective requires an understanding of the risks that a company could face if the underlying issues that the SDGs represent are not solved".

While there was clear commonality, though not complete uniformity, in the specific SDGs prioritised by the selected European retailers, they all prioritised SDGs 12 and 13, but here their approach to both these SDGs has its problems. On the one hand, all the selected retailers effectively redefined SDG 12 as responsible, rather than sustainable, consumption. However, none of the retailers offers a definition of responsible retailing, though their approach can perhaps best be seen to put customers, rather than retailers, in the driving seat. As such, retailers might be seen to have an important role to play in promoting sustainable or responsible consumption at store level. However, a study by Jones Wynn and Comfort (2020) of leading UK retailers, which included two of the retailers in the current study, found little or no attempt to promote sustainable or responsible consumption at the point of sale.

On the other hand, SDG 13, action to combat climate change and its impacts, presents a daunting challenge for retailers. Not least in that "climate change presents the single biggest threat to sustainable development" (United Nations Climate Change 2020) and in that Liverman (2018) claimed "climate change has been identified as the one stress that could undermine the other environmental goals, as well as those on poverty or health". The selected European retailers typically reported on their actions to reduce carbon emissions in their own operations. Here, in theory at least, they have direct control, but cutting carbon emissions throughout their supply chains is a much more difficult task. Encouraging suppliers, spread throughout the world, to reduce carbon emissions and independently monitor their emissions data is both costly and time consuming and an operationally difficult exercise. At the same time, the majority of the leading retailers' stores are located in out of town centre locations and customers effectively rely on car transport to do their shopping at such stores, so reducing carbon emissions from their vehicles presents significant problems and challenges to well established patterns of shopping behaviour.

Secondly, there are both general and specifically retail, issues about measurement and metrics. Generally, there are issues about the data that is required to measure progress, about the collection of such data and the mechanisms and procedures that will need to be established in order to monitor progress. The dominant approach to the measurement and monitoring of the SDGs is to identify indicators for each SDG. The UN's Tier Classification of SDG indicators, updated in 2020, are all considered "equally important", (United Nations 2020) but they were designed to enable member states, rather than private companies, to review progress at the national and sub-national level, and thus have limited value for large retailers. That said, Bali Swain (2018) argued that "this approach if not flawed is inadequate" not least, in that it ignores the complex interrelationships between some of the SDGs. At the same time, Nightingale (2018) insisted that some of the SDGs (e.g., poverty, justice and gender equality) are "not a state of being and, as such.... not conducive to static measurement". Rather, she argued, poverty is a "punctuated experience for the individuals and populations in question" 
and "if counting does not reflect the reality of being in poverty, it is not an adequate guide for understanding how to alleviate poverty" (Nightingale 2018).

Such critiques present a dilemma for retailers in that they can be seen to call into question the measures the leading European retailers have used to monitor their sustainability achievements in their annual sustainability reports, and which some retailers are already using to celebrate their contribution to the SDGs. This is not to suggest that the data currently being used is inaccurate per se, but that it may not necessarily measure what needs to be measured if the retail industry's contribution to the SDGs is to be captured accurately. At the same time, the selected European retailers have used their own measures to report on their current achievements in contributing to the SDGs. This does not generate any comparable results, which would allow retailers to benchmark their performance, one with another, or to contribute to wider national reporting mechanisms. A number of the leading European retailers have used cameo case studies in an attempt to depict the real life, everyday experiences of individuals and communities in their sustainability reports. As such, the retailers might be seen to looking to capture the experiences of those individuals and communities, the SDGs look to address. Here however there are issues surrounding the relationship between the 'particular' and the 'general', in that the cameo case studies employed in the sustainability reporting process have been specially chosen and choreographed by the selected retailers. Such cameo case studies may well have a strong human interest, and some of them have a powerful emotive appeal, which may well resonate with audiences on corporate websites and social media, but they cannot necessarily be seen to be wholly representative of the leading European retailers' contributions to the SDGs.

Thirdly, there are issues about reporting and communication. There is no official or generally agreed framework for companies to report on the SDGs, and so it is not surprising that the selected European retailers report on their contribution to the SDGs in a variety of ways. While J. Sainsbury, for example, included information on how they are contributing to the SDGs within their sustainability report, Schwarz and Tesco produced a dedicated short report on their contribution to the SDGs, and Carrefour included how it was working towards the SDGs in the Corporate Social Responsibility section of the company's Annual Financial Report. The lack of a common reporting framework effectively makes it impossible to make any meaningful comparison of the contribution of retailers, or to assess the overall contribution of the retail sector to that of wider business community.

At the same time, Dentsu Aegis Network (2018) warned of the danger of "SDG Wash". Here, "companies use the SDGs in their communication to expand the corporate value and sales of their own company" (Dentsu Aegis Network 2018). Clear parallels are drawn with Green Wash, the environmentally pejorative term used when green communication messages are deceptively used to promote the perception that a company's products, aims or policies are environmentally friendly. As such, Dentsu Aegis Network (2018) argued that SDG Wash damages both "the relationship of trust between consumers and individual companies' as well as 'the appeal of the company as an investment and loan destination". 
Looking to the future, if the retailers' contributions to the SDGs increasingly become fully integrated into the retailers' corporate sustainability strategies, then that contribution will be reported in their annual sustainability/corporate social responsibility reports. However, while European retailers have been reporting on their sustainability strategies and their achievements against those strategies across a wide range of environmental, social and economic issues for some time, in the past there has often been little or no independent external assurance of the majority of the data in these sustainability reports (Jones et al. 2012). This can be seen to reduce the credibility, integrity and reliability of the sustainability reporting process and of the retailers' achievements in contributing to the SDGs.

Finally, there are potentially fundamental, tensions between sustainability narratives and economic growth. The one seemingly dependent on the continuing exploitation of scarce natural resources, and the other looking to promote development that meets the needs of the present without compromising the needs of the future. Such tensions are thrown into sharp relief in the case of the SDGs in that SDG 8 specifically looks to promote sustainable economic growth. The United Nations (undated) argued that "sustainable economic growth will require societies to create the conditions that allow people to have quality jobs that stimulate the economy while not harming the environment", though they made no attempt to specify how this balance was to be achieved or to define sustainable economic growth. More pointedly, the German Retail Federation (2018) claimed "steady and inclusive economic growth is a precondition for sustainable development" and all the leading European retailers are committed to continuing growth. More generally, Sultana's (2018) expressed surprise at choice of the term "sustainable development", which she described as being "at the heart of this new framework of titled SDGs", because she argued that "sustainable development has been very contested, conflictual and contradictory in definition and reality since its uptake in the 1980's" and that "sustainable development can mean anything to anybody" (Sultana 2018). As such, retailers may be able to justify their commitment to sustainability, while continuing to pursue growth policies, which are dependent on the depletion of the earth's finite resource base.

Attempts to reconcile continuing economic growth and sustainable development are often couched in terms of decoupling and of the role of technological innovation. The former refers to economic growth, which does not lead to increases in the pressure on environmental resources, while the latter looks to innovative technologies to increase energy efficiency, cut greenhouse gas emissions, reduce waste and facilitate the development of a more circular economy. While both approaches are close to the heart of the European retailers' approach to the SDGs, others have taken a more critical view. In examining the decoupling thesis Alexander et al. (2017), for example, concluded "the decoupling strategy cannot lead to a growing global economy that is just and sustainable". In addressing the role of technological development in promoting sustainability, Huesemann (2003) argued that "improvements in technological eco-efficiency alone will be insufficient to bring about the transition to sustainability". Schor (2005) argued that "the popularity of technological solutions is also attributable to the fact that they are apolitical and do not challenge the macrostructures of 
production and consumption". This in turn, reflects Liverman's (2018) concerns that "growth goals cannot be met without sacrificing many environmental ones or that sustainability cannot be achieved under the current economic model of capitalism".

\section{Conclusion}

The United Nations' SDG programme is ambitious and wide ranging and a number of the leading European retailers have claimed a general commitment to the SDGs. Within this general commitment, some of the selected retailers prioritised a number of specific SDGs, that reflected their business strategy and their opportunity to make a meaningful contribution, while others looked to contribute to all 17 SDGs. As such, the leading retailers can be seen to be responding positively, albeit in varying measure, to the United Nations' rallying cry for private sector engagement with the SDGs. That said, given the Sustainable Development Solutions Network/Institute for European Environmental Policy's (2019) report which concluded that none of the countries within the European Union were on track to meet their SDG targets, the leading European retailers may need to step up their contribution if these targets are to be achieved. However, the authors suggested that the retailers will face a number of major challenges if they are to make a significant and a lasting contribution to the achievement of the SDGs. These challenges include, the strategic prioritisation of SDGs, issues about measurement, reporting and communication and fundamental tensions between sustainability and economic growth.

This paper has a number of limitations, as outlined earlier, but the authors believe it provides a platform for future research, which will move beyond how retailers are claiming a commitment to addressing the SDG's, and on to examine their achievements in contributing to the achievement of the SDGs. Looking to the future, a first step might be for researchers, or more probably for research teams or institutes, to establish a formal collaborative research project with one, or possibly more, large retailers, designed to investigate how the retailer(s) is (are) contributing to the achievement of the SDG's. The negotiation of agreements between researchers and retailers for such a collaborative research venture would be complicated, even more so if it also involved research access to suppliers, not least in that researchers might well want access to sensitive commercial data and retailers, and suppliers, might demand the right to control or veto the researchers' findings.

More practically, academic research might, for example, might profitably be undertaken at the strategic and the operational level. At the strategic level, for example, primary research amongst senior retail executives, might profitably explore a number of issues. Such issues might include corporate thinking and policy development on the SDG's, the forces driving the pursuit retailers' pursuit of the SDGs, the challenges of, and opportunities for, integrating the SDGs within corporate retail strategies, how and why certain SDGs have been prioritised, retailers' relationships with suppliers in the pursuit of SDG agendas and 
perceptions of the locus of power within such relationships, and the mechanisms developed by retailers to enable different groups of stakeholders to influence retailers' approach to the SDGs. At the operational level, specific research investigations might focus, for example, on how corporate policy towards the SDG's is communicated both to employees, at store level and in distribution centres, as well as to customers at the point of sale, on how data on environmental, social and economic impacts is collected within supply chains and on how such data is independently verified, and on the success of practical schemes designed to reduce waste and encourage and facilitate recycling. Such research endeavours could include comparative investigations across a number of retailers and detailed case studies of individual retailers.

\section{References}

Aldi North (2017) Sustainability at Aldi North. Retrieved from: https://bit.ly/39iOoS4. [Accessed 20 February 2020].

Aldi South (2018) Sustainable development goals. Retrieved from: https://bit.ly/3eSm 1ew. [Accessed 20 February 2020].

Alexander S, Rutherford J, Floyd J (2017) A critique of the decoupling strategy: a limits to growth perspective. Retrieved from: https://bit.ly/2ZPrn5Y. [Accessed 15 November 2018].

Appau S, Mabefam MG (2020) Prosperity for the poor: religion, poverty and development in Sub-Saharan Africa. In SA Churchill (ed), 243-266. Moving from the Millennium to the sustainable development goals. Singapore: Palgrave-Macmillan.

Auchan (2018) Corporate social responsibility section of 2017 management report. Retrieved from: https://bit.ly/3jzbacT. [Accessed 20 February 2020].

Bali Swain, R. (2018) SDG measurement, challenges and policies. Retrieved from: https:// bit.ly/39jBiUu. [Accessed 13 November 2018].

Carrefour (2019) Registration document: 2017 annual financial report. Retrieved from: https://bit.ly/3hxEZJ1. [Accessed 20 February 2020].

Dentsu Aegis Network (2018) SDG communications guide. Retrieved from: https://bit.ly/ 2WNpHrQ. [Accessed 15 November 2018].

European Commission (2017) The 2030 agenda for sustainable development and SDGs. Retrieved from: https://ec.europa.eu/environment/sustainable-development/\%20SD Gs/index_en.htm. [Accessed 10 June 2018].

European Commission (2019) Sustainable development in the European Union 2019. Retrieved from: https://bit.ly/2ONQhg5. [Accessed 19 July 2020].

Fehling M, Nelson B, Venkatapuram S (2013) Limitations of the Millennium development goals: a literature review. Public Health 8(10): 1109-1122.

German Retail Federation (2018) Sustainable action: retail sector's contribution to the 2030 agenda. Retrieved from: https://bit.ly/39lPWup. [Accessed 28 February 2020].

Hinton E, Redclift M (2009) Austerity and sufficiency: the changing politics of sustainable consumption. Working Paper Series, no. 17. UK: King's College London.

Hobson K (2006) Competing discourses of sustainable consumption: does the rationalisation of lifestyles make sense. In T Jackson (ed), 305-327. The Earthscan reader in sustainable consumption. London: Earthscan.

Huesemann MH (2003) The limits of technological solutions to sustainable development. Clean Technologies and Environmental Policy 5(Dec): 21-34. 
Institute for Human Rights and Business (2015) State of play: business and the sustainable development goals: mind the gap - challenges for implementation. Retrieved from: https://bit.ly/3fOlCLv. [Accessed 28 May 2016].

International Institute for Sustainable Development (2017) Oslo roundtable on sustainable production and consumption. Retrieved from: https://enb.iisd.org/consume/oslo004. html. [Accessed 4 December 2017].

J Sainsbury (2018) Our values make us different: Sustainability update 2018. Retrieved from: https://bit.ly/2WNwrGa. [Accessed 20 February 2020].

Jackson T (2006) Readings in sustainable consumption. In T Jackson (ed), 1-26. The Earthscan reader in sustainable consumption. London: Earthscan.

Jones P, Comfort D, Hillier D (2012) Sustainability in the European shop window. In T Rudolph, T Foscht, D Morschett, P Schnedlitz, H Schramm-Klein, B Swoboda (eds), 1-19. European retail research. Wiesbaden: Gabler Verlag.

Jones P, Wynn MG, Comfort D (2020) SDG 12, Sustainable consumption and the UK's leading retailers. In L McNeill (ed), Transitioning to Sustainability. Basel: MDPI. [In Press].

Lambert C (2020) From philanthropy to investment: considering the new role of the private sector in global development. Philologia 12(1): 4-10.

Liverman D (2018) Geographical perspectives on development goals: constructive engagement and critical perspectives on the MDs ad the SDGs. Dialogue in Human Geography 8(2): 168-185.

Morhardt JE (2009) Corporate social responsibility and sustainability reporting on the Internet. Business Strategy and the Environment 19(7): 436-452.

Nightingale, A. J. (2018) Geography's contribution to the Sustainable Development Goals: Ambivalence and performance. Dialogue in Human Geography 8(3): 196-200.

Nordic Council of Ministers (2018) Sustainable consumption and production. Retrieved from: http://norden.diva-portal.org/smash/get/diva2:1260102/FULLTEXT01.pdf. [Accessed 18 December 2019].

Pantzar M, Strube R, Gionfra S, Modee K (2018) Sustainable consumption - policy approaches for systems change. Policy Paper Produced for the Think 2030 Conference. Institute for European Environmental Policy.

PWC (2018) SDG prioritisation - is business on the right track. Retrieved from: https:// bit.ly/3g5i1Zq. [Accessed 12 November 2018].

Retail Index (2020) Major retailers in Europe, their rankings and profiles. Retrieved from: https://www.retail-index.com/. [Accessed 19 February 2020].

Rewe (2017) Sustainability report. Retrieved from: https://bit.ly/2BoUZ0F. [Accessed 20 February 2020]

Ruiz-Real JL, Uribe-Toril J, Gazquez-Abad JC, De Pablo Valencian J (2018) Sustainability and retail: analysis of global research. Sustainability 11(1): 14.

Saunders M, Lewis P, Thornhill A (2009) Research methods for business students. Harlow: Prentice-Hall.

Scheyvens R, Banks G, Hughes E (2016) The private sector and the SDGs: the need to move beyond business as usual. Sustainable Development 24(6): 371-382.

Schor JB (2005) Prices and quantities: unsustainable consumption and the global economy. Ecological Economics 55(3): 309-320.

Schwarz (2018) Acting responsibly. Retrieved from: https://bit.ly/3jzqTIX. [Accessed 20 February 2020].

Sultana F (2018) An (other) geographical critique of development and SDG's. Dialogues in Human Geography 8(2): 186-190.

Sustainable Development Solutions Network/Institute for European Environmental Policy (2019) 2019 European sustainable development report: towards a strategy for 
achieving the sustainable development goals in the European Union. Retrieved from: https://bit.ly/3fUWPpd. [Accessed 11 March 2020].

Tesco (2018) Contributing to the United Nations sustainable development goals. Retrieved from: https://bit.ly/3fU74tT. [Accessed 20 February 2020].

United Nations (2015a) Transforming our world: the 2030 agenda for sustainable development. Retrieved from: https://bit.ly/32O6OJ8. [Accessed 29 January 2019].

United Nations (2015b) The Millennium development goals report 2015. Retrieved from: https://bit.ly/3eSAY0m. [Accessed 3 June 2016].

United Nations (2020) IAEG-SDGs: Tier classification of global SDG indicators. Retrieved from: https://bit.ly/3eQUx9i. [Accessed 23 May 2020].

United Nations (undated) Sustainable development goals. Retrieved from https://www.un. org/sustainabledevelopment/economic-growth/. [Accessed 11 March 2020].

United Nations Climate Change (2019) Impacts of Climate Change on Sustainable Development Goals Highlighted at High-Level Political Forum. Retrieved from: https://bit.ly/3eUK2lk. [Accessed 5 March 2020].

United Nations Climate Change (2020) Action on climate and SDGs. Retrieved from: https://bit.ly/3hzwpd7. [Accessed 5 March 2020].

United Nations Environment Programme (1972) Declaration of the United Nations conference on the human environment. Retrieved from: https://bit.ly/3hu1BKF. [Accessed 3June 2016].

United Nations Global Compact and KPMG (2016) SDG industry matrix: food beverages and consumer goods. Retrieved from: https://bit.ly/3eSBZFI. [Accessed 22 May 2020].

Walmart (2019) 2019 Environmental, social and governance report. Retrieved from: https://bit.ly/2WM5GSq. [Accessed 23 May 2020].

World Business Council for Sustainable Development (2018) Business and the SDGs: a survey of WBCSD members and global network partners. Retrieved from: https://bit. ly/30IMx4Y. [Accessed 12 March 2020].

World Economic Forum (2018) How the private sector can help fund the sustainable development Goals. Retrieved from: https://bit.ly/32HMTeW. [Accessed 2 March 2020].

Wynn MG, Jones P (2020) The sustainable development goals: industry sector approaches. London: Routledge. 
